Cochrane Database of Systematic Reviews

\title{
Fluoride toothpastes for preventing dental caries in children and adolescents (Review)
}

Marinho VCC, Higgins J, Logan S, Sheiham (deceased) A

Marinho VCC, Higgins J, Logan S, Sheiham (deceased) A.

Fluoride toothpastes for preventing dental caries in children and adolescents.

Cochrane Database of Systematic Reviews 2003, Issue 1. Art. No.: CD002278.

DOI: $10.1002 / 14651858 . C D 002278$.

www.cochranelibrary.com 
TABLE OF CONTENTS

HEADER 1

ABSTRACT

PLAIN LANGUAGE SUMMARY

BACKGROUND

OBJECTIVES

METHODS

RESULTS

DISCUSSION

AUTHORS' CONCLUSIONS

ACKNOWLEDGEMENTS

REFERENCES

CHARACTERISTICS OF STUDIES

DATA AND ANALYSES

Analysis 1.1. Comparison 1 Fluoride toothpaste versus placebo, Outcome $1 \mathrm{D}(\mathrm{M})$ FS increment (prevented fraction) - nearest to 3 years (70 trials).

Analysis 1.2. Comparison 1 Fluoride toothpaste versus placebo, Outcome $2 \mathrm{D}(\mathrm{M}) \mathrm{FT}$ increment (prevented fraction) - nearest to 3 years (53 trials).

Analysis 1.3. Comparison 1 Fluoride toothpaste versus placebo, Outcome $3 \mathrm{D}(\mathrm{M}) \mathrm{FS}$ increment (SMD) - nearest to 3 years (70 trials).

Analysis 1.4. Comparison 1 Fluoride toothpaste versus placebo, Outcome 4 D(M)FT increment (SMD) - nearest to 3 years (53 trials).

Analysis 1.5. Comparison 1 Fluoride toothpaste versus placebo, Outcome 5 Developing one or more new caries (6 trials). ......

Analysis 1.6. Comparison 1 Fluoride toothpaste versus placebo, Outcome 6 Acquiring extrinsic tooth staining (5 trials). ......... ADDITIONAL TABLES

APPENDICES

WHAT'S NEW

HISTORY

CONTRIBUTIONS OF AUTHORS

DECLARATIONS OF INTEREST

SOURCES OF SUPPORT

NOTES

INDEX TERMS

1

2

3

4

4

8

14

15

15

16

27

81

82 
[Intervention Review]

\section{Fluoride toothpastes for preventing dental caries in children and adolescents}

Valeria CC Marinho1, Julian Higgins ${ }^{2}$, Stuart Logan ${ }^{3}$, Aubrey Sheiham (deceased) ${ }^{4 a}$

${ }^{1}$ Clinical and Diagnostic Oral Sciences, Barts and The London School of Medicine and Dentistry, Queen Mary University of London, London, UK. ${ }^{2}$ School of Social and Community Medicine, University of Bristol, Bristol, UK. ${ }^{3}$ NIHR CLAHRC South West Peninsula (PenCLAHRC), University of Exeter Medical School, Exeter, UK. ${ }^{4}$ University College London Medical School, London, UK

aDeceased November 2015

Contact address: Valeria CC Marinho, Clinical and Diagnostic Oral Sciences, Barts and The London School of Medicine and Dentistry, Queen Mary University of London, Turner Street, Whitechapel, London, E1 2AD, UK. vcmarinho@yahoo.com, v.marinho@qmul.ac.uk.

Editorial group: Cochrane Oral Health Group.

Publication status and date: Stable (no update expected for reasons given in 'What's new'), published in Issue 11, 2016.

Citation: Marinho VCC, Higgins J, Logan S, Sheiham (deceased) A. Fluoride toothpastes for preventing dental caries in children and adolescents. Cochrane Database of Systematic Reviews 2003, Issue 1. Art. No.: CD002278. DOI: 10.1002/14651858.CD002278.

Copyright () 2016 The Cochrane Collaboration. Published by John Wiley \& Sons, Ltd.

\section{A B S T R A C T}

\section{Background}

Fluoride toothpastes have been widely used for over 3 decades and remain a benchmark intervention for the prevention of dental caries.

\section{Objectives}

To determine the effectiveness and safety of fluoride toothpastes in the prevention of caries in children and to examine factors potentially modifying their effect.

\section{Search methods}

We searched the Cochrane Oral Health Group's Trials Register (May 2000), the Cochrane Central Register of Controlled Trials (CENTRAL) (The Cochrane Library 2000, Issue 2), MEDLINE (1966 to January 2000), plus several other databases. We handsearched journals, reference lists of articles and contacted selected authors and manufacturers.

\section{Selection criteria}

Randomised or quasi-randomised controlled trials with blind outcome assessment, comparing fluoride toothpaste with placebo in children up to 16 years during at least 1 year. The main outcome was caries increment measured by the change in decayed, missing and filled tooth surfaces $(D(M) F S)$.

\section{Data collection and analysis}

Inclusion decisions, quality assessment and data extraction were duplicated in a random sample of one third of studies, and consensus achieved by discussion or a third party. Authors were contacted for missing data. The primary measure of effect was the prevented fraction (PF) that is the difference in caries increments between the treatment and control groups expressed as a percentage of the increment in the control group. Random-effects meta-analyses were performed where data could be pooled. Potential sources of heterogeneity were examined in random-effects metaregression analyses.

\section{Main results}

Seventy-four studies were included. For the 70 that contributed data for meta-analysis (involving 42,300 children) the D(M)FS pooled PF was 24\% (95\% confidence interval $(\mathrm{Cl}), 21$ to $28 \%$; $P<0.0001)$. This means that 1.6 children need to brush with a fluoride toothpaste (rather than a non-fluoride toothpaste) to prevent one $D(M) F S$ in populations with caries increment of 2.6 D(M)FS per year. In populations 
with caries increment of 1.1 D(M)FS per year, 3.7 children will need to use a fluoride toothpaste to avoid one $D(M) F S$. There was clear heterogeneity, confirmed statistically $(P<0.0001)$. The effect of fluoride toothpaste increased with higher baseline levels of $D(M) F S$, higher fluoride concentration, higher frequency of use, and supervised brushing, but was not influenced by exposure to water fluoridation. There is little information concerning the deciduous dentition or adverse effects (fluorosis).

\section{Authors' conclusions}

Supported by more than half a century of research, the benefits of fluoride toothpastes are firmly established. Taken together, the trials are of relatively high quality, and provide clear evidence that fluoride toothpastes are efficacious in preventing caries.

\section{PLAIN LANGUAGE SUMMARY}

\section{Fluoride toothpastes for preventing dental caries in children and adolescents}

Children who brush their teeth at least once a day with a toothpaste that contains fluoride will have less tooth decay.

Tooth decay (dental caries) is painful, expensive to treat and can sometimes lead to serious damage to teeth. Fluoride is a mineral that prevents tooth decay. The review of trials found that children aged 5 to 16 years who used a fluoridated toothpaste had fewer decayed, missing and filled permanent teeth after three years (regardless of whether their drinking water was fluoridated). Twice a day use increases the benefit. No conclusion could be reached about the risk that using fluoride toothpastes could mottle teeth (fluorosis), an effect of chronic ingestion of excessive amounts of fluoride when children are young. 


\section{B A C K G R O U N D}

The prevention of dental caries in children and adolescents is generally regarded as a priority for dental services and considered more cost-effective than its treatment (Burt 1998). Fluoride therapy has been the centrepiece of caries-preventive strategies since the introduction of water fluoridation schemes over 5 decades ago (Murray 1991). These were introduced when caries was highly prevalent and severe, and when even modest prevention activities led to considerable reductions in disease levels. In the last 20 years, with the substantial decline in dental caries rates in many western countries, an increase in dental fluorosis levels in some countries, and intensive research on the mechanism of action of fluoride highlighting the primary importance of its topical effect, greater attention has been paid to the appropriate use of other fluoride-based interventions (Glass 1982; Featherstone 1988; Ripa 1991; O'Mullane 1994; Marthaler 1996; Featherstone 1999).

The use of topically applied fluoride products in particular, which are much more concentrated than the fluoride in drinking water, has increased over recent decades. By definition, the term 'topically applied fluoride' is used to describe those delivery systems which provide fluoride to exposed surfaces of the dentition, at elevated concentrations, for a local protective effect, and are therefore not intended for ingestion. The most important anti-caries effect of fluoride is considered to result from its action on the tooth/plaque interface, through promotion of remineralization of early caries lesions and by reducing tooth enamel solubility (Featherstone 1988). Fluoride-containing toothpastes (dentifrices), mouthrinses, gels and varnishes are the modalities most commonly used at present, either alone or in combination. Various products are marketed in different countries and a variety of caries preventive programs based on these have been implemented. Toothpastes are by far the most widespread form of fluoride usage (Murray 1991a; Ripa 1991) and although the reasons for the decline in the prevalence of dental caries in children from different countries continues to be debated (Nadanovsky 1995; Krasse 1996; Marthaler 1996; de Liefde 1998), it has been mainly attributed to the gradual increase in, and regular home use of fluoride in toothpaste (Glass 1982; Ripa 1991; Rolla 1991; Marthaler 1994; O'Mullane 1994; Bratthall 1996).

At the same time, the lower caries prevalence now prevailing in many countries and the widespread availability of fluoride from multiple sources have raised the question of whether topically applied fluorides are still effective in reducing caries, and safe, mainly in terms of the potential risk of fluorosis (mottled enamel). This is particularly important as nearly all child populations in developed countries are exposed to some source of fluoride (notably in toothpaste), and adverse effects may be rare (such as acute fluoride toxicity) or more subtle (such as mild dental fluorosis).

The evidence on the effect of topical fluorides on the prevention of dental caries in children has been extensively reviewed in a number of traditional narrative reviews. A small number of reviews focusing on the evaluation of specific topical fluoride active agents within specific delivery systems have used a quantitative meta-analytical approach to synthesise studies results (Clark 1985; Johnson 1993; Helfenstein 1994; Stamm 1995; van Rijkom 1998). However, a systematic quantitative evaluation of the available evidence on the effect of the main modalities of topical fluorides has never been undertaken.

This review is one in a series of systematic reviews of topical fluoride interventions and assesses the effectiveness of fluoride toothpastes in the prevention of dental caries in children.

\section{Fluoride toothpastes (dentifrices)}

Toothbrushing with fluoride toothpaste is by far the most common form of caries control in use today. The intensive promotion of fluoride toothpastes by the oral healthcare industry has been a major factor in their increased use, and, in the developed world, since the 1980s, nearly all commercially available toothpaste formulations contain fluoride. Various fluoride compounds have been used alone or combined in the formulations, including sodium fluoride, sodium monofluorophosphate, amine fluoride and stannous fluoride, and, according to each manufacturer's specifications these must be compatible with other basic ingredients, especially abrasive systems (which account for almost half of the entire toothpaste formulation). Fluoride toothpastes must be differentiated from fluoride prophylactic pastes, since their fluoride concentrations, methods and frequencies of application differ, as well as amounts of abrasives in their formulation (abrasives account for almost the entire content of a prophylactic paste). In addition, although some toothpastes are available in the translucent form of gel, they are different from fluoride gels, which have higher fluoride levels, no abrasives and are applied much less frequently, usually by a professional.

Consensus among researchers and public health authorities places fluoride toothpaste as the method of choice for preventing caries, as it is convenient and culturally approved, widespread, and it is commonly linked to the decline in caries prevalence in many countries. There is an argument that the effect of fluoride toothpastes are underestimated in 'short term' clinical trials of two to three years duration, as these are used throughout life. In addition, it is argued that the use of fluoride toothpaste in fluoridated areas offers more protection than either alone. However, concern has been expressed that dental fluorosis, enamel defects caused by young children chronically ingesting excessive amounts of fluoride during the period of tooth formation (up to the age of 6 years), is increasing in both fluoridated and non-fluoridated communities, and the early use of fluoride toothpastes by young children may be an important risk factor (Horowitz 1992; Stookey 1994; Ellwood 1995).

The usual concentration of fluoride in toothpastes is $1000 / 1100$ parts per million (ppm F); toothpastes with higher (1500 ppm F) and lower than conventional fluoride levels (around 500 ppm F) are available in many countries. While the evidence of the effectiveness of low fluoride-containing toothpastes in reducing dental caries appears to be conflicting, toothpastes containing higher concentrations of fluoride confer greater protection against caries (Stephen 1988; O'Mullane 1997), but increase the risk of fluorosis, which is related to both, the amount ingested and the fluoride concentration. Chronic ingestion of fluoride from toothpaste in children is common (Bentley 1999; Rojas-Sanchez 1999) and despite the large variation in the amount swallowed, the younger children are, the more likely they are to swallow larger amounts, which often represent a substantial part of the total daily fluoride intake and can be enough to cause fluorosis (Levy 1994; Lewis 1996). Although the amount of fluoride ingested 
beyond which fluorosis may occur is not known accurately, a threshold of 0.05 to $0.07 \mathrm{mgF} / \mathrm{kg}$ body weight has been suggested (Burt 1992). A child-sized toothbrush covered with a full strip of toothpaste holds approximately 0.75 to $1.0 \mathrm{~g}$ of toothpaste, and each gram of fluoride toothpaste, contains approximately $1.0 \mathrm{mg}$ of fluoride; children aged less than 6 years may swallow an estimated $0.3 \mathrm{~g}$ of toothpaste per brushing ( $0.3 \mathrm{mg}$ of fluoride) and can inadvertently swallow as much as $0.8 \mathrm{~g}$ (Levy 1994). As a result, it is generally recommended that children under 6 years of age should be supervised when brushing their teeth, and that no more than a pea-sized amount, approximately $5 \mathrm{~mm}$, should be used. The frequency of toothpaste use and the rinsing method after toothbrushing would be other factors influencing the effectiveness of fluoride toothpastes (and also their safety). Brushing twice a day or more, or rinsing less thoroughly, or not rinsing at all would confer greater caries reductions than brushing once a day or less, or rinsing with larger volumes of water after toothbrushing (Chesters 1992; O'Mullane 1997; Chestnutt 1998; Ashley 1999). A formal investigation of these aspects should help to clarify the optimal level of fluoride toothpaste needed to achieve caries prevention while limiting objectionable enamel fluorosis.

Although acute toxicity is extremely rare, young children are particularly at risk of ingesting toxic doses of fluoride from a standard toothpaste tube of $125 \mathrm{~g}$, generally containing $1100 \mathrm{ppm}$ $\mathrm{F}$ (1.1 $\mathrm{mgF} / \mathrm{g}$ paste). As the probable toxic dose (PTD) is around 5 $\mathrm{mgF} / \mathrm{kg}$ body weight (Whitford 1992), the accidental swallowing of one-third of a toothpaste tube $(45 \mathrm{~g})$ or two-thirds of it $(90 \mathrm{~g})$ is potentially life-threatening for a 1-year-old $(10 \mathrm{~kg})$ or for a 5 to 6 year-old $(20 \mathrm{~kg}$ ) respectively (Ellwood 1998). For this reason it is recommended that a fluoride toothpaste tube should be kept out of the reach of young children.

More than 100 clinical trials conducted in many areas of the world since the 1940s, and summarised in several narrative reviews since the 1950s, have investigated the caries-reducing effect of fluoride toothpastes in children. In the late 1970s, the acceptance of fluoride toothpastes as effective caries inhibiting agents had become so well established that clinical trials in many developed countries had to be benchmarked against standard fluoride toothpastes, as it was considered unethical to withdraw their benefit from a study group. Thus, the effectiveness of new forms and concentrations of fluoride toothpastes has not been so extensively investigated in placebocontrolled trials in children with the lower levels of dental caries prevalence prevailing in many countries.

In the last 20 years, guidelines for caries clinical trials have changed (FDI 1982; CDT-ADA 1988; ICW-CCT 2002) in recognition of the fact that with the decline in caries prevalence and the need, for ethical reasons, to use a positive control instead of a placebo in fluoride toothpaste trials, differences between treatments had become smaller in both absolute and percentage terms. In order to overcome this problem of small group differences, study design approaches have been modified. The most important general strategies have focused on increasing sample size and power, reducing measurement error and conducting studies with high risk subjects, mainly defined on the basis of initial caries scores.

To date, there are two published meta-analyses investigating the comparative efficacy of the two commercially available fluoride toothpaste compounds used most commonly nowadays: sodium fluoride (NaF) and sodium monofluorophosphate (SMFP) (Johnson 1993; Stamm 1995), a question that is not addressed in the present review. There is, however, no systematic quantitative investigation assessing the overall effectiveness and safety of fluoride toothpastes in comparison to placebo and examining formally the main factors that may influence their effectiveness.

\section{O B JECTIVES}

(1) To determine the effectiveness and safety of fluoride toothpaste in preventing dental caries in the child/adolescent population.

(2) To examine whether the effect of fluoride toothpaste is influenced by the initial level of caries severity.

(3) To examine whether the effect of fluoride toothpaste is influenced by the background exposure to fluoride in water (or salt), or reported fluoride sources other than the study option.

(4) To examine whether the effect of fluoride toothpaste is influenced by fluoride concentration or application features, such as frequency of use.

\section{MET HOD S}

\section{Criteria for considering studies for this review \\ Types of studies}

Randomised or quasi-randomised controlled trials (RCTs) using or indicating blind outcome assessment, in which fluoride toothpaste is compared concurrently to placebo toothpaste during at least 1 year/school year.

RCTs with open outcome assessment or no indication of blind assessment, or lasting less than 1 year/school year, or controlled trials where random or quasi-random allocation is not used or indicated were excluded.

\section{Types of participants}

Children or adolescents aged 16 or less at the start of the study (irrespective of initial level of dental caries, background exposure to fluorides, dental treatment level, nationality, setting where intervention is received or time when it started).

Studies where participants were selected on the basis of special (general or oral) health conditions were excluded.

\section{Types of interventions}

Topical fluoride in the form of toothpastes only, using any of the following fluoride agents combined or not in the formulation: sodium fluoride (NaF), sodium monofluorophosphate (SMFP), stannous fluoride (SnF2), acidulated phosphate fluoride (APF), amine fluoride (AmF). These may be formulated with any compatible abrasive system and are considered at any fluoride concentration (ppm F), frequency of use, amount or duration of application, and with any technique of toothbrushing or postbrushing procedure. The control group is placebo (non-fluoride toothpaste) which makes the following as the relevant comparison: Fluoride toothpaste compared with placebo toothpaste.

Studies where the intervention consisted of any other active agent(s) or caries preventive measure(s) (e.g. chlorhexidine agent, other fluoride-based procedures, oral hygiene procedures, sealants, xylitol chewing gums, glass ionomers) used in addition to fluoride toothpaste were excluded.

\section{Types of outcome measures}

The primary outcome measure in this review is caries increment, as measured by change from baseline in the decayed, (missing) 
and filled surface $(\mathrm{D}(\mathrm{M}) \mathrm{FS})$ index, in all permanent teeth erupted at start and erupting over the course of the study. Dental caries is defined here as being clinically and radiographically recorded at the dentine level of diagnosis. (See Methods for the different ways of reporting the decayed, (missing) and filled teeth or surfaces $(\mathrm{D}(\mathrm{M}) \mathrm{FT} / \mathrm{S})$ scores in clinical trials of caries preventives).

The following outcomes were considered relevant: coronal dental caries and dental fillings, in both the permanent and the deciduous dentitions; tooth loss; dental pain/discomfort; specific side effects (fluorosis, tooth staining/discolouration, oral allergic reactions, adverse symptoms such as nausea, vomiting); use of health service resources (such as visits to dental care units, length of dental treatment time).

Studies reporting only on plaque/gingivitis, calculus, dentine hypersensitivity or fluoride physiological outcome measures (fluoride uptake by enamel or dentine, salivary secretion levels, etc) were excluded.

\section{Search methods for identification of studies}

With a comprehensive search, we attempted to identify all relevant studies irrespective of language, from 1965 onwards.

\section{Electronic searching}

\section{Up to 1998}

Relevant studies were identified (for the series of topical fluoride reviews) by searching several databases from date of inception: MEDLINE (1966 to 1997), EMBASE (1980 to 1997), SCISEARCH (1981 to 1997), SSCISEARCH (1981 to 1997), ISTP (1982 to 1997), BIOSIS (1982 to 1997), CINAHL (1982 to 1997), ERIC (1966 to 1996), DISSERTATION ABSTRACTS (1981 to 1997) and LILACS/BBO (1982 to 1997).

Two overlapping but complementary subject search phrases (Appendix 1) with very low specificity (but high sensitivity), using 'free-text 'and 'controlled vocabulary', were formulated within Silverplatter MEDLINE around two main concepts, fluoride and caries, and combined with all three levels of the Cochrane Optimal Search Strategy for Randomised Controlled Trials (RCTs). These subject search phrases were customised for searching EMBASE and the other databases.

RCT filters were also adapted to search EMBASE, BIOSIS, SCISEARCH, DISSERTATION ABSTRACTS, and LILACS/BBO. All the strategies (subject search and methodological filters) developed to search each database are fully described in a report produced for the Systematic Reviews Training Unit (Marinho 1997), and are available on request. These were used for the development of a register of topical fluoride clinical trials for the systematic reviews, as the Cochrane Oral Health Group's Trials Register was not yet developed in 1997/98.

The Cochrane Central Register of Controlled Trials (CENTRAL) (The Cochrane Library 1997, Issue 1), the Community of Science database (1998), which included ongoing trials funded by the National Institute of Dental Research (NIDR), the System for Information on Grey Literature in Europe (SIGLE) database (1980 to 1997), and OLDMEDLINE (1963 to 1965) were searched using the terms 'fluor' and 'carie' truncated. (Grey literature search had also been carried out by searching the Index to Scientific and Technical Proceedings (ISTP) and DISSERTATION ABSTRACTS.)

\section{From 1999 to 2001}

The strategy included in Appendix 2 was used to search LILACS/BBO in 1999 (1982 to 1998), where free-text subject search terms were combined with a methodological filter for RCTs.

A supplementary and more specific subject search phrase (including 'free-text' and 'controlled vocabulary' terms), refined exclusively for this review, formulated around three concepts: toothpaste, fluoride and caries, was used to search Silverplatter MEDLINE (up to January 2000) without methodological filters (Appendix 3). This strategy was adapted to search the Cochrane Oral Health Group's Trials Register (up to May 2000), and has also been run on CENTRAL (The Cochrane Library 2000, Issue 2) to doublecheck.

The metaRegister of Controlled Trials was searched in October 2001 for ongoing RCTs using the terms 'fluoride' and 'caries'.

\section{Reference searching}

All eligible trials retrieved from the searches, meta-analyses and review articles were scanned for relevant references. Reviews had been identified mainly by a MEDLINE search strategy specifically carried out to provide information on available systematic reviews or meta-analyses and on the scope of the literature on the topic, when the Cochrane Database of Systematic Reviews (CDSR), and the Database of Abstracts of Reviews of Effects (DARE) and NHS Economic Evaluation Database (NHSEED), were also searched. Reference lists of relevant chapters from preventive dentistry textbooks on topically applied fluoride interventions were also consulted.

\section{Full-text searching}

Prospective handsearching of those journals (seven) identified as having the highest yield of eligible RCTs/controlled clinical trials (CCTs) were carried out, from January 1999 until January 2000: British Dental Journal, Caries Research, Community Dentistry and Oral Epidemiology, Journal of the American Dental Association, Journal of Dental Research, Journal of Public Health Dentistry and European Journal of Oral Sciences. The handsearch of Community Dentistry and Oral Epidemiology was undertaken (1990 to December 1999), as this was the journal with the highest yield of eligible reports.

\section{Personal contact}

Searching for unpublished studies (or 'grey' literature such as technical reports and dissertations, or studies published in languages other than English which may not have been indexed to major databases) started by contacting experts in the field of preventive dentistry. A letter was sent to the author(s) of each included study published during the last two decades in order to obtain information on possible unpublished studies eligible for inclusion. All the authors of studies who had been contacted in order to clarify reported information to enable assessment of eligibility or obtain missing data were also asked for unpublished studies.

Based on information extracted mainly from included studies, a list of manufacturers of fluoride toothpastes was created for locating unpublished trials. Letters to manufacturers were sent out by the Cochrane Oral Health Group, in the hope that companies might be more responsive to contact from the editorial base than from 
individual reviewers. Nine fluoride toothpaste manufacturers were contacted (October 2000) and information on any unpublished trials requested: Colgate-Palmolive, Unilever/Gibbs, Gaba AG, Smithkline Beecham, Procter and Gamble, Oral-B, Bristol-Myers Co, Warner-Lambert, Synthelabo.

\section{Data collection and analysis}

\section{Identification of reports produced by the searches}

Because multiple databases were searched, the downloaded set of records from each database, starting with MEDLINE, was imported to the bibliographic software package Reference Manager and merged into one core database to remove duplicate records and to facilitate retrieval of relevant articles. The records yielded from LILACS, BBO, CENTRAL, SIGLE and NIDR databases were not imported to Reference Manager and were scanned without the benefit of eliminating duplicates. The records produced by OLDMEDLINE and by the specific MEDLINE search performed without methodological filter were imported to Reference Manager for inspection, in a database separate from the core database. The records produced by searching the Cochrane Oral Health Group's Trials Register and the metaRegister of Controlled Trials were also checked outside Reference Manager.

All records electronically identified by the searches were printed off and scanned on the basis of title first, then by abstract (when this was available in English or in languages known by the reviewer) and/or keywords by one reviewer, Valeria Marinho (VM). Obviously irrelevant records were discarded and the full text of all remaining were obtained. Records were considered irrelevant according to study design/duration, participants, or interventions/ comparisons (if it could be determined that the article was not a report of a randomised/quasi-randomised controlled trial; or the trial was of less than 6 to 8 months duration; or the trial was exclusively in adults; or the trial did not address a fluoride toothpaste intervention; or the trial compared fluoride toothpaste exclusively to no treatment, instead of fluoride-free toothpaste).

All potentially relevant reports identified when searching other sources (reference lists of relevant studies, review articles and book chapters, journal handsearch, personal contact) were also obtained. (Reports that might be identified by contacting manufacturers will be obtained to feature in updates of this review.)

It was considered essential to identify and check all reports related to the same study; in case of any discrepancy, authors were contacted.

\section{Selection of studies}

With the inclusion criteria form previously prepared and pilot tested, one reviewer (VM) assessed all studies for inclusion in the review, and a second reviewer, Julian Higgins (JH), independently duplicated the process for a sample of those (approximately $30 \%$ ). In addition, any study that could not be classified by the first reviewer was independently assessed by the second. A third reviewer was consulted, Stuart Logan (SL) or Aubrey Sheiham (AS), to resolve any disagreement. It was decided in advance to exclude any trial where agreement could not be reached (but this did not occur). Trial reports thought to be potentially relevant in languages not known by the reviewers were translated and the reviewer (VM) completed the inclusion form with reference to the translator.
Attempts were made to contact authors of trials that could not be classified in order to ascertain whether inclusion criteria were met.

\section{Data extraction}

Data from all included studies were extracted by one reviewer (VM) using a pilot tested data extraction form. A second reviewer (JH) extracted data from a random sample of approximately one third of included studies. However, in future updates all reports will be data extracted and quality assessed in duplicate. Checking of interobserver reliability was limited to validity assessments. Again, data that could not be coded by the first reviewer were independently coded by the second, any disagreement was discussed and a third reviewer consulted to achieve consensus where necessary. Provision was made to exclude data where agreement could not be reached but this situation did not occur. Data presented only in graphs and figures were extracted whenever possible, but were included only if two reviewers independently had the same result. Attempts were made to contact authors through an open-ended request in order to obtain missing information or for clarification whenever necessary.

Additional information related to study methodology or quality that was extracted included: study duration (years of follow up); comparability of baseline characteristics: methods used pre-randomisation in sizing/balancing (stratification based on relevant variables) or used post-randomisation in analysing/ adjusting for possible differences in prognostic factors between groups; objectivity/reliability of primary outcome measurement (diagnostic methods and thresholds/definitions used and included, and monitoring of diagnostic errors); any co-intervention and/ or contamination. Information on sponsoring institutions and manufacturers involved was also recorded.

Characteristics related to participants that were extracted included: age (range) at start, caries severity at start (average DMFS, DFS, or other measure), background exposure to other fluoride sources (in water, topical applications, etc), year study began, location where study was conducted (country), setting where participants were recruited, and dental treatment level (F/DMF). Characteristics of the intervention that were extracted included: mode of application (how the intervention was delivered), methods (technique/device) of application, prior- and post-application (rinsing with water), fluoride active agents and concentrations used, frequency and duration of application, and amount applied.

Different ways of assessing/reporting caries increment in the trials (change from baseline as measured by the DMF index) were recorded separately and/or combined according to the components of the index chosen and units of measurement (DMFT/S, or DFT/S, or DT/S, or FT/S), types of tooth/surface considered (permanent/deciduous teeth/surfaces, first molar teeth, approximal surfaces, etc), state of tooth eruption considered (erupted and/or erupting teeth or surface), diagnostic thresholds used (cavitated/dentine lesions, non-cavitated incipient lesions), methods of examination adopted (clinical and/or radiolographical), and approaches to account or not for reversals in caries increment adopted (in a net or observed/crude caries increment respectively). In addition, caries increments have been recorded whenever the authors reported them (various follow ups).

As we were aware that caries increment could be reported differently in different trials we developed a set of a priori rules 
to choose the primary outcome data for analysis from each study: data on permanent teeth would be chosen over data on deciduous teeth; data on surface level would be chosen over data on tooth level; DFS data would be chosen over DMFS data, and this would be chosen over DS or FS; data for 'all surface types combined' would be chosen over data for 'specific types' only; data for 'all erupted and erupting teeth combined' would be chosen over data for 'erupted' only, and this over data for 'erupting' only; data from 'clinical and radiological examinations combined' would be chosen over data from 'clinical' only, and this over 'radiological' only; data for dentinal/cavitated caries lesions would be chosen over data for enamel/non-cavitated lesions; net caries increment data would be chosen over crude (observed) increment data; and follow up nearest to 3 years (often the one at the end of the treatment period) would be chosen over all other lengths of follow up, unless otherwise stated. When no specification was provided with regard to the methods of examination adopted, diagnostic thresholds used, groups of teeth and types of tooth eruption recorded, and approaches for reversals adopted, the primary choices described above were assumed.

The Characteristics of included studies table provides a description of all the main outcome data reported from each study with the primary measure chosen featuring at the top. All other relevant outcomes assessed/reported in the trials are also listed in this table.

\section{Quality assessment}

The methodological quality of the included studies was assessed according to the criteria for concealment of treatment allocation described in the Cochrane Reviewers' Handbook (Clarke 2000) used in the Cochrane Review Manager software (RevMan). Allocation concealment for each trial was rated as belonging to one of three categories.

A. Adequately concealed (an adequate method to conceal allocation is described).

B. Concealment unclear ('random' allocation stated/indicated but the actual allocation concealment method is not described or an apparently adequate concealment scheme is reported but there is uncertainty about whether allocation is adequately concealed).

C. Inadequately concealed (an inadequate method of allocation concealment is described).

Excluded: random (or quasi-random) allocation clearly not used in the trial, or 'random' allocation not stated and not implied/ possible.

Blinding of main outcome assessment was also rated according to the following three categories defined for the topical fluoride reviews.

A. Double-blind (blind outcome assessment and use of placebo described).

B. Single-blind (blind outcome assessment stated and no placebo used).

C. Blinding indicated (blind outcome assessment not stated but likely in any element/phase of outcome assessment, e.g. clinical and/or radiographic examinations performed independently of previous results, or radiographic examinations performed independently of clinical examinations with results reported separately/added later, or examiners clearly not involved in giving treatment, or use of placebo described) or reported but unclear (blind outcome assessment reported but there is information that leads to suspicion/uncertainty about whether the examination was blind).
Excluded: clearly open outcome assessment used or blind outcome assessment not reported and unlikely (no description of an examination performed independently of previous results, of $x$ rays registered independently of clinical examination, of use of a placebo, and of examiners clearly not involved in giving treatment).

One reviewer (VM) assessed the quality of all included studies. A second reviewer $(\mathrm{JH})$ duplicated the process for a random sample of approximately one third of those. Any disagreement was discussed and where necessary a third reviewer was consulted to achieve consensus. Where uncertainty could not be resolved an effort was made to contact authors directly to clarify the method used to conceal allocation or whether assessment of the main outcome had been carried out blind.

Other methodological characteristics of the trials such as completeness of follow up (proportion excluded) and handling of exclusions (extent to which reasons for attrition are explicitly reported, or losses are independent of treatment allocated) were not used as thresholds for inclusion. However, all assessments of study quality are described in the table of included studies, and were coded for possible use in metaregression/sensitivity analyses.

\section{Data analyses}

\section{Handling of missing main outcome data}

It was decided that missing standard deviations for caries increments that were not revealed by contacting the original researchers would be imputed through linear regression of $\log$ (standard deviation)s on $\log$ (mean caries) increments. This is a suitable approach for caries prevention studies since, as they follow an approximate Poisson distribution, caries increments are closely related to their standard deviations (van Rijkom 1998).

\section{Handling of results of studies (main outcome) with more than one treatment arm}

In the studies with more than one relevant intervention group and a common control group, such as those comparing different active fluoride agents or concentrations of fluoride ions to a placebo group, raw results (the numbers, mean caries increments and standard deviations) from all relevant experimental groups were combined in order to obtain a measure of treatment effect. This enables the inclusion of all relevant data in the primary meta-analysis, although may slightly compromise the secondary investigations of dose response.

\section{Choice of measure of effect and meta-analyses of main outcome}

The chosen measure of treatment effect was the prevented fraction $(\mathrm{PF})$, that is (mean increment in the controls minus mean increment in the treated group) divided by mean increment in the controls. For an outcome such as caries increment (where discrete counts are considered to approximate to a continuous scale and are treated as continuous outcome) this measure was considered more appropriate than the mean difference or standardised mean difference, since it allows combination of different ways of measuring caries increment and a meaningful investigation of heterogeneity between trials. It is also simple to interpret. The meta-analyses were conducted as inverse variance weighted averages. Variances were estimated using the formula presented in Dubey 1965 which was more suitable for use in a weighted average, and for large sample sizes the approximation should be reasonable. Random-effects meta-analyses were performed throughout. 
With the use of prevented fraction, it was not possible to perform the main outcome analyses in RevMan/MetaView. However, the raw results of the studies (mean/SD/n) were entered in RevMan and mean differences were presented without meta-analyses. If metaanalyses using standardised mean differences yielded materially similar results to those using prevented fractions, we would also present these within MetaView. Deciduous and permanent teeth would be analysed separately throughout.

For illustrative purposes the results were also presented as the number of children needed to treat (NNT) to prevent one carious teeth/surface. These were calculated by combining the overall prevented fraction with an estimate of the caries increment in the control groups of the individual studies.

\section{Assessment of heterogeneity and investigation of reasons for heterogeneity}

Heterogeneity was assessed by inspection of a graphical display of the estimated treatment effects from the trials along with their $95 \%$ confidence intervals and by formal tests of homogeneity undertaken prior to each meta-analysis (Thompson 1999).

In addition to aspects of study quality, three potential sources of heterogeneity were specified a priori as investigations of these formed part of the primary objectives of the review. We hypothesised that: (1) the effect of fluoride toothpastes differs according to the baseline levels of caries severity; (2) the effect of fluoride toothpastes differs according to exposure to other fluoride sources (in water, etc); and (3) the effect of fluoride toothpastes differs according to concentration of fluoride. The association of these factors with estimated effects ( $D(M) F S$ PFs) were examined by performing random effects meta-regression analyses in Stata version 6.0 (Stata Corporation, USA) using the program Metareg (Sharp 1998).

To allow such investigation, relevant data were dealt with as follows: data on 'baseline levels of caries' were calculated from the study sample analysed (final sample) and in connection with the caries increment index chosen unless otherwise stated, and were averaged among all relevant study groups. Data on 'background exposure to other fluoride sources' combined reported data on the use (outside the trial) of topical fluorides/fluoride rinses or even fluoride toothpastes (in studies where the intervention was tested under supervision at school and no supply of any toothpaste had been provided for home use) and the consumption of fluoridated water/salt/tablets, and were grouped into two categories: one for studies which were based on samples not using/not reporting background use of fluorides and which were from non-fluoridated areas (clearly non-exposed), and another for studies based on samples using fluorides or studies in fluoridated communities, or both. Background use of other fluorides (rinses, gels, tablets, etc) should be clearly reported as used by the majority in a study to be considered as such, and exposure to water/salt fluoridation should be above $0.3 \mathrm{ppm} F$. When background use or not of fluoride toothpaste (again, only for studies where the intervention was tested under supervision at school and no supply of any toothpaste had been provided for home use) was not clearly indicated in studies carried out in developed countries, it was assumed that fluoride toothpaste was widely used from the middle of the 1970s (Ripa 1989). This information was sought from authors (or obtained from other sources) when missing from studies carried out in other locations. When data on the year a study had begun was not provided this was calculated as a 'probable date' by subtracting the duration of the study (in years) plus one extra year, from the publication date of the study. Data on 'concentration applied' and 'frequency of use' have not been categorised, but a 'total intensity of application per year' covariate was produced by multiplying frequency of application (per year) by concentration of toothpaste applied (in ppm F). Concentrations in multiple arm studies were averaged over fluoride toothpaste groups prior to this calculation. Frequency of use of once a day (365 times a year) was assumed when it was not precisely reported in studies of supervised use of fluoride toothpaste at school (where participants were provided with appropriate toothpastes for home use) or in studies of 'unsupervised' home use of fluoride toothpaste (even if it was reported that instructions to brush more than once a day were given); frequency of 200 times (days) a year was assumed when it was not precisely reported in studies of supervised use of fluoride toothpaste at school (where children were provided with non-fluoride toothpastes for home use or not provided with any toothpaste for home use).

Further potential sources of heterogeneity were investigated by metaregression. These 'post hoc' analyses are clearly identified and the results should be treated with caution. These include assessment of the effect of toothpaste application mode', classified as either self-applied under supervision (at school/institution) or as unsupervised use (at home).

Sensitivity analyses were performed using a random-effects model for combining trials.

\section{Investigation of publication and other biases}

A funnel plot (plots of effect estimates versus the inverse of their standard errors) was drawn. Asymmetry of the funnel plot may indicate publication bias and other biases related to sample size, though may also represent a true relationship between trial size and effect size. A formal investigation of the degree of asymmetry was performed using the method proposed by Egger 1997.

\section{Measures of effect and meta-analysis of other outcomes}

For outcomes other than caries increment, continuous data were to be analysed according to differences in mean treatment effects and their standard deviations. Dichotomous outcome data were analysed by calculating risk ratios (RR) or, for adverse effects of fluoride treatment, risk differences (RD). RevMan was used for estimation of overall treatment effects. Again, a random-effects model was used to calculate a pooled estimate of effect. As a general rule only (relevant) outcomes with useable data would be shown in the analyses tables.

\section{RE S U L T S}

\section{Description of studies}

\section{Search results}

Searching the core database in Reference Manager retrieved 2600 records from MEDLINE, EMBASE, BIOSIS, SCISEARCH, SSCISEARCH, CINAHL, ERIC, ISTP and DISSERTATION ABSTRACTS. The specific search used was: 'dentifrice*' or 'fluoride dentifrice*1 or 'toothpaste*1 or 'toothbrush" or 'tooth brush" or 'acidulated fluorophosphate*' or 'acidulated phosphate fluoride ${ }^{\star \prime}$ or 'fluorophosphate* or 'amine fluoride ${ }^{\star 1}$ or 'sodium fluoride ${ }^{\star 1}$ or 'stannous fluoride*' as keywords, combined with 'dentifrice' or 
'toothpaste' or 'tooth paste' or 'paste' or 'toothbrush' or 'tooth brush' or 'brush' in titles, notes and all other fields. There were 211 records scanned outside Reference Manager produced by searching LILACS (48 records), BBO (47 records), CENTRAL ( 86 records), SIGLE (6 records), and NIDR/Community of Science Database (24 records). When LILACS and BBO were searched for the second time with a modified search strategy the yield was 210 records (142 and 68 records respectively) also scanned outside Reference Manager. Searching OLDMEDLINE produced 545 records. Thus, 3566 records yielded by the original electronic searches for topical fluoride trials were scanned, but many of these were duplicates not merged in the core database. The specific MEDLINE search for fluoride toothpaste trials performed without a randomised controlled trial (RCT) filter produced 1005 records, and the search performed in the Cochrane Oral Health Group's Trials Register produced 244 records. The search for ongoing studies in the metaRegister of Controlled Trials produced five records.

Searching other non-electronic sources (reference lists of potentially relevant reports, review articles or book chapters, journals, and contacting authors) produced 99 additional records for inspection. One of the nine manufacturers of fluoride toothpastes contacted, GABA, provided a list of 409 records from a search performed in GALIDENT (Database of GABA Library in Dentistry) using the keyword 'amine fluoride'. However, search results from these and, if provided, from other manufacturers will be taken into account in updates of this review.

From the search results above a total of 299 records were considered potentially eligible, and sought for further assessment.

\section{Selection of studies}

Two hundred and ninety-nine (299) reports were sought for detailed assessment for inclusion, of which 10 full-text reports could not be obtained (most of these were incomplete references to unpublished studies conducted decades ago by toothpaste manufacturers). One hundred and ten (110) reports were considered immediately irrelevant for this review (largely as a result of the type of interventions compared with, or used in addition to fluoride toothpaste, including head to head studies without a placebo group). Thus, 118 studies (179 reports) are considered/ cited in this review. These comprise 120 reports relating to 74 included studies, 49 reports relating to 36 excluded studies, and 10 reports relating to eight studies waiting assessment: either because they require translation (three reports in Polish of two studies, two reports/studies in Japanese, one report/study in German), or because translations and/or attempted contact with the authors have not ascertained whether all inclusion criteria have been met (two reports, one in French and another in Dutch, of one study), or because additional information could not be obtained yet for two studies in abstract form. There were no reports of ongoing studies.

Thirty non-English reports (19 studies) are listed either under excluded or included studies. Three of these (three studies) were excluded either on the basis of the English abstract alone, or due to the availability of a full-text English report of the same study; four reports/studies were included based on an English publication related to the same study; and one report of an excluded study had other publications that did not require translation. There remained 22 non-English reports that have been fully assessed (12 studies): 14 in German (by a German translator, with the contact reviewer), three in French (by a French translator, with the reviewer), one in
Russian (by a Russian translator, with the reviewer), one in Czech (by a Czech translator, with the reviewer), one in Japanese (by a Japanese translator, with the reviewer), and two in Italian (by the contact reviewer).

\section{Excluded studies}

See Characteristics of excluded studies table for the description of reasons for rejecting each study.

The thirty-six studies in this section were excluded for a variety of reasons. One study was clearly not randomised/quasi-randomised. One study randomised two clusters, each to one of the two groups compared. Six studies did not mention or indicate random/quasirandom allocation nor blind outcome assessment. Six studies did not mention random or quasi-random allocation (but used/ indicated blind outcome assessment), and two other studies did not state/indicate blind outcome assessment (but indicated random allocation); the attempt to contact the author(s) of these studies was unsuccessful and they were excluded.

Ten studies had other active agents or other fluoride-based interventions in addition to fluoride toothpaste. Three of these also did not state/indicate blind outcome assessment; another had only two clusters (one as each group); and another included participants older than those considered in this review.

Two studies included institutionalised children with specific health problems. One of these also included young adults. Eight studies included participants older than 16 years old. One of these did not mention blind outcome assessment; three others did not mention or indicate random/quasi-random allocation; and another did not mention or indicate random/quasi-random allocation nor blind outcome assessment.

\section{Included studies}

See Characteristics of included studies table for details of each study.

There are 74 trials included. The studies by Forsman 1974; Hargreaves 1973; Marthaler 1970; Zacherl 1970; Held 1968; Marthaler 1965; Torell 1965 and one of the three studies by Koch 1967 have been treated as two (or more) independent trials each, since the results for two (or more) age groups and/or study sites in these studies have been reported separately as distinct studies. There were also completely distinct studies published as such in the same year by the same author: Zacherl 1972/Zacherl 1972a; Koch 1967a/Koch 1967b/Koch 1967c; and Slack 1967/Slack 1967a. All 120 reports were published between 1955 and 1996. The seventy-four trials were conducted between 1954 and 1994: three in the 1950s, 41 in the 1960s, 28 in the 1970s, one in the 1980s, and one in the 1990s. Twenty-four trials were conducted in USA, 20 in UK, nine in Sweden, six in Switzerland, five in France, three in Australia, two in Canada, and one in each of the following countries: Denmark, Norway, FRG, Italy, and Israel. Thirty-five studies had more than one publication, 12 of these had four or more published reports each. Fifty-five studies acknowledged assistance (product provision, etc) and/or financial support from fluoride toothpaste manufacturers. Of a total of twenty-two studies whose authors were sent request letters for unpublished information, replies related to four studies were obtained. 


\section{Design and methods}

Twenty-two studies had more than one fluoride toothpaste treatment group compared to a control (multi-treatment studies) and among these, two trials had two treatment groups and two placebo control groups. Ten trials used a factorial design to investigate the effects of multiple topical fluoride interventions. All trials used a placebo or non-fluoride toothpaste control group. The study duration (indicated by the total length of follow up as well as the treatment duration) ranged from 1 to 7 years among included trials: seven lasted 4 years or more, 36 lasted 3 years, 27 lasted around 2 years, and the remaining four lasted $1 / 1.5$ years. Studies were generally large with only nine allocating less than 100 children to relevant study groups. The total number of children participating in the 74 trials (given by the sample analysed at the end of the trial period) was 45,073, and ranged from 32 in the smallest trial to 2008 in the largest trial (average of 609 participants per trial). With the exception of five trials, where participants were in orphanages/ institutions, participants were recruited from school settings.

\section{Participants}

All included trials reported that the participants were aged 16 or less at the start, with similar numbers from both sexes (where these data were reported); the exceptions were Ran 1991, who included male participants only in the study, and the two trials of Slack 1967; Slack 1967a that included only females. The ages of the children at the start of the trials ranged from 5 to 16 years; at least 49 trials included children who were 12, at least four trials included children younger than 6 years of age (5 year-olds) and 18 trials included children who were 5 or 6 (in which deciduous teeth caries increment data could have been reported). Decayed, (missing) and filled surfaces $(D(M) F S)$ data at baseline were reported in all but five studies, and ranged from 0.97 to 17.4 (this includes the study by Cahen 1982, where data for the control group only were available); only baseline data for deciduous tooth surface (dfs) were reported in one of the studies by Hargreaves 1973 (although it did not report caries increment data for the deciduous dentition). Where information on 'background exposure to other fluoride sources' was available/obtained, 11 studies were conducted in fluoridated communities (water fluoridation in six, low salt fluoridation in five), and 49 in low/non-fluoridated areas; generalised use of other fluoride programmes (rinsing) was reported in only two of these. For the two trials where the intervention was tested under supervision at school and no supply of any toothpaste had been provided for home use, data on general use of fluoride toothpaste at home could not be obtained for one trial (Ran 1991) and was assumed based on study location and year started for the other (Koch 1967c). Thus, some form of fluoride exposure could be considered for 13 trials, and no exposure for 46; this information was not available for 15 trials.

\section{Interventions}

Fifty-six of the included trials reported unsupervised (ad libitum) use of toothpaste at home, and in the remaining trials toothpaste was used under supervision either at school (13 trials, 11 of which reported provision of enough toothpaste for ad libitum home use) or institution (five trials). Toothpaste was administered using a toothbrush in all trials. A variety of fluoride agents were tested, including stannous fluoride (SnF2) in 29 trials, sodium monofluorophosphate (SMFP) in 27 trials, sodium fluoride (NaF) in 14 trials, amine fluoride (AmF) in eight trials, acidulated phosphate fluoride (APF) in five trials, and mixed agents in five trials (SMFP-
$\mathrm{NaF}$ in three, NaF-SnF2 in two); these were formulated with various abrasive systems (see table). The fluoride concentrations used in a toothpaste ranged from $250 \mathrm{ppm} F$ to 2500 ppm F (SMFP-NaF); but the $1000 / 1100 \mathrm{ppm} F$ toothpaste concentration was tested in at least 56 trials (the two studies which did not report these data are likely to have used this fluoride concentration). Ten studies investigated toothpaste with fluoride levels of $1250 / 1500$ ppm F, and five studies investigated toothpaste with fluoride levels less than 1000 ppm F (250 ppm F was tested in three studies and 500 ppm F was also tested in three studies but one of the studies tested both concentrations). Six studies tested toothpaste with fluoride levels above 1500 ppm F (2400/2500 ppm F).

The brushing frequency did not vary greatly among studies, with only 12 studies among the 74 reporting other than daily frequencies (this was assumed when data were not reported): a frequency of less than once a day in five studies where supervised toothbrushing at school was performed, and a frequency of twice a day or more in seven studies (five of which were also studies where supervised brushing was performed). Data on the amount of toothpaste used and the duration of toothbrushing were reported in very few studies (amount reported either in ' $g r$ ' or in ' $\mathrm{cm}$ ' dispensed over the brush). As regards the performance of some form of oral rinsing after toothbrushing, this was reported in two studies in the UK only (where toothpaste use was supervised at school) and was said to have been 'instructed' in three studies in Sweden (where toothpaste use was not supervised), but there were no reports specifying the method used for post-brushing rinse (e.g. with or without a beaker); as long as performed with water (if with a fluoride solution the trial would have been excluded), the postbrushing rinsing was considered by the reviewers as part of the method of toothpaste use and not as a separate intervention on its own.

\section{Outcome measures}

All but three of the 74 included trials reported caries increment data: 71 trials reported caries increment at the tooth surface level $(\mathrm{D}(\mathrm{M}) \mathrm{FS})$, but $\mathrm{d}(\mathrm{e} / \mathrm{m}) \mathrm{fs} / \mathrm{d}$ was not reported in any of these, and 53 trials reported caries increment at the tooth level (D(M)FT). With regard to the components of the DMFS index used, 49 trials reported DMFS data, 33 reported DFS data, and one trial reported DS data only (DFS data were chosen over DMFS data in 12 of the trials). With regard to the types of teeth/surfaces assessed, results based on all tooth surface types were reported in all 71 trials that reported caries increment data, but results have also been reported separately for first molars, anterior/posterior teeth, approximal surfaces, occlusal and other surface types in many trials (see table). Thirty-three trials presented D(M)FS data at more than one follow-up time; follow up of 3 years was the most common (reported in 44 trials). In three trials, assessments of $D(M) F S$ increments were also made during a post-intervention follow-up period.

Clinical (73 trials) and radiographic (65 trials) examinations provided the definition of different stages or grades of caries lesions. These have been grouped into two basic grades for each method of examination: NCA = non-cavitated incipient enamel lesions clinically visible as white spots or discoloured fissures; CA $=$ lesions showing loss of enamel continuity that can be recorded clinically (undermined enamel, softened floor/walls) or showing frank cavitation; $E R$ = any radiolucency in enamel/enamel-dentine junction; $\mathrm{DR}=$ radiolucency into dentine. Many trials presented results using one caries grade only (usually $C A / E R$ or CA/DR), others 
either did not report the grade, in which case CA was assumed, or reported caries increment data at both levels of diagnosis, in which case CA was chosen. Data on the state of tooth eruption considered were not clearly specified in many trials. The five studies of Marthaler used partial recording as opposed to the full-mouth recording used in all others.

Other dental caries data reported: caries incidence/attack rate (13 trials, including one trial reporting caries rate in the deciduous dentition), caries progression (five trials, four of which reporting the Extrapolated Carious Surface Increment Index (ECSI)), proportion of children developing new caries (six trials), proportion of children not remaining caries-free (two trials), proportion of teeth developing new caries and failures, carious teeth, over time (one trial), proportion of caries-free teeth/surfaces which developed caries (two trials).

Data on adverse effects were (partially or fully) reported in 12 trials: stain score (three trials), proportion of children with tooth staining (seven trials), proportion of children who complained of tooth staining (one trial), oral soft tissues lesions (three trials, none of which with complete or useable data, and with the following statement in all three: "no lesions attributable to product use were noted"). Fluorosis data have not been reported in any of the trials.

\section{Risk of bias in included studies}

Based on 28 studies included in the topical fluoride reviews and randomly selected for assessment of reproducibility and agreement between two reviewers, inter-rater reliability was excellent (89\%) for both allocation concealment and blinding, and agreement was good for allocation (Kappa $=0.61$ ) and very good for blinding (Kappa $=0.73)$.

In general, studies included essential features of clinical trials: randomised groups, double-blind designs and placebo controls. Nevertheless, there were differences in their methodological quality (using the reported information and additional information obtained from a few investigators).

\section{Allocation concealment}

Eleven of the trials which described the randomisation process or whose investigators provided further information in answer to our enquiry could be coded A (e.g. adequate concealment of allocation). Fifty-six included trials were described as randomised but provided no description of the allocation process and were coded B. Seven trials were quasi-randomised and coded C.

\section{Blinding}

Blind outcome assessment and use of placebo (double-blinding, score A) was described in all but two trials where blind outcome assessment was unclear but indicated (score C), and these were placebo-controlled trials. In three trials the fluoride-free toothpaste used as control was not a true placebo (flavour and/or colour somewhat different from test toothpastes). Single-blinding (blind dental caries assessment but no placebo used) was not described in any trial.

\section{Follow up and withdrawals}

All the participants included in the final analysis/present at the end of each study, as a proportion of all the participants present at start in all studies was $72 \%(38,868$ analysed out of 53,710 randomised), excluding the 13 studies with no data on participants randomised to relevant groups. Drop-out rates could be obtained from all but one of the 74 included studies. There was considerable variation in drop-out rates ranging from $4 \%$ at 2 years to $66 \%$ at 3 years. A common reason for attrition was that participants were not available for follow-up examination at the end of the study; exclusions based on presence in all follow-up examinations were reported in 26 trials, and exclusions based on compliance were reported in three trials. Other reasons for exclusions (when given) included change of residence, and characteristics of participants also used as eligibility criteria before randomisation (e.g. starting use of orthodontic bands). A few trials reported the numbers excluded according to reason for attrition, but only two trials reported this by study arm.

\section{Others}

Type of randomisation: stratified randomisation was used in the majority of trials (but only one described use of blocking).

Unit of randomisation/analysis: none of the trials reported the use of cluster randomisation. Individuals were allocated to study arms in all trials, and each participant's caries increment, over a period of time was used as the unit of analysis (as the units of recording, the tooth or surface, are not independent within a given subject). Baseline comparisons and handling of any differences: two trials did not report any baseline data, four of the trials described as 'balanced' (for which randomisation may have produced nearly exact balance) did not report the actual values for the baseline characteristic 'initial caries levels' (D(M)FS/T). Some degree of imbalance was reported in a few trials (for characteristics considered most influential, usually initial caries levels) and generally either described as not significant or adjustment mentioned to have resulted in trivial differences in effect estimates. In three of the smallest trials by Held 1968, imbalances were most pronounced.

Objectivity/reliability of primary outcome measurement: diagnostic methods used (clinical or radiographic) were described in all studies, but thresholds/definitions used for caries and monitoring of diagnostic errors were not always clearly described (see 'Notes' in the Characteristics of included studies table for methodological features assessed).

\section{Effects of interventions}

\section{Effect of fluoride toothpaste on dental caries increment}

The effects of fluoride tooothpastes on dental caries increment (as measured by the DMF index) were reported in a variety of different ways in the included studies. Where appropriate and possible these have been combined to produce pooled estimates as described in the Methods section. The results are reported separately here for: (1) Decayed, (Missing) and Filled Surface Prevented Fraction (D(M)FS PF);

(2) Decayed, (Missing) and Filled Teeth Prevented Fraction (D(M)FT $\mathrm{PF})$;

(3) $\mathrm{D}(\mathrm{M}) \mathrm{FS}$ and $\mathrm{D}(\mathrm{M}) \mathrm{FT}$ pooled using a standardised mean difference (SMD). Estimates of the effects of fluoride toothpastes on caries increment as measured by the $\mathrm{dmf}$ index in deciduous teeth/ surfaces could not be produced for this review, as there was no study contributing data. However, there was a single trial reporting caries incidence rate data for deciduous teeth, the results of which are described below. 
Three included studies (Homan 1969; Powell 1981; Slack 1964) had no (caries increment) data suitable for meta-analysis, although they are retained in the review. Standard deviations (SD) of mean caries increment data (new $\mathrm{D}(\mathrm{M}) \mathrm{FS}$ ) were (partly) missing in 16 of the 71 studies which contributed data (Abrams 1980; Dolles 1980; Fogels 1979; Forsman 1974; Forsman 1974a; Hargreaves 1973; Hargreaves 1973a; Hargreaves 1973b; Held 1968; Held 1968a; Held 1968b; James 1977; Kinkel 1972; Muhler 1955; Ran 1991; Segal 1967). From the analysis of the 179 available treatment arms for the topical fluoride reviews with complete information (as of October 1999) we derived a regression equation log (SD caries increment $)=0.64+0.55 \log$ (mean caries increment), $\left(R^{2}=77 \%\right)$. This equation was used to estimate missing standard deviations from mean $D(M) F S$ increments for the meta-analyses. Similarly, this same regression equation was used to estimate missing standard deviation data for 10 of the 53 trials reporting D(M)FT data (Abrams 1980; Fogels 1979; Hargreaves 1973; Hargreaves 1973a; Hargreaves 1973b; Held 1968; Held 1968a; Held 1968b; Muhler 1955).

We have decided to exclude the trial of Ran 1991 from all analyses because the control DMFS increment was very small $(0.2)$ in this trial, resulting in a poor estimate of PF.

\section{(1) Effect on tooth surfaces: D(M)FS PF}

For all 70 trials combined, the D(M)FS PF pooled estimate was 0.24 (95\% confidence interval $(\mathrm{Cl}), 0.21$ to $0.28 ; \mathrm{P}<0.0001$ ), suggesting a substantial benefit from the use of fluoride toothpaste. The $\mathrm{Cls}$ are relatively narrow, but substantial heterogeneity in results could be observed graphically and statistically $(\mathrm{Q}=489.89$ on 69 degrees of freedom, $\mathrm{P}<0.0001$ ).

For each study, the D(M)FS PF and $95 \%$ Cls can be viewed in the Additional tables; the results of the random-effects meta-analysis of $\mathrm{D}(\mathrm{M}) \mathrm{FS}$ PFs (performed in Stata) are presented in Additional Table 1: Meta-analyses of prevented fractions. A forest plot showing the effects of fluoride toothpaste (PFs and 95\% Cls) on D(M)FS increments resulting from this meta-analysis is available on the Cochrane Oral Health Group web site (www.ohg.cochrane.org).

\section{Metaregression and sensitivity analyses: $D(M) F S$ PF}

Univariate metaregression suggested a significant association between estimates of D(M)FS PFs and the following trial characteristics: baseline caries levels, fluoride concentration, and frequency of use, as well as 'total intensity of application' (frequency times concentration). There was no significant association between estimates of D(M)FS PFs and the pre-specified factors background exposure to fluoridated water or background exposure to any fluoride source. Further univariate metaregression analyses showed a significant association of mode of toothpaste use (supervised/unsupervised) and of drop-out rate with the PF, but no significant association between this and length of follow up (duration of study) or allocation concealment (random/ quasi-random).

The association between baseline caries and D(M)FS PF remained significant (and the regression coefficients almost unchanged) when each one of the above investigated potential effect modifiers were included in bivariate metaregression analyses (for each covariate, significant and non-significant associations remained the same as in the previous univariate analyses). The association between fluoride concentration and D(M)FS PF did not remain significant when adjusted for background exposure to water fluoridation/exposure to any fluoride, frequency of use, or intensity of application in bivariate metaregression, but the association between frequency of use or intensity of application and $D(M) F S$ PF remained significant when adjusted for fluoride concentration. Further bivariate metaregression analyses showed that the association between frequency of toothpaste use and $D(M) F S$ PF remained significant when adjusted for each one of the above investigated covariates, except for background exposure to water fluoridation/exposure to any fluoride. Likewise, mode of toothpaste use (supervised/unsupervised) or drop-out rate remained significant when adjusted for each covariate, except for background exposure to water fluoridation/exposure to any fluoride.

When the effect of each covariate (baseline caries, background exposure to water fluoridation, exposure to any fluoride, fluoride concentration, frequency of use, mode of toothpaste use, allocation concealment and drop-out rate) was controlled for all others there remained strong associations between PF with baseline caries $(0.7 \%$ increase in PF per unit increase in caries, $95 \% \mathrm{Cl}, 0.3$ to $1.17 \%$; $P=0.002)$, mode of use (10\% lower PF with unsupervised brushing, $95 \% \mathrm{Cl},-17$ to $-4 \% ; \mathrm{P}=0.001$ ), and dropout rate $(2.8 \%$ increase in $\mathrm{PF}$ per 10 drop outs, $95 \% \mathrm{Cl}, 0.6$ to $5 \% ; P=0.012$ ); and a just non-significant association with fluoride concentration $(7.7 \%$ increase in $\mathrm{PF}$ per $1000 \mathrm{ppm} \mathrm{F,} 95 \% \mathrm{Cl},-0.03$ to $15 \% ; P=0.051)$.

The influence of type of fluoride agent present in the toothpaste on the prevented fraction was also investigated in metaregression. This analysis was restricted to the two-arm trials that tested only one of the four main fluoride agents in toothpaste $(22$ trials of sodium monofluorophosphate, 19 of stannous fluoride, 10 of sodium fluoride, and five of amine fluoride). No significant differences among these or between each and the others were indicated.

Other potential effect modifiers have not been investigated either because they were not relevant for this review (e.g. blind outcome assessment, since virtually all trials were double-blind) or due to lack of data (e.g. post-brushing rinsing habit).

Metaregression results for all potential effect modifiers (univariate analyses) are given in Additional Table 2: Random-effects metaregression analyses of prevented fractions: $D(M) F S$. Although the number of data points (studies) in this review is unusually high, reducing the possibility of spurious claims of association, these results must be interpreted with caution given the large number of comparisons made and the observational nature of the comparisons.

We performed a sensitivity analysis for the main meta-analysis of D(M)FS PFs by excluding two trials (Dolles 1980; Kleber 1996) in which non-fluoride active agents were present in both fluoride and control groups (distinct agents in each trial), making these trials different in this way from all others that had been included. The $D(M) F S$ PF pooled estimate resulting from the exclusion of both trials was identical to the analysis that includes them. These are small trials that carry little weight, and had minimal effect in a meta-analysis that includes so many larger studies.

In order to illustrate the magnitude of the effect, numbers of children needed to treat (NNT) to prevent one D(M)FS were calculated based on the pooled D(M)FS PF and on the caries 
increments in the control groups of the trials that contributed data to the meta-analysis. The overall caries-inhibiting effect (\%PF) derived from the pooled results of the 70 trials was $24 \%(95 \% \mathrm{Cl}$, 21 to 28); the caries increments ranged from 1.14 to $7.66 \mathrm{D}(\mathrm{M}) \mathrm{FS}$ per year. In populations with a caries increment of $1.14 \mathrm{D}(\mathrm{M}) \mathrm{FS}$ per year (at the lowest end of the results seen in the included studies), this implies an absolute caries reduction of $0.27 \mathrm{D}(\mathrm{M}) \mathrm{FS}$ per year, equivalent to an NNT of $3.7(95 \% \mathrm{Cl}, 3.1$ to 4.2$)$ : i.e. 3.7 children need to brush with a fluoride toothpaste (rather than a non-fluoride toothpaste) to avoid one $\mathrm{D}(\mathrm{M}) \mathrm{FS}$. In populations with a caries increment of $2.6 \mathrm{D}(\mathrm{M}) \mathrm{FS}$ per year (at the mid range of the results seen in the included studies), this implies an absolute caries reduction of $0.62 \mathrm{D}(\mathrm{M}) \mathrm{FS}$ per year, equivalent to an NNT of 1.6 $(95 \% \mathrm{Cl}, 1.4$ to 1.8$)$ : i.e. 1.6 children need to brush with a fluoride toothpaste to avoid one $\mathrm{D}(\mathrm{M}) \mathrm{FS}$.

\section{Funnel plot and test for funnel plot asymmetry: D(M)FS PF}

A funnel plot of the 70 trials reporting $D(M) F S$ PFs may look asymmetrical, but the weighted regression test for asymmetry (Egger 1997) was not statistically significant (asymmetry intercept $(95 \% \mathrm{Cl})=-0.85(-2.53$ to 0.83$)(\mathrm{P}=0.32))$. There is, therefore, no evidence of bias using this method.

The funnel plot is available on the Cochrane Oral Health Group web site (www.ohg.cochrane.org).

\section{(2) Effect on whole teeth: D(M)FT PF}

Fifty-three trials reported data which allowed the calculation of the $D(M) F T$ PF. All 53 are also included in the analysis of D(M)FS PF. The results of these analyses are very similar to those reported above.

The pooled estimate of $\mathrm{D}(\mathrm{M}) \mathrm{FT}$ PF was $0.23(95 \% \mathrm{Cl}, 0.18$ to 0.28 ; $P<0.0001$ ), suggesting, again, a substantial benefit of fluoride toothpaste, within relatively narrow $\mathrm{Cls}$, and with substantial heterogeneity between trials $(Q=541.04$ on 52 degrees of freedom, $\mathrm{P}<0.0001$ ).

For each study, the D(M)FT PF and $95 \% \mathrm{Cl}$ can be viewed in the Additional tables. The results of the random-effects meta-analyses of D(M)FT PFs performed in Stata are also presented in Additional Table 1: Meta-analyses of prevented fractions.

\section{(3) Alternative treatment effect measure: Standardised mean difference (SMD)}

Due to the character of $D(M) F S$ data, mean caries increments are closely related to their SDs (they are about the same). Thus, metaanalyses using SMDs (the difference between two means divided by an estimate of the within group standard deviation) yielded materially similar results to those using PFs (the difference in mean caries increments between the treatment and control groups divided by the mean increment in the control group). We therefore decided to present $D(M) F S$ and $D(M) F T$ SMDs in RevMan, since it was not possible to present the main outcome analyses with PFs in MetaView/RevMan.

For the seventy trials, the pooled $\mathrm{D}(\mathrm{M}) \mathrm{FS}$ SMD estimate was $0.31(95 \% \mathrm{Cl}, 0.27$ to $0.36 ; \mathrm{P}<0.0001)$. There was substantial heterogeneity between trials $\left(\mathrm{Chi}^{2}=271.88\right.$ on 69 degrees of freedom, $P<0.0001$ ). Although the results of this analysis are similar to that of the random-effects meta-analysis of $D(M) F S P F$, they are not totally consistent. This may well be due to differences between caries increment rates and standard deviations in some of the arms of the included studies.

The pooled estimate of $\mathrm{D}(\mathrm{M}) \mathrm{FT}$ SMD based on the 53 trials that contributed data was $0.28(95 \% \mathrm{Cl}, 0.24$ to 0.33 ; $\mathrm{P}<0.0001)$. There was statistically significant heterogeneity $\left(\mathrm{Chi}^{2}=177.38\right.$ on 52 degrees of freedom, $P<0.0001)$. These results are consistent with those found in the random-effects meta-analysis of D(M)FT PF.

\section{Effect on deciduous dentition: df-rate PF (results from one trial)}

There was one large trial involving 2008 children aged 6 to 9 years (Cahen 1982) reporting on the number of new decayed or filled teeth per 100 observed primary teeth ('df-rate'). Although the SDs (or data from which these could be derived) were missing the PF for this trial was 0.37 ( $95 \% \mathrm{Cl}$ not available), significant at the $0.1 \%$ level $(P<0.001)$.

\section{Effect of fluoride toothpaste on other outcomes}

Some trials report data for other relevant outcomes (see 'Outcome measures' under Description of studies). Most of these are simply other measures/indices for dental caries increment in permanent teeth/surfaces and require no further consideration; seven trials report on the proportion of children developing new caries. Metaanalyses results for the proportion of children developing new caries are presented below. The few trials that report data on adverse effects are mainly early studies conducted in the 1960 s reporting on tooth staining from the use of stannous fluoride toothpaste. Meta-analyses results for the proportion of children with tooth staining are also described below.

\section{Proportion of children developing new caries}

Seven trials reported results on the proportion of children developing one or more new caries (Dolles 1980; Forsman 1974; Forsman 1974a; Hanachowicz 1984; Kleber 1996; Marthaler 1974; Torell 1965). The pooled estimate (random-effects meta-analysis) of the risk ratio (RR) was $0.91\left(95 \% \mathrm{Cl}, 0.80\right.$ to 1.04 ; $\mathrm{Chi}^{2}$ for heterogeneity 23.09 on 6 degrees of freedom, $\mathrm{P}=0.0008$ ). This corresponds to an NNT to prevent one child from developing caries of $20(95 \% \mathrm{Cl}, 8$ to 100$)$ in a population with a caries risk the same as that found in the control groups in these trials $(20$ children using fluoride toothpaste for 2 to 3 years will prevent new caries development in one child).

\section{Proportion of children with tooth staining}

Data on the proportion of children with extrinsic tooth staining (light to dark coloured) were fully reported in five trials of stannous fluoride toothpaste carried out in the UK (James 1967; Naylor 1967; Slack 1964; Slack 1967; Slack 1967a). These trials measured this outcome at the end of 2 to 3 years ( 2 trials) and during the last year of a 3-year period ( 3 trials). The pooled estimate (random-effects meta-analysis) of the risk difference (RD) between the toothpaste and placebo arms was $0.24(95 \% \mathrm{Cl}, 0.19$ to 0.30 ; $\mathrm{Chi}^{2}$ for heterogeneity 17.3 on 4 degrees of freedom, $\mathrm{P}=0.0017$ ), i.e. clearly favouring the placebo arm. This is equivalent to a number needed to harm (NNH) of $4.2(95 \% \mathrm{Cl}, 3.3$ to 5.3): i.e. in a population of children with the same underlying risk of tooth staining as controls in these studies, 4.2 children using stannous fluoride containing toothpaste would be associated with one extra case of tooth staining. 


\section{DISCUSSION}

The main question addressed by this review is the effectiveness of fluoride toothpaste for the prevention of dental caries in children compared to placebo. Over 42,300 children participated in the 74 included trials. For the great majority of children the fluoride toothpaste they used was either a sodium monofluorophosphate (SMFP) or a stannous fluoride (SnF2) formulation, usually in the concentration of $1000 \mathrm{ppm} F$, followed by sodium fluoride ( $\mathrm{NaF}$ ) and the other fluoride formulations.

There is clear evidence that fluoride toothpastes have a cariesinhibiting effect. The pooled results of the 70 studies assessing the effect of fluoride toothpaste on the permanent dentition suggest that the use of this intervention is associated on average with a $24 \%$ reduction in decayed, missing and filled tooth surfaces $(D(M) F S)$, and this reduction falls within narrow confidence intervals (Cls) $(21$ to $28 \%$ ). This means that 1.6 children need to brush with a fluoride toothpaste (rather than a non-fluoride toothpaste) to prevent one decayed, missing or filled tooth surface, in a child population with a caries increment of 2.6 D(M)FS per year (at the mid range of control group caries rates seen in the included studies). In populations with caries increment at the lowest level seen in the included studies (1.1 $D(M) F S$ per year), 3.7 children will need to use a fluoride toothpaste to avoid one decayed, missing or filled tooth surface.

Only one study reported the effects of fluoride toothpastes on caries increment in deciduous teeth/surfaces. This large trial involving 2008 children aged 6 to 9 years, reported on the number of new decayed or filled teeth per 100 observed primary teeth ('df-rate'). The authors report a substantial reduction in caries increment $(37 \%)$ which is reported to be highly statistically significant $(P<$ 0.001).

A secondary aim of this review was to examine whether there was any relationship between the caries-preventive effectiveness of fluoride toothpaste and the initial level of caries severity, background exposure to other fluoride sources, fluoride concentration, and application features such as the frequency of toothpaste use. A significant influence of the variables initial level of caries, concentration of fluoride, and frequency of fluoride toothpaste use on the prevented fraction (PF) was shown in the metaregression analyses performed. There was a clear $1 \%$ increase in the PF per unit increase in mean baseline caries, an $8 \%$ increase in the PF per $1000 \mathrm{ppm} F$ concentration, and a 14\% increase in the PF moving from once to twice a day frequency of fluoride toothpaste use.

There was a constant relative increase in the PF as trials involved children with higher initial D(M)FS scores (baseline risk of the study population), although the magnitude of the effect was small. This implies that as the caries levels of a community decline, the percentage caries reductions will decrease. This does not necessarily imply that a low baseline caries level in a community justifies reducing the concentration of fluoride in the paste or reducing the frequency with which it is used, a decision which must depend on the overall balance of risks and benefits.

The suggested greater treatment effect with increased fluoride concentration is consistent with that reported in two large clinical trials directly comparing different fluoride concentrations in toothpaste (dose-response relationship): they reported that an increase in fluoride of around $500 \mathrm{ppm} \mathrm{F}$ in toothpastes containing $1000-2500$ ppm $\mathrm{F}$ brings an additional $6 \%$ reduction in caries (Stephen 1988; O'Mullane 1997). The influence of application frequency on treatment effect suggested in this review is substantial ( $14 \%$ absolute increase in the PF). This is also in agreement with results from recent clinical trials, which show that the habits of children and adults using fluoride toothpaste, for instance, the frequency of use, influence effectiveness (Chesters 1992; O'Mullane 1997; Chestnutt 1998; Ashley 1999). These studies indicate that brushing twice a day or more with a fluoride toothpaste confers greater caries reductions than brushing once a day or less. Furthermore, significantly greater treatment effect with increased frequency and intensity of topical fluoride application is indicated in a previous systematic review in this series (Marinho 2002). Although metaregression analyses including 70 trials should have sufficient power to detect such relationships, more robust investigations of these aspects of the intervention require direct, head to head comparisons of different fluoride concentrations and frequencies of application, which were not within the scope of this review.

We were unable to detect a clear relationship between background exposure to other fluoride sources and the magnitude of the treatment effect. This may have been partly influenced by potential misclassification, especially due to the incomplete reporting of data for exposure to fluorides other than water. However, the lack of association between exposure to water/salt fluoridation and treatment effect, based on analysis including 56 trials (11 of which in fluoridated areas) implies that estimates of treatment effect were similar between trials conducted in fluoridated and non-fluoridated areas (fluoride toothpaste use provides additional caries reduction in subjects from fluoridated areas).

We made a thorough attempt to investigate potential sources of heterogeneity in this review, examining factors related to participants, interventions and study quality. Most of the a priori specified factors were clearly related to heterogeneity. An association with treatment effect was found for two of the other factors investigated in post hoc analyses. The $11 \%$ lower estimate of treatment effect found in trials where the use of fluoride was unsupervised is perhaps unsurprising. This is likely to reflect more intensive use of toothpaste when supervised.

We did not detect an association between the main types of fluoride compounds present in toothpaste formulations and the magnitude of the treatment effect. This comparison was restricted to the two-arm trials that tested one of the four main fluoride agents in toothpaste (22 trials of sodium monofluorophosphate, 19 of stannous fluoride, 10 of sodium fluoride, and five of amine fluoride). Although it can provide indirect evidence of relative treatment effects, this is less reliable than evidence from head to head comparisons which, again, were not within the scope of the review. Two published meta-analyses of the comparative efficacy of sodium fluoride and sodium monofluorophosphate, the fluoride toothpaste compounds that currently dominate the market internationally, report a $7 \%$ greater reduction in caries increment with the use of sodium fluoride formulated in compatible abrasive systems (Johnson 1993; Stamm 1995).

Although visual inspection suggests a degree of funnel plot asymmetry the Egger test provided no evidence of a significant relationship between trial size and effect estimate. 
Unfortunately this review provides little information about the risk of adverse effects. Only five of the trials, all of stannous fluoride containing toothpaste, reported the risk of tooth staining. Stannous fluoride is seldom used in modern toothpaste formulations. No information was reported on other adverse effects. The lack of data on enamel fluorosis in particular is likely in part to reflect the type of studies considered, the age ranges of the participants in such trials (5 year-olds and above), and their usual duration of 2 to 3 years. In addition, it is mainly since the late 1980 s that the risks of fluoride toothpaste use by young children have become controversial, but by this time placebo-controlled trials would not obtain ethical approval. It could be argued, with regard to the public health impact of the two conditions, dental caries and fluorosis, that one public health problem has been substantially reduced and that there is little evidence that another has risen to take its place. However, the lack of direct evidence on fluorosis from clinical trials makes it more difficult for policy makers to weigh the benefits of fluoride toothpaste use in preventing caries against potential negative effects. The selection of appropriate concentrations of fluoride in toothpaste, for example, requires evaluation of how they may affect fluorosis as well as caries in young children.

\section{AUTHORS' CONCLUSIONS}

\section{Implications for practice}

This review suggests that the regular use of fluoride toothpaste is associated with a clear reduction in caries increment. We found evidence that this relative effect may be greater in those who have higher baseline levels of decayed, missing and filled tooth surfaces $(D(M) F S)$. A higher $D(M) F S$ prevented fraction was shown with increased fluoride concentration, increased frequency of use, and with supervised brushing (where a higher compliance with fluoride toothpaste use as recommended should be expected). We found no evidence that this relative effect was dependent on background exposure to fluoridated water. Unfortunately, the review provides little information on the effects of fluoride toothpaste on outcomes such as caries incidence in the deciduous dentition, and provides no useful information on the likelihood of adverse effects such as enamel fluorosis.

\section{Implications for research}

The quality of the trials included in this review is generally better than those assessing the effects of other topical fluoride interventions, although many reports lacked important methodological details. This is likely in part to be due to the fact that most are relatively old. Many characteristics considered crucial for excluding bias, such as clearly stated randomisation and allocation concealment, have only been more emphasised in later years, long after most of the toothpaste trials were reported. However, given the clarity of the results, further randomized comparisons of fluoride toothpaste and placebo alone would be hard to justify. Head to head comparisons of fluoride toothpaste and other topically applied fluoride interventions (or non-fluoride caries preventive strategies) may provide more useful information. These should be carried out in pre-school children and include the assessment of caries incidence in the deciduous teeth and of fluorosis in erupting permanent anterior teeth, and should be of long duration.

\section{ACK N O WLEDGEMENTS}

We would like to thank the following investigators who provided additional information about their trials: A Blinkhorn (University of Manchester), P Gjermo (University of Oslo), H Messer (University of Melbourne), J Murray (University of Newcastle upon Tyne). We would also like to thank the help and expertise of the following: A Schreiber (German translations), O Duperrex (French translations), H Pikhart (Czech translation), K Turai (Russian translation), I Masao (Japanese translation); B Anagnostelys and L Jones (Systematic Reviews Training Unit, London), E Tavender, L Fernandez and S Bickley (Cochrane Oral Health Group, Manchester). Finally, we would like to thank those who have provided comments or editorial input to this review: R Davies (University of Manchester), M Esposito (Goteborg University), A-M Glenny (Cochrane Oral Health Group), L Hooper (Cochrane Oral Health Group), M Lennon (University of Liverpool), I Needleman (Eastman Dental Institute), S Poulsen (University of Aarhus), and K Stephen (University of Glasgow). 


\section{REFERE N CE S}

\section{References to studies included in this review}

Abrams 1980 \{published data only (unpublished sought but not used)\}

Abrams RG, Chambers DW. Caries-inhibiting effect of a stannous fluoride silica gel dentifrice: a three-year clinical study. Clinical Preventive Dentistry 1980;2:22-7.

Andlaw 1975 \{published data only\}

* Andlaw RJ, Tucker GJ. A dentifrice containing 0.8 per cent sodium monofluorophosphate in an aluminium oxide trihydrate base. A 3-year clinical trial. British Dental Journal 1975;138:426-32.

Tucker GJ, Andlaw RJ, Burchell CK. The relationship between oral hygiene and dental caries incidence in 11-year-old children. A 3-year study. British Dental Journal 1976;141:75-9.

Ashley 1977 \{published data only\}

Ashley FP, Mainwaring PJ, Emslie RD, Naylor MN. Clinical testing of a mouthrinse and a dentifrice containing fluoride. A twoyear supervised study in school children. British Dental Journal 1977;143:333-8.

Blinkhorn 1983 \{published and unpublished data\}

Blinkhorn AS, Holloway PJ, Davies TG. Combined effects of a fluoride dentifrice and mouthrinse on the incidence of dental caries. Community Dentistry and Oral Epidemiology 1983;11:7-11.

\section{Brudevold 1966 \{published data only\}}

* Brudevold F, Chilton NW. Comparative study of a fluoride dentifrice containing soluble phosphate and a calcium-free abrasive: second-year report. Journal of the American Dental Association 1966;72:889-94.

Brudevold F, Chilton NW, Wellock WD. A preliminary comparison of a dentifrice containing fluoride and soluble phosphate and employing a calcium-free abrasive with other types of fluoride dentifrices. First year report of a clinical study. Journal of Oral Therapeutics and Pharmacology 1964;56:1-6.

Buhe 1984 \{published data only (unpublished sought but not used)\} Barlage B, Buhe H, Buttner W. A 3-year clinical dentifrice trial using different fluoride levels: 0.8 and $1.2 \%$ sodium monofluorophosphate [abstract]. Caries Research 1981;15:185.

* Buhe H, Buttner W, Barlage B. 3-year clinical tooth cream test with toothpastes of varying fluoride content: $0.8 \%$ and $1.2 \%$ sodium monofluorophosphate [Uber einen dreijahrigen klinischen Zahncremetest mit Zahnpasten unterschiedlicher Fluoridkonzentration: $0,8 \%$ und $1,2 \%$ Natriummonofluorphosphat]. Quintessenza 1984;35:103-11.

Cahen 1982 \{published data only (unpublished sought but not used)\}

Cahen PM, Frank RM, Turlot JC, Jung MT. Comparative unsupervised clinical trial on caries inhibition effect of monofluorophosphate and amine fluoride dentifrices after
3 years in Strasbourg, France. Community Dentistry and Oral Epidemiology 1982;10:238-41.

Di Maggio 1980 \{published data only (unpublished sought but not used)\}

Di Maggio M, Zuccarino L. Cariostatic effect of Fluocaril; controlled clinical research [Effetto cariostatico del Fluocaril; ricerca clinica controllata]. Minerva Stomatologica 1980;29:45-50.

Dolles 1980 \{published and unpublished data\}

Dolles OK, Eriksen HM, Gjermo P. Tooth stain during 2 years' use of chlorhexidine - and fluoride-containing dentifrices. Scandinavian Journal of Dental Research 1979;87:268-74.

* Dolles OK, Gjermo P. Caries Increment and gingival status during 2 years' use of chlorhexidine- and fluoridecontaining dentifrices. Scandinavian Journal of Dental Research 1980;88:22-7.

\section{Fanning 1968 \{published data only\}}

Cellier KM, Fanning EA, Gotjamanos T, Vowles NJ. Some statistical aspects of a clinical study on dental caries in children. Archives of Oral Biology 1968;13:483-508.

Fanning EA, Cellier KM, Gotjamanos T, Vowles NJ. The effect of fluoride dentifrices on the caries incidence of individual tooth surfaces. Australian Dental Journal 1971;16:287-90.

Fanning EA, Gotjamanos T, Vowles NH, Wielen I. The effects of fluoride dentifrices on the incidence and distribution of stained tooth surfaces in children. Archives of Oral Biology 1968;13:467-9.

* Fanning EA, Gotjamanos T, Vowles NJ. The use of fluoride dentifrices in the control of dental caries: methodology and results of a clinical trial. Australian Dental Journal 1968;13:201-6.

Fanning EA, Gotjamanos T, Vowles NJ, Cellier KM, Simmons DW. The use of fluoride dentifrices in the control of dental caries: a preliminary report of a clinical trial. Medical Journal of Australia 1967;1:383-5.

Fogels 1979 \{published data only\}

Fogels HR, Alman JE, Meade JJ, O'Donnell JP. The relative caries-inhibiting effects of a stannous fluoride dentifrice in a silica gel base. Journal of the American Dental Association 1979;99:456-9.

\section{Forsman 1974 \{published data only\}}

Forsman B. Studies on the effect of dentifrices with low fluoride content. Community Dentistry and Oral Epidemiology 1974;2:166-75.

Forsman 1974a \{published data only\}

Forsman B. Studies on the effect of dentifrices with low fluoride content. Community Dentistry and Oral Epidemiology 1974;2:166-75. 
Gish 1966 \{published data only\}

Gish CW, Muhler JC. Effectiveness of a stannous fluoride dentifrice on dental caries. ASDC Journal of Dentistry for Children 1971;38:211-4

* Gish CW, Muhler JC. Effectiveness of a stannous fluoridecalcium pyrophosphate (SnF2-Ca2P2O7) dentifrice on dental caries in children whose teeth calcified in a natural fluoride area. II. Results at the end of 24 months. Journal of the American Dental Association 1966;73:853-5.

Gish CW, Muhler JC, Stookey GK. Effectiveness of a stannous fluoride-calcium pyrophosphate (SnF2-Ca2P2O7) dentifrice on dental caries in children whose teeth calcified in a natural fluoride area. I. Results at the end of 12 months. Journal of the American Dental Association 1965;71:60-5.

Glass 1978 \{published data only (unpublished sought but not used)\}

Glass RL. Caries reduction by a dentifrice containing sodium monofluorophosphate in a calcium carbonate base. Partial explanation for diminishing caries prevalence. Clinical Preventive Dentistry 1981;3:6-8.

* Glass RL, Shiere FR. A clinical trial of a calcium carbonate base dentifrice containing $0.76 \%$ sodium monofluorophosphate. Caries Research 1978;12:284-9.

Glass 1983 \{published data only (unpublished sought but not used)\}

Glass RL, Peterson JK, Bixler D. The effects of changing caries prevalence and diagnostic criteria on clinical caries trials. Caries Research 1983;17:145-51.

Hanachowicz 1984 \{published data only (unpublished sought but not used)\}

* Hanachowicz L. Caries prevention using a $1.2 \%$ sodium monofluorophosphate dentifrice in an aluminium oxide trihydrate base. Community Dentistry and Oral Epidemiology 1984;12:10-6.

Hanachowicz L. Prevention of caries with a dentifrice containing a $1.2 \%$ concentration of sodium monofluorophosphate in an alumina base (a 3-year clinical trial) [Prevention des caries par un dentrifrice contenant du monofluorophosphate de sodium a la concentration de $1.2 \%$ dans une base alumine (Test clinique de 3 ans)]. Chirurgien Dentiste de France 1984;54:59-67.

Hargreaves 1973 \{published data only\}

Hargreaves JA, Chester CG. Clinical trial among Scottish children of an anti-caries dentifrice containing 2 percent sodium monofluorophosphate. Community Dentistry and Oral Epidemiology 1973;1:47-57.

\section{Hargreaves 1973a \{published data only\}}

Hargreaves JA, Chester CG. Clinical trial among Scottish children of an anti-caries dentifrice containing 2 percent sodium monofluorophosphate. Community Dentistry and Oral Epidemiology 1973;1:47-57.

\section{Hargreaves 1973b \{published data only\}}

Hargreaves JA, Chester CG. Clinical trial among Scottish children of an anti-caries dentifrice containing 2 percent sodium monofluorophosphate. Community Dentistry and Oral Epidemiology 1973;1:47-57.

Held 1968 \{published data only\}

Held AJ, Spirgi M. Clinical Experimentation with a fluoridated toothpaste [Experimentation clinique d'une pate dentifrice fluores]. SSO Schweiz Monatsschrift Fuer Zahnheilkund 1965;75:883-905.

Held AJ, Spirgi M. Clinical experimentation with a fluoridated dentifrice [Experimentation clinique d'une pate dentifrice fluoree]. Revue Francaise d'Odontostomatologie 1966;13:1109-20.

Held AJ, Spirgi M. Clinical experiments with a fluoridated toothpaste [Klinische versuche mit einer mit fluor versetzten zahnpasta]. DDZ (Das Deutsche Zahnarzteblatt) 1966;20:288-93.

* Held AJ, Spirgi M. Three years of clinical observations with fluoridated tooth-pastes [Trois ans d'observations cliniques avec des pates dentifrices fluorees]. Bulletin du Groupement International pour la Recherche Scientifique en Stomatologie 1968;11:539-70.

\section{Held 1968a \{published data only\}}

Held AJ, Spirgi M. Clinical Experimentation with a fluoridated dentifrice [Experimentation clinique d'une pate dentifrice fluores]. SSO Schweizerische Monatsschrift Fuer Zahnheilkund 1965;75:883-905.

Held AJ, Spirgi M. Clinical experimentation with a fluoridated dentifrice [Experimentation clinique d'une pate dentifrice fluoree]. Revue Francaise d'Odontostomatologie 1966;13:1109-20.

Held AJ, Spirgi M. Clinical experiments with a fluoridated toothpaste [Klinische versuche mit einer mit fluor versetzten zahnpasta]. DDZ (Das Deutsche Zahnarzteblatt) 1966;20:288-93.

* Held AJ, Spirgi M. Three years of clinical observations with fluoridated tooth-pastes [Trois ans d'observations cliniques avec des pates dentifrices fluorees]. Bulletin du Groupement International pour la Recherche Scientifique en Stomatologie 1968;11:539-70.

\section{Held 1968b \{published data only\}}

Held AJ, Spirgi M. Clinical Experimentation with a fluoridated toothpaste [Experimentation clinique d'une pate dentifrice fluores]. SSO Schweizerische Monatsschrift Fuer Zahnheilkund 1965;75:883-905.

Held AJ, Spirgi M. Clinical experimentation with a fluoridated dentifrice [Experimentation clinique d'une pate dentifrice fluoree]. Revue Francaise d'Odontostomatologie 1966;13:1109-20.

Held AJ, Spirgi M. Clinical experiments with a fluoridated toothpaste [Klinische versuche mit einer mit fluor versetzten zahnpasta]. DDZ (Das Deutsche Zahnarzteblatt) 1966;20:288-93. 
* Held AJ, Spirgi M. Three years of clinical observations with fluoridated tooth-pastes [Trois ans d'observations cliniques avec des pates dentifrices fluorees]. Bulletin du Groupement International pour la Recherche Scientifique en Stomatologie 1968;11:539-70.

\section{Hodge 1980 \{published data only (unpublished sought but not used)\}}

Hodge HC, Holloway PJ, Davies TG, Worthington HV. Caries prevention by dentifrices containing a combination of sodium monofluorophosphate and sodium fluoride. Report of a 3-year clinical trial. British Dental Journal 1980;149:201-4.

\section{Homan 1969 \{published and unpublished data\}}

Homan BT, Messer HH. The comparative effect of three fluoride dentifrices on clinical dental caries in Brisbane schoolchildren. Preliminary report [abstract]. Journal of Dental Research 1969;48:1094.

\section{Horowitz 1966 \{published data only\}}

Horowitz HS, Chamberlin SR. Evaluation of a stannous fluoride dentifrice for use in dental public health programs. II. Operational procedures. Journal of the American Dental Association 1966;73:1090-4.

* Horowitz HS, Law FE, Thompson MB, Chamberlain SR, Shirley R. Evaluation of a stannous fluoride dentifrice for use in dental public health programs. I. Basic findings. Journal of the American Dental Association 1966;72:408-21.

Horowitz HS, Thompson MB, Mary B. Evaluation of a stannous fluoride dentifrice for use in dental public health programs. III. Supplementary findings. Journal of the American Dental Association 1967;74:979-86.

\section{Howat 1978 \{published data only\}}

Howat AP, Hollaway PJ, Davies TG. Caries prevention by daily supervised use of a MFP gel dentifrice. Report of a 3-year clinical trial. British Dental Journal 1978;145:233-5.

\section{Jackson 1967 \{published data only\}}

Jackson D. Allocation to control and experimental groups in short-term clinical trials designed to test a caries preventive. In: Hardwick JL, Dustin JP, Held HR editor(s). Advances in fluorine research and dental caries prevention. Oxford: Pergamon Press, 1964:17-19.

* Jackson D, Sutcliffe P. Clinical testing of a stannous fluoridecalcium pyrophosphate children in Yorkshire school children. British Dental Journal 1967;123:40-8.

\section{James 1967 \{published data only\}}

* James PM, Anderson RJ. Clinical testing of stannous fluoridecalcium pyrophosphate dentifrices in Buckinghamshire school children. British Dental Journal 1967;123:33-9.

James PMC. Organization of a clinical trial. In: James PMC, Konig KG, Held HR editor(s). Advances in fluorine research and dental caries prevention. Oxford: Pergamon Press, 1966:33-9.

\section{James 1977 \{published data only\}}

James PM, Anderson RJ, Beal JF, Bradnock G. A 3-year clinical trial of the effect on dental caries of a dentifrice containing $2 \%$ sodium monoflurophosphate. Community Dentistry and Oral Epidemiology 1977;5:67-72.

\section{Kinkel 1972 \{published data only\}}

Kinkel HJ, Raich R. Caries prevention by means of a Na 2 FPO 3 toothpaste after 3 years of application [Die Karieshemmung einer Na 2 FPO 3 -Zahnpasta nach 3 Jahren Applikation]. SSO Schweizerische Monatsschrift Fuer Zahnheilkund 1972;82:1240-4.

Kinkel HJ, Raich R. Caries-inhibiting properties of Na2FPO3 toothpaste after 5-year evaluation studies [Die Karieshe-mung einer Na2FPO3-Zahnpasta nach 5 Jahren Applikation]. SSO Schweizerische Monatsschrift Fuer Zahnheilkund 1974;84:1245-7.

* Kinkel HJ, Raich R. Effectiveness of a Na2FP03 toothpaste on caries in children [Zur Wirkung einer Na2FPO3-Zahnpasta auf die Karies bei Kindern]. SSO Schweizerische Monatsschrift Fuer Zahnheilkund 1972;82:169-75.

Kinkel HJ, Raich R. The caries-inhibiting property of a $\mathrm{Na2FPO} 3$ toothpaste after 4-year use [Die Karieshemmung einer Na2FPO3-Zahnpasta nach 4 Jahren Applikation]. SSO Schweizerische Monatsschrift Fuer Zahnheilkund 1974;84:226-9.

Kinkel HJ, Raich R, Muller M. Caries prevention by means of a Na2FPO3-toothpaste after 7 year's application [Die Karieshemmung durch eine Na2FPO3-Zahnpasta nach 7 Jahren Applikation]. Deutsche Zahnarztliche Zeitschrift 1977;32:859-60.

Kinkel HJ, Raich R, Muller M. Caries prevention by the use of a Na2FPO3 containing toothpaste, after 7 years [Die Karieshemmung einer Na2FPO3-Zahnpasta nach 7 Jahren Applikation]. SSO Schweizerische Monatsschrift Fuer Zahnheilkund 1977;87:1218-20.

\section{Kleber 1996 \{published data only\}}

Kleber CJ, Putt MS, Smith CE, Gish CW. Effect of supervised use of an alum mouthrinse on dental caries incidence in cariessusceptible children: a pilot study. ASDC Journal of Dentistry for Children 1996;63:393-402.

\section{Koch 1967 \{published data only\}}

Hollender L, Koch G. Influence of topical application of fluoride on rate of progress of carious lesions in children. A long-term roentgenographic follow-up. Odontologisk Revy 1969;20:37-41.

* Koch G. Effect of sodium fluoride in dentifrice and mouthwash on dental caries in school children. 8. Effect of daily supervised toothbrushing with a sodium fluoride dentifrice. A 3-year double-blind clinical test. Odontologisk Revy 1967;18:48-66.

Koch G. Effect of sodium fluoride in dentifrice and mouthwash on incidence of dental caries in school-children. Odontologisk Revy 1967;18(Suppl. 12):1-125.

Koch G. Long-term study of effect of supervised toothbrushing with a sodium fluoride dentifrice. Caries Research 1970;4:149-57. 
Koch G, Lindhe J. The effect of supervised oral hygiene on the gingiva of children. The effect of sodium fluoride. Journal of Periodontal Research 1967;2:64-9.

Koch G, Lindhe J. The state of the gingivae and the cariesincrement in school-children during and after withdrawal of various prophylactic measures. In: McHugh WD editor(s). Dental Plaque. A symposium held at the University of Dundee, 22 to 24 September, 1969. Edinburgh and London: E. \& S. Livingstone, 1970:271-81.

\section{Koch 1967a \{published data only\}}

Hollender L, Koch G. Influence of topical application of fluoride on rate of progress of carious lesions in children. A long-term roentgenographic follow-up. Odontologisk Revy 1969;20:37-41.

* Koch G. Effect of sodium fluoride in dentifrice and mouthwash on dental caries in school children. 8. Effect of daily supervised toothbrushing with a sodium fluoride dentifrice. A 3-year double-blind clinical test. Odontologisk Revy 1967;18:48-66.

Koch G. Effect of sodium fluoride in dentifrice and mouthwash on incidence of dental caries in school-children. Odontologisk Revy 1967;18(Suppl. 12):1-125.

Koch G. Long-term study of effect of supervised toothbrushing with a sodium fluoride dentifrice. Caries Research 1970;4:149-57.

Koch G, Lindhe J. The effect of supervised oral hygiene on the gingiva of children. The effect of sodium fluoride. Journal of Periodontal Research 1967;2:64-9.

Koch G, Lindhe J. The state of the gingivae and the cariesincrement in school-children during and after withdrawal of various prophylactic measures. In: McHugh WD editor(s). Dental Plaque. A symposium held at the University of Dundee, 22 to 24 September, 1969. Edinburgh and London: E. \& S. Livingstone, 1970:271-81.

\section{Koch 1967b \{published data only\}}

Koch G. Effect of sodium fluoride in dentifrice and mouthwash on incidence of dental caries in school children. 9. Effect of unsupervised toothbrushing at home with sodium fluoride dentifrice. A 2-year double-blind clinical test. Odontologisk Revy 1967;18:67-71.

\section{Koch 1967c \{published data only\}}

Koch G. Effect of sodium fluoride in dentifrice and mouthwash on incidence of dental caries in school children. 10. Effect of supervised toothbrushing with a sodium fluoride dentifrice at the regular visits to the school dentist. A 3-year double-blind clinical test. Odontologisk Revy 1967;18:72-6.

\section{Lind 1974 \{published data only\}}

Lind OP, Larsen MJ, Moller IJ, von der Fehr FR. A 2\% sodium monofluorophosphate toothpaste's caries preventive effect in a Danish fluoride area [En 2\% natrium monofluorfosfattandpasta's cariesforebyggende effekt i et dansk fluoromrade]. Tandlaegebladet 1975;79:793-9.

Lind OP, Moller IJ, von der Fehr FR, Larsen MJ. Cariespreventive effect of a dentifrice containing 2 percent sodium monofluorophosphate in a natural fluoride area. Results after 3 years. Helvetica Odontologica Acta 1974;18:53.

* Lind OP, Moller IJ, von der Fehr FR, Larsen MJ. Cariespreventive effect of dentifrice containing 2 percent sodium monofluorophosphate in a natural fluoride area in Denmark. Community Dentistry and Oral Epidemiology 1974;2:104-13.

Lind OP, von der Fehr FR, Larsen MJ, Moller IJ. Anti-caries effect of a 2\% Na2PO3F-dentifrice in a Danish fluoride area. Community Dentistry and Oral Epidemiology 1976;4:7-14.

Mainwaring 1978 \{published data only\}

Mainwaring PJ, Naylor MN. A three-year clinical study to determine the separate and combined caries-inhibiting effects of sodium monofluorophosphate toothpaste and an acidulated phosphate-fluoride gel. Caries Research 1978;12:202-12.

Mainwaring 1983 \{published data only (unpublished sought but not used)\}

* Mainwaring PJ, Naylor MN. A four-year clinical study to determine the caries-inhibiting effect of calcium glycerophosphate and sodium fluoride in calcium carbonate base dentifrices containing sodium monofluorophosphate. Caries Research 1983;17:267-76.

Mainwaring PJ, Naylor MN. Anti-caries effects of NaMFP/CaCO3 toothpastes containing calcium glycerohosphate (CaGP) or sodium fluoride (NaF) - A 4 year clinical study [abstract]. Journal of Dental Research 1981;60:1091.

\section{Marthaler 1965 \{published data only\}}

Konig KG, Muhlemann HR. Caries inhibiting effect of aminfluoride containing dentifrices tested in an animal experiment and in a clinical study. In: Muhlemann HR, Konig KG editor(s). The present status of caries prevention by fluorinecontaining dentifrices. Caries Symposium Zurich. Berne and Stuttgart: Hans Huber, 1961:30.

* Marthaler T. The caries inhibiting effect of amine fluoride dentifrices in children during three years of unsupervised use. British Dental Journal 1965;119:153-63.

Marthaler TM. Caries inhibition after five years of unsupervised use of a dentifrice containing amine fluoride. SSO Schweizerische Monatsschrift Fuer Zahnheilkund 1965;75:509-15.

Marthaler TM. Caries inhibiton with amino fluoride toothpastes following a 7-year-long study [Karieshemmung durch Aminfluoridzahnpasten nach 7 jahriger Studiendauer]. SSO Schweizerische Monatsschrift Fuer Zahnheilkund 1968;78:134-47.

Marthaler TM. Caries-inhibition after seven years of unsupervised use of an amine fluoride dentifrice. British Dental Journal 1968;124:510-5.

Marthaler TM. The cariostatic effect of amine fluoride containing dentifrices in an unsupervised clinical study. In: Muhlemann $\mathrm{HR}$, Konig KG editor(s). The present status of caries prevention by fluorine-containing dentifrices. Caries Symposium Zurich. Berne and Stuttgart: Hans Huber, 1961:14-25. 
Marthaler 1965a \{published data only\}

Konig KG, Muhlemann HR. Caries inhibiting effect of aminfluoride containing dentifrices tested in an animal experiment and in a clinical study. In: Muhlemann HR, Konig KG editor(s). The present status of caries prevention by fluorinecontaining dentifrices. Caries Symposium Zurich. Berne and Stuttgart: Hans Huber, 1961:30.

* Marthaler T. The caries inhibiting effect of amine fluoride dentifrices in children during three years of unsupervised use. British Dental Journal 1965;119:153-63.

Marthaler TM. Caries inhibition after five years of unsupervised use of a dentifrice containing amine fluoride. SSO

Schweizerische Monatsschrift Fuer Zahnheilkund 1965;75:509-15.

Marthaler TM. Caries inhibiton with amino fluoride toothpastes following a 7-year-long study [Karieshemmung durch Aminfluoridzahnpasten nach 7 jahriger Studiendauer]. SSO Schweizerische Monatsschrift Fuer Zahnheilkund 1968;78:134-47.

Marthaler TM. Caries-inhibition after seven years of unsupervised use of an amine fluoride dentifrice. British Dental Journal 1968;124:510-5.

Marthaler TM. The cariostatic effect of amine fluoride containing dentifrices in an unsupervised clinical study. In: Muhlemann HR, Konig KG editor(s). The present status of caries prevention by fluorine-containing dentifrices. Caries Symposium Zurich. Berne and Stuttgart: Hans Huber, 1961:14-25.

\section{Marthaler 1970 \{published data only\}}

Marthaler TM, Konig KG, Muhlemann HR. The effect of a fluoride gel used for supervised toothbrushing 15 or 30 times per year. Helvetica Odontologica Acta 1970;14:67-77.

\section{Marthaler 1970a \{published data only\}}

Marthaler TM, Konig KG, Muhlemann HR. The effect of a fluoride gel used for supervised toothbrushing 15 or 30 times per year. Helvetica Odontologica Acta 1970;14:67-77.

\section{Marthaler 1974 \{published data only\}}

Marthaler TM. Caries-inhibition by an amine fluoride dentifrice. Results after 6 years in children with low caries activity. Helvetica Odontologica Acta 1974;18(Suppl. VIII):35-44.

\section{Mergele 1968 \{published data only\}}

Mergele M. Report II. An unsupervised brushing study on subjects residing in a community with fluoride in the water. Bulletin of the New York Academy of Medicine 1968;14:251-5.

\section{Muhler 1955 \{published data only\}}

Muhler JC, Radike AW, Nebergall WH, Day HG. A comparison between the anticariogenic effects of dentifrices containing stannous fluoride and sodium fluoride. Journal of the American Dental Association 1955;51:556-9.

\section{Muhler 1970 \{published data only\}}

Muhler JC. A clinical comparison of a fluoride and antienzyme dentifrices [abstract]. Journal of Dental Research 1967;IADR

Abstr. No 273:105.
* Muhler JC. A clinical comparison of fluoride and antienzyme dentifrices. ASDC Journal of Dentistry for Children 1970;37:501.

Murray 1980 \{published and unpublished data\}

Murray JJ, Shaw L. A 3-year clinical trial into the effect of fluoride content and toothpaste abrasivity on the caries inhibitory properties of a dentifrice. Community Dentistry and Oral Epidemiology 1980;8:46-51.

Naylor 1967 \{published data only (unpublished sought but not used)\}

Ashley FP, Naylor MN, Emslie RD. Stannous fluoride and sodium monofluorophosphate dentifrices. Clinical testing in London school children--radiological findings. British Dental Journal 1969;127:125-8.

* Naylor MN, Emslie RD. Clinical testing of stannous fluoride and sodium monofluorophosphate dentifrices in London school children. British Dental Journal 1967;123:17-23.

Naylor 1979 \{published data only (unpublished sought but not used)\}

Naylor MN, Glass RL. A 3-year clinical trial of calcium carbonate dentifrice containing calcium glycerophosphate and sodium monofluorophosphate. Caries Research 1979;13:39-46.

\section{Peterson 1967 \{published data only\}}

Peterson JK, Williamson L. Comparative effectiveness of a sodium fluoride-acid orthophosphate-insoluble metaphosphate dentifrice on caries reduction in children [abstract]. Journal of Dental Research 1966;IADR Abstr. No 249:100.

* Peterson JK, Williamson L. Field test of a sodium fluoride dentifrice containing acid orthophosphate and an insoluble metaphosphate abrasive--second year report. Journal of Oral Therapeutics and Pharmacology 1967;4:1-4.

Peterson JK, Williamson L. Three-years caries inhibition of a sodium fluoride acid orthophosphate dentifrice compared with a stannous fluoride dentifrice and a non-fluoride dentifrice [abstract]. Journal of Dental Research 1968;IADR Abstr. No 255:101.

\section{Peterson 1979 \{published data only\}}

* Peterson JK. A supervised brushing trial of sodium monofluorophosphate dentifrices in a fluoridated area. Caries Research 1979;13:68-72.

Peterson JK, Williamson L, Casad R. Caries inhibition with MFPcalcium carbonate dentifrice in fluoridated area [abstract]. Journal of Dental Research 1975;54:L85.

Powell 1981 \{published data only (unpublished sought but not used)\}

Powell KR, Barnard PD, Craig GG. Effect of stannous fluoride treatments on the progression of initial lesions in approximal surfaces of permanent posterior teeth. Journal of Dental Research 1981;60:1648-54. 
Ran 1991 \{published data only (unpublished sought but not used)\} Ran F, Gedalia I, Fried M, Hadani P, Tved A. Effectiveness of fortnightly tooth brushing with amine fluorides in caries-prone subjects. Journal of Oral Rehabilitation 1991;18:311-6.

\section{Reed 1973 \{published data only\}}

Reed MW. Clinical evaluation of three concentrations of sodium fluoride in dentifrices. Journal of the American Dental Association 1973;87:1401-3.

\section{Reed 1975 \{published data only\}}

* Reed MW, King JD. A clinical evaluation of a sodium fluoride dentifrice. Pharmacology and Therapeutics in Dentistry 1975;2:77-82

Reed MW, King JD. A clinical evaluation of a sodium fluoride dentifrice [abstract]. Journal of Dental Research 1970;IADR

Abstr. No 340:133.

Ringelberg 1979 \{published data only (unpublished sought but not used)\}

Ringelberg ML, Webster DB. Effects of an amine fluoride mouthrinse and dentifrice on the gingival health and the extent of plaque of school children. Journal of Periodontology 1977;48:350-3.

Ringelberg ML, Webster DB, Dixon DO. Effects of an amine fluoride dentifrice and mouthrinse on the dental caries of school children after 18 months. Journal of Preventive Dentistry 1978;5:26-30.

Ringelberg ML, Webster DB, Dixon DO, Fairchild S, Driscoll WS. Results of gingival, plaque, and stain assessments after 30 months use of amine fluorides and their inorganic counterparts. Pharmacology and Therapeutics in Dentistry 1979;4:27-31.

* Ringelberg ML, Webster DB, Dixon DO, LeZotte DC. The cariespreventive effect of amine fluorides and inorganic fluorides in a mouthrinse or dentifrice after 30 months of use. Journal of the American Dental Association 1979;98:202-8.

Rule 1984 \{published data only (unpublished sought but not used)\} Rule J, Smith M, Truelove R, Macko D, Castaldi C. Anticaries properties of a $0.78 \%$ sodium monofluorophosphate-silica base dentifrice [abstract]. Journal of Dental Research 1982;61:281.

* Rule JT, Smith MR, Truelove RB, Macko DJ, Castaldi CR. Caries inhibition of a dentifrice containing $0.78 \%$ sodium monofluorophosphate in a silica base. Community Dentistry and Oral Epidemiology 1984;12:213-7.

\section{Segal 1967 \{published data only\}}

Segal AH, Stiff RH, George WA. Caries inhibiting effectiveness of a stannous fluoride-insoluble sodium metaphosphate (IMP) dentifrice in children. Two year results. Journal of Dental Research 1966;IADR Abstr. No 250:101.

* Segal AH, Stiff RH, George WA, Picozzi A. Cariostatic effect of a stannous fluoride-containing dentifrice on children: twoyear report of a supervised toothbrushing study. Journal of Oral Therapeutics and Pharmacology 1967;4:175-80.

\section{Slack 1964 \{published data only\}}

Slack GL, Martin WJ. The use of a dentifrice containing stannous fluoride in the control of dental caries. Report of an unsupervised clinical trial. British Dental Journal 1964;117:275-80.

\section{Slack 1967 \{published data only\}}

Slack GL, Berman DS, Martin WJ, Young J. Clinical testing of stannous fluoride-insoluble metaphosphate dentifrice in kent girls. British Dental Journal 1967;123:9-16.

\section{Slack 1967a \{published data only\}}

Slack GL, Berman DS, Martin WJ, Hardie JM. Clinical testing of a stannous fluoride-calcium pyrophosphate dentifrice in Essex school girls. British Dental Journal 1967;123:26-33.

\section{Slack 1971 \{published data only\}}

Slack GL, Bulman JS, Osborn JF. Clinical testing of fluoride and non-fluoride containing dentifrices in Hounslow school children. British Dental Journal 1971;130:154-8.

\section{Thomas 1966 \{published data only\}}

Thomas AE, Jamison HC. Effect of SnF2 dentrifices on caries in children: two-year clinical study of supervised brushing in children's homes. Journal of the American Dental Association 1966; 73:844-52.

\section{Torell 1965 \{published data only\}}

Torell P. The Goteborg studies of methods of applying fluorides topically. In: Hardwick JL, Held HR, Konig KG editor(s). Advances in fluorine research and dental caries prevention. Vol. 3, Oxford: Pergamon Press, 1965:255-8.

* Torell P, Ericsson Y. Two year clinical tests with different methods of local caries-preventive fluorine application in Swedish school-children (Part I: The Goteborg study). Acta Odontologica Scandinavica 1965;23:287-312.

Torell 1965a \{published data only\}

Torell P, Ericsson Y. Two-year clinical tests with different methods of local caries-preventive fluorine application in Swedish school-children (Part II: The Sodertalje study). Acta Odontologica Scandinavica 1965;23:313-22.

Torell 1965b \{published data only\}

Torell P, Ericsson Y. Two-year clinical tests with different methods of local caries-preventive fluorine application in Swedish school-children (Part II: The Sodertalje study). Acta Odontologica Scandinavica 1965;23:313-22.

\section{Weisenstein 1972 \{published data only\}}

Weisenstein PR, Zacherl WA. A multiple-examiner clinical evaluation of a sodium fluoride dentifrice. Journal of the American Dental Association 1972;84:621-3.

Zacherl 1970 \{published data only (unpublished sought but not used)\}

Zacherl WA, McPhail CW. Evaluation of a stannous fluoridecalcium pyrophosphate dentifrice. Journal of the Canadian Dental Association 1965;31:174-80. 
* Zacherl WA, McPhail CW. Final report on the efficacy of a stannous fluoride-calcium pyrophosphate dentifrice. Journal of the Canadian Dental Association 1970;36:262-4.

Zacherl 1970a \{published data only (unpublished sought but not used)\}

Zacherl WA, McPhail CW. Evaluation of a stannous fluoridecalcium pyrophosphate dentifrice. Journal of the Canadian Dental Association 1965;31:174-80.

* Zacherl WA, McPhail CW. Final report on the efficacy of a stannous fluoride-calcium pyrophosphate dentifrice. Journal of the Canadian Dental Association 1970;36:262-4.

Zacherl 1972 \{published data only (unpublished sought but not used)\}

Zacherl WA. Clinical evaluation of an aged stannous fluoridecalcium pyrophosphate dentifrice. Journal of the Canadian Dental Association 1972;38:155-7.

Zacherl 1972a \{published data only (unpublished sought but not used)\}

Zacherl WA. A clinical evaluation of a sodium fluoride and stannous fluoride dentifrices [abstract]. Journal of Dental Research 1968;IADR Abstr. No 253:101.

* Zacherl WA. Clinical evaluation of neutral sodium fluoride, stannous fluoride, sodium monofluorophosphate and acidulated fluoride-phosphate denifrices. Journal of the Canadian Dental Association 1972;38:35-8.

Zacherl 1973 \{published data only (unpublished sought but not used)\}

* Zacherl WA. A clinical evaluation of a stannous fluoride and a sarcosinate dentifrice. ASDC Journal of Dentistry for Children 1973;40:451-3.

Zacherl WA. Clinical evaluation of a sarcosinate dentifrice [abstract]. Journal of Dental Research 1970;IADR Abstr. No 339:133.

Zacherl 1981 \{published data only (unpublished sought but not used)\}

Biesbrock AR, Faller RV, Bartizek RD, Court LK, McClanahan SF. Reversal of incipient and radiographic caries through the use of sodium and stannous fluoride dentifrices in a clinical trial. Journal of Clinical Dentistry 1998;9:5-10.

Caplan DJ, Slade GD, Biesbrock AR, Bartizek RD, McClanahan SF, Beck JD. A comparison of increment and incidence density analyses in evaluating the anticaries effects of two dentifrices. Caries Research 1999;33:16-22.

* Zacherl WA. A three-year clinical caries evaluation of the effect of a sodium fluoride-silica abrasive dentifrice. Pharmacology and Therapeutics in Dentistry 1981;6:1-7.

Zacherl WA. Clinical evaluation of a sodium fluoride-silica abrasive dentifrice [abstract]. Journal of Dental Research 1981;60:577.

\section{References to studies excluded from this review}

Antia 1974 \{published data only (unpublished sought but not used)\}

Antia FE, Shahani DR, Kapadia JD. A clinical study of sodium monofluorophosphate dentifrice in institutionalized children in the city of Bombay. Journal of the Indian Dental Association 1974;46:165-70.

Axelsson 1976 \{published data only\}

Axelsson P, Lindhe J, Waseby J. The effect of various plaque control measures on gingivitis and caries in schoolchildren. Community Dentistry and Oral Epidemiology 1976;4:232-9.

Bibby 1945 \{published data only\}

Bibby BG. A test of the effect of fluoride containing-dentifrices on dental caries. Journal of Dental Research 1945;24:297-303.

Bixler 1962 \{published data only\}

Bixler D, Muhler JC. Experimental clinical human caries test design and interpretation. Journal of the American Dental Association 1962;65:482-8.

Bixler 1966 \{published data only\}

Bixler D, Muhler JC. Effectiveness of a stannous fluoridecontaining dentifrice in reducing dental caries in children in a boarding school environment. Journal of the American Dental Association 1966;72:653-8.

Bixler 1966a \{published data only\}

Bixler D, Muhler JC. Combined use of three agents containing stannous fluoride: a prophylactic paste a solution and a dentifrice. Journal of the American Dental Association 1964;68:792-800

* Bixler D, Muhler JC. Effect on dental caries in children in a nonfluoride area of combined use of three agents containing stannous fluoride: a prophylactic paste, a solution, and a dentifrice. II. Results at the end of 24 and 36 months. Journal of the American Dental Association 1966;72:392-6.

Downer 1976 \{published data only\}

* Downer MC, Holloway PJ, Davies TG. Clinical testing of a topical fluoride caries preventive programme. British Dental Journal 1976;141:242-7.

Downer MC, Spencer SJ. Evaluating a dental caries preventive programme. Royal Society Health Journal 1973;93:129-32.

Ennever 1980 \{published data only (unpublished sought but not used)\}

Ennever J, Peterson JK, Hester WR, Segreto VA, Radike AW. Influence of alkaline $\mathrm{pH}$ on the effectiveness of sodium fluoride dentifrices. Journal of Dental Research 1980;59:658-61.

Finn 1963 \{published data only\}

Finn SB, Jamison HC. A comparative clinical study of three dentifrices. ASDC Journal of Dentistry for Children 1963;30:17-25.

Gish 1965 \{published data only\}

Gish CW, Muhler JC. Effect on dental caries in children in a natural fluoride area of combined use of three agents 
containing stannous fluoride: a prophylactic paste, a solution and a dentifrice. Journal of the American Dental Association 1965;70:914-20.

\section{Gutherz 1968 \{published data only\}}

Gutherz M. Clinical demonstration of the inhibitory effect on caries of a metaphosphate containing fluoride toothpaste [Klinischer Nachweis der Karieshemmwirkung einer metaphosphathaligen Fluorzahnpaste]. SSO Schweizerische Monatsschrift Fuer Zahnheilkund 1968;78:235-47.

Halikis 1966 \{published data only (unpublished sought but not used)\}

Halikis SE. A pilot study on the effectiveness of a stannous fluoride dentifrice on dental caries in children. Australian Dental Journal 1966;11:336-7.

Hill 1959 \{published data only\}

Hill TJ. Fluoride dentifrices. Journal of the American Dental Association 1959;59:1121-7.

\section{Jiraskova 1965 \{published data only\}}

Jiraskova M, Bures H, Hoskova M, Kotrba V, Thorova J, Mrklas L. Effect of Czechoslovakian-made toothpaste containing sodium fluoride [Ucinek cs. zubni pasty s pridavkem fluoridu sodneho]. Ceskoslovenske Stomatologie 1965;65:433-6.

\section{Jordan 1959 \{published data only\}}

* Jordan WA, Peterson JK. Caries-inhibiting value of a dentifrice containing stannous fluoride: final report of a two year study. Journal of the American Dental Association 1959;58:42-4.

Jordan WA, Peterson JK. Caries-inhibiting value of a dentifrice containing stannous fluoride: first year report of a supervised toothbrushing study. Journal of the American Dental Association 1957:54:589-94.

\section{Kunzel 1977 \{published data only\}}

Franke W, Kunzel W, Treide A, Bluthner K. Caries prevention by means of aminofluoride after 7 years of collectively conducted oral hygiene [Karieshemmung durch Aminfluorid nach 7 Jahren kollektiv angeleiteter Mundhygiene]. Stomatologie der DDR 1977;27:13-6.

Franke W, Kunzel W, Treide A, Bluthner K. Longitudinal studies on the inhibition of caries by amine fluoride within the framework of guided and supervised oral hygiene actions [Langsschnittstudien zur Karieshemmung durch Aminfluorid im Rahmen angeleiteter und uberwachter Mundhygiene-Aktionen]. Stomatologie der DDR 1976;26:532-7.

Franke W, Kunzel W, Treide A, Bluthner K. Wirkungsweise und effwktivitat lokal applizierter aminofluoride zur kariespravention. Medicamentum 1975;16:362.

Geiger L, Kunzel W, Treide A. Comparative clinical-radiological studies on the increase of caries after controlled mouth hygiene with aminofluoride [Vergleichende klinisch-rontgenologische Untersuchungen uber den Karieszuwachs nach kontrollierter Mundhygiene mit Aminfluorid]. Deutsch Stomatologie 1971:21:132-5.
Kunzel W. Comparative clinical and $\mathrm{x}$-ray study of the cariostatic effectiveness of aminofluorides [Sravnitel'noe klinikorentgenologicheskoe issledovanie protivokarioznoi effektivnosti aminoftoridov]. Stomatologiia Mosk 1980;59:67-70.

* Kunzel W, Franke W, Treide A. Clinical-radiological parallel control of a longitudinal study of the anti-caries effect of aminofluoride applied locally for 7 years in a double-blind test [Klinisch-rontgenologische Paralleluberwachung einer Langsschnittstudie zum Nachweis der Karieshemmenden Effektivitat 7 Jahre lokal angewandten Aminfluorids im Doppelblindtest]. Zahn Mund und Kieferheilkund mit Zentralblatt 1977;65:626-37.

\section{Lehnhoff 1966 \{published data only\}}

Lehnhoff RW. Clinical measurement of the effect of an anticaries dentifrice by three examiners [abstract]. Journal of Dental Research 1966;IADR Abstr No 246:100.

Lu 1985 \{published data only\}

Lu KH, Yen DJ, Zacherl WA, Ruhlman CD, Sturzenberger OP, Lehnhoff RW. The effect of a fluoride dentifrice containing an anticalculus agent on dental caries in children. ASDC Journal of Dentistry for Children 1985;52:449-51.

Luoma 1978 \{published data only\}

Luoma H, Murtomaa H, Nuuja T, Nyman A, Nummikoski P, Ainamo J, et al. A simultaneous reduction of caries and gingivitis in a group of schoolchildren receiving chlorhexidinefluoride applications. Results after 2 years. Caries Research 1978;12:290-8.

Mergele 1968a \{published data only\}

Mergele M. A supervised brushing study in state institution schools. Bulletin of the New York Academy of Medicine 1968;14:247-50.

\section{Moller 1968 \{published data only\}}

Bay I, Moller IJ. The effect of a sodium monofluorophosphate dentifrice on the gingiva. Journal of Periodontal Research 1969;4:103-8.

* Moller IJ, Holst JJ, Sorensen E. Caries reducing effect of a sodium monofluorophosphate dentifrice. British Dental Journal 1968;124:209-13.

Moller IJ, Holst JJ, Sorensen E. Effect of a toothpaste containing sodium monofluorophosphate with controlled toothbrushing [Effekten af en natriummonofluorfosfatholdig tandpasta ved kontrolleret tandborstning]. Tandlaegebladet 1968;72:705-17.

\section{Muhler 1955a \{published data only\}}

* Muhler JC, Radike AW, Nebergall WH, Day HG. Effect of a stannous fluoride-containing dentifrice on caries reduction in children II. Caries experience after one year. Journal of the American Dental Association 1955;50:163-6.

Muhler JC, Radike AW, Nebergall WH, Day HG. The effect of a stannous fluoride-containing dentifrice on caries reduction in children. Journal of Dental Research 1954;33:606-12. 
Muhler 1957 \{published data only\}

Muhler JC. Effect on dental caries of a dentifrice containing stannous fluoride and dicalcium phosphate. Journal of Dental Research 1957;36:399-402.

\section{Muhler 1958 \{published data only\}}

Muhler JC. The effect of a modified stannous fluoride-calcium pyrophosphate dentifrice on dental caries in children. Journal of Dental Research 1958;37:448-50.

\section{Muhler 1960 \{published data only\}}

* Muhler JC. Combined anticariogenic effect of a single stannous fluoride solution and the unsupervised use of a stannous fluoride-containing dentifrice. II. Results at the end of three years. Journal of Dental Research 1960;39:955-8.

Muhler JC. The combined anticariogenic effect of a single stannous fluoride treatment and the unsupervised use of a stannous fluoride-containing dentifrice. Journal of Dental Research 1959;38:994-7.

\section{Muhler 1962 \{published data only\}}

* Muhler JC. Effect of a stannous fluoride dentifrice on caries reduction in children during a three year study period. Journal of the Americal Dental Association 1962;64:216-24.

Muhler JC. The effect of a stannous fluoride dentifrice on caries reduction in children during a three-year study period (Summary). In: Muhlemann HR, Konig KG editor(s). Caries Symposium Zurich. Berne and Stuttgart: Hans Huber, 1961:9-13.

\section{Niwa 1975 \{published data only\}}

Niwa T, Baba K, Niwa M. A study on caries prevention effects of dentifrices containing sodium monofluorophosphate, sodium monofluorophosphate plus dextranase, and sodium monofluorophosphate plus sodium phosphate. Koku Eisei Gakkai Zasshi 1975;25:172-94.

\section{Onisi 1970 \{published data only\}}

Onisi M, Tani H. Clinical trial on the reduction of caries incidence by use of two different fluoride dentifrices. Koku Eisei Gakkai Zasshi 1970;20:105-11.

\section{Onisi 1974 \{published data only\}}

Onisi M, Kitamura T, Tokumasu A, Murakami Y, Makino S. Cariostatic effect of a new fluoride dentifrice. Koku Eisei Gakkai Zasshi 1974;24:1-5.

\section{Patz 1970 \{published data only\}}

Patz J, Naujoks R. The caries prophylactic effect of an aminofluoride containing toothpaste in adolescents after 3 years of controlled use [Die kariesprophylaktische Wirkung einer aminfluoridhaltigen Zahnpaste bei Jugendlichen nach dreijahrigem unuberwachten Gebrauch]. Deutsche Zahnarztliche Zeitschrift 1970;25:617-25.

\section{Peffley 1960 \{published data only\}}

Peffley GE, Muhler JC. Effect of a commercial stannous fluoride dentifrice under controlled bruhing habits on dental caries incidence in children: preliminary report. Journal of Dental Research 1960;39:871-4.
Piccione 1979 \{published data only (unpublished sought but not used)\}

Piccione N. Controlled clinical study of the caries prophylactic activity of a new bifluoride toothpaste (sodium monofluorophosphate + sodium fluoride) [Studio clinico controllato sull'attivita carioprofilattica di una nuova pasta dentifricia bifluorurata (monofluorofosfato di sodio + fluoruro di sodio)]. Minerva Stomatologica 1979;28:325-7.

Riethe 1975 \{published data only (unpublished sought but not used)\}

Riethe P, Schubring G. Clinical studies on a sodium monofluorophosphate toothpaste in school children [Klinische Prufung einer Natriummonofluorphosphat-Zahnpaste an Schulkindern]. Deutsche Zahnarztliche Zeitschrift 1975;30:513-7.

Stookey 1975 \{published data only (unpublished sought but not used)\}

Stookey GK, Beiswanger BB. Influence of an experimental sodium fluoride dentifrice on dental caries incidence in children. Journal of Dental Research 1975;54:53-8.

Wrinkler 1953 \{published data only\}

Wrinkler KC, Backer-Dirks O, van Amerongen J. A reproducible method for caries evaluation. Test in a therapeutic experiment with a fluorinated dentifrice. British Dental Journal 1953;95:119-24.

\section{Zickert 1982 \{published data only\}}

Zickert I, Lindvall AM, Axelsson P. Effect on caries and gingivitis of a preventive program based on oral hygiene measures and fluoride application. Community Dentistry and Oral Epidemiology 1982;10:289-95.

\section{References to studies awaiting assessment}

Cichocka 1981 \{published data only\}

Cichocka E. Economic evaluation of selected methods of contact fluoridation of the teeth [Ocena ekonomiczna wybranych metod kontaktowego fluorkowania zebow]. Czasopismo Stomatologiczne 1981;34:245-50.

* Cichocka E. Oral hygiene and the efficacy of selected methods of contact tooth fluoridation [Higiena jamy ustnej a skutecznosc wybranych metod kontaktowego fluorkowania zebow]. Czasopismo Stomatologiczne 1981;34:145-53.

\section{Kinkel 1968 \{published data only\}}

Kinkel HJ, Stolte G. On the effect of a sodium monofluorophosphate-bromochlorophenol containing toothpaste in a chronic animal experiment and on caries in children during a 2-year long unsupervised use [Zur Wirkung einer natriummonofluorphosphat- und bromchlorophenhaltigen Zahnpasta im chronischen Tierexperiment und auf die Karies bei Kindern wahrend eines zqei Jahre langen, unuberwachten Gebrauches]. DDZ (Deutsche Zahnarzteblatt) 1968;22:455-60.

Kinkel 1974 \{published data only\}

* Kinkel HJ, Stolte G, Weststrate J. The effectiveness of a fluorophosphate toothpaste on children's teeth [Etude de 
l'efficacite d'une pate dentifrice au fluorophosphate sur la denture des enfants]. SSO Schweizerische Monatsschrift Fuer Zahnheilkunde 1974;84:577-89.

Rijnbeek PLC, Weststrate J. Development and study of the efficacy of a fluoridated dentifrice [Ontwikkeling en effectiviteitsonderzoek van een gefluorideerde tandpasta]. Nederlands Tijdschrift voor Tandheelkunde 1976;83:123-8.

\section{Kobylanska 1975 \{published data only\}}

Kobylanska M. [Evaluation of caries-inhibiting effects of fluoride-containing dentifrices of Polish production] Ocena profilaktycznego dzialania krajowych past do zebow zawierajacych niektore zwiazki fluoru. Czasopismo Stomatologie 1975;28:247-51.

\section{Onishi 1967 \{published data only\}}

Onishi E, Okada S, Hinoide M, Akada H, Kon K, Sugano N, et al. Effect of stannous fluoride dentifrice on the reduction of dental caries in schoolchildren. Koku Eisei Gakkai Zasshi 1967;17:68-74.

\section{Takeuchi 1968 \{published data only\}}

Takeuchi M, Shimizu T, Kawasaki T, Kizu T. A field study on effect of a dentifrice containing sodium monofluorophosphate in caries prevention. Koku Eisei Gakkai Zasshi 1968;18:26-38.

\section{Weisenstein 1967 \{published data only\}}

Weisenstein PR, Lehnhoff RW. A clinical evaluation of an anticaries dentifrice comparing conventional and radiographic measures [abstract]. Journal of Dental Research 1967;IADR Abstr. No 425:143.

\section{Wilson 1978 \{published data only (unpublished sought but not} used)\}

Wilson CJ, Triol CW, Volpe AR. The clinical anticaries effect of a fluoride dentifrice and mouthrinse [abstract]. Journal of Dental Research 1978;57(IADR Abstr. No 808):276.

\section{Additional references}

\section{Ashley 1999}

Ashley FP, Attrill DC, Ellwood RP, Worthington HV, Davies RM. Toothbrushing habits and caries experience. Caries Research 1999;33:401-2.

\section{Bentley 1999}

Bentley EM, Ellwood RP, Davies MR. Fluoride ingestion from toothpaste by young children. British Dental Journal 1999;186:460-2.

\section{Bratthall 1996}

Bratthall D, Hansel Petersson G, Sundberg H. Reasons for the caries decline: what do the experts believe?. European Journal of Oral Sciences 1996;104:416-22.

\section{Burt 1992}

Burt BA. The changing patterns of systemic fluoride intake. Journal of Dental Research 1992;71:1228-37.

\section{Burt 1998}

Burt BA. Prevention policies in the light of the changed distribution of dental caries. Acta Odontologica Scandinavica 1998;56:179-86.

\section{CDT-ADA 1988}

Council on Dental Therapeutics. Report of workshop aimed at defining guidelines for caries clinical trials: superiority and equivalency claims for anticaries dentifrices. Journal of the American Dental Association 1988;117:663-5.

\section{Chesters 1992}

Chesters RK, Huntington E, Burchell CK, Stephen KW. Effect of oral care habits on caries in adolescents. Caries Research 1992;26:299-304.

\section{Chestnutt 1998}

Chestnutt IG, Schafer F, Jacobson AP, Stephen KW. The influence of toothbrushing frequency and post-brushing rinsing on caries experience in a caries clinical trial. Community Dentistry and Oral Epidemiology 1998;26:406-11.

\section{Clark 1985}

Clark DC, Hanley JA, Stamm JW, Weinstein PL. An empirically based system to estimate the effectiveness of caries-preventive agents. A comparison of the effectiveness estimates of APF gels and solutions, and fluoride varnishes. Caries Research 1985;19:83-95.

\section{Clarke 2000}

Clarke M, Oxman AD, editors. Assessment of study quality. Cochrane Reviewers' Handbook version 4.1 [updated June 2000]; Section 6. The Cochrane Collaboration, 2000.

\section{de Liefde 1998}

de Liefde B. The decline of caries in New Zealand over the past 40 years [see comments]. New Zealand Dental Journal 1998;94:109-13.

\section{Dubey 1965}

Dubey SD, Lehnhoff RW, Radike AW. A statistical confidence interval for true per cent reduction in caries-incidence studies. Journal of Dental Research 1965;44:921-3.

\section{Egger 1997}

Egger M, Davey-Smith G, Schneider M, Minder C. Bias in meta-analysis detected by a simple graphical test. BMJ 1997;315(7109):629-34.

\section{Ellwood 1995}

Ellwood RP, O' Mullane DM. Dental enamel opacities in the groups with varying levels of fluoride in their drinking water. Caries Research 1995;29:137-42.

\section{Ellwood 1998}

Ellwood RP, Blinkhorn AS, Davies RM. Fluoride: how to maximize the benefits and minimize the risks. Dental Update 1998;25:365-72. 


\section{FDI 1982}

Federation Dentaire Internationale. Principal requirements for controlled clinical trials of caries preventive agents and procedures. Technical report of the commision on oral health, research and epidemiology. International Dental Journal 1982;32:292-310.

\section{Featherstone 1988}

Featherstone JDB, Ten Cate JM. Physicochemical aspects of fluoride-enamel interactions. In: Ekstrand J, Fejerskov O, Silverstone LM editor(s). Fluoride in Dentistry. Copenhagen: Munksgaard, 1988:125-49.

\section{Featherstone 1999}

Featherstone JD. Prevention and reversal of dental caries: role of low level fluoride. Community Dentistry and Oral Epidemiology 1999;27:31-40.

\section{Glass 1982}

Glass RL. The first international conference on the declining prevalence of dental caries. Journal of Dental Research 1982;61:1301-83.

\section{Helfenstein 1994}

Helfenstein U, Steiner M. Fluoride varnishes (Duraphat): a meta-analysis. Community Dentistry and Oral Epidemiology 1994;22:1-5.

\section{Horowitz 1992}

Horowitz HS. The need for toothpastes with lower than conventional fluoride concentrations for preschool-aged children. Journal of Public Health Dentistry 1992;52:216-21.

\section{ICW-CCT 2002}

Professors Pitts, Stamm - Co-Chairs. Clinical trials - agreeing where the evidence leads. International Consensus Workshop on Caries. Loch Lomond, January 6th-10th 2002.

\section{Johnson 1993}

Johnson MF. Comparative efficacy of NaF and SMFP dentifrices in caries prevention: a meta-analytic overview. Caries Research 1993;27:328-36.

\section{Krasse 1996}

Krasse $B$. The caries decline: is the effect of fluoride toothpaste overrated?. European Journal of Oral Sciences 1996;104:426-9.

\section{Levy 1994}

Levy SM. Review of fluoride exposures and ingestion. Community Dentistry and Oral Epidemiology 1994;22:173-80.

\section{Lewis 1996}

Lewis DW, Limeback H. Comparison of recommended and actual mean intakes of fluoride by Canadians. Journal of the Canadian Dental Association 1996;62:708-9,712-5.

\section{Marinho 1997}

Marinho VC. A systematic review of the effectiveness of topical fluoride therapy in the prevention of dental caries in children and adolescents [dissertation]. London: University of London 1997.

\section{Marinho 2002}

Marinho VCC, Higgins J, Logan S, Sheiham A. Fluoride gels for preventing dental caries in children and adolescents. Cochrane Database of Systematic Reviews 2002, Issue 2. [DOI: 10.1002/14651858.CD002280]

\section{Marthaler 1994}

Marthaler TM, Steiner M, Menghini G, Bandi A. Caries prevalence in Switzerland. International Dental Journal 1994;44:393-401.

\section{Marthaler 1996}

Marthaler TM, O'Mullane DM, Vrbic V. The prevalence of dental caries in Europe 1990-1995. ORCA Saturday afternoon symposium 1995. Caries Research 1996;30:237-55.

\section{Murray 1991}

Murray JJ, Rugg-Gunn AJ, Jenkins GN, editors. A history of water fluoridation. Fluorides in Caries Prevention. Oxford: Wright, 1991:7-37.

\section{Murray 1991a}

Murray JJ, Rugg-Gunn AJ, Jenkins GN, editors. Fluoride toothpastes and dental caries. Fluorides in caries prevention. Oxford: Wright, 1991:127-60.

\section{Nadanovsky 1995}

Nadanovsky P, Sheiham A. Relative contribution of dental services to the changes in caries levels of 12 -year-old children in 18 industrialized countries in the 1970s and early 1980s. Community Dentistry and Oral Epidemiology 1995;23:331-9.

\section{O'Mullane 1994}

O'Mullane DM. Introduction and rationale for the use of fluoride for caries prevention. International Dental Journal 1994;44:257-61.

\section{O'Mullane 1997}

O'Mullane DM, Kavanagh D, Ellwood RP, Chesters RK, Schafer F, Huntington $\mathrm{E}$, et al. A three-year clinical trial of a combination of trimetaphosphate and sodium fluoride in silica toothpastes. Journal of Dental Research 1997;76:1776-81.

\section{Ripa 1989}

Ripa LW. Review of the anticaries effectiveness of professionally applied and self-applied topical fluoride gels. Journal of Public Health Dentistry 1989;49:297-309.

\section{Ripa 1991}

Ripa LW. A critique of topical fluoride methods (dentifrices, mouthrinses, operator-, and self-applied gels) in an era of decreased caries and increased fluorosis prevalence. Journal of Public Health Dentistry 1991;51:23-41.

\section{Rojas-Sanchez 1999}

Rojas-Sanchez F, Kelly SA, Drake KM, Eckert GJ, Stookey GK, Dunipace AJ. Fluoride intake from foods, beverages and dentifrice by young children in communities with negligibly and optimally fluoridated water: a pilot study. Community Dentistry and Oral Epidemiology 1999;27:288-97. 


\section{Rolla 1991}

Rolla G, Ogaard B, Cruz R-d-A. Clinical effect and mechanism of cariostatic action of fluoride-containing toothpastes: a review. International Dental Journal 1991;41:171-4.

\section{Sharp 1998}

Sharp S. Meta-analysis regression. Stata Technical Bulletin 1998; Vol. 42:16-22.

\section{Stamm 1995}

Stamm JW. Clinical studies of neutral sodium fluoride and sodium monofluorophosphate dentifrices. In: Bowen WH editor(s). Relative efficacy of sodium fluoride and sodium monofluorophosphate as anti-caries agents in dentifrices. London: The Royal Society of Medicine Press Limited, 1995:43-58.

\section{Stephen 1988}

Stephen KW, Creanor SL, Russell JI, Burchell CK, Huntington E, Downie CF. A 3-year oral health dose-response study of sodium monofluorophosphate dentifrices with and without zinc citrate: anti- caries results. Community Dentistry and Oral Epidemiology 1988;16:321-5.

\section{CHARACTERISTICS OF STUDIES}

Characteristics of included studies [ordered by study ID]

\section{Stookey 1994}

Stookey GK. Review of fluorosis risk of self-applied topical fluorides: dentifrices, mouthrinses and gels. Community Dentistry and Oral Epidemiology 1994;22:181-6.

\section{Thompson 1999}

Thompson SG, Sharp SJ. Explaining heterogeneity in metaanalysis: a comparison of methods. Statistics in Medicine 1999;18(20):2693-708.

\section{van Rijkom 1998}

van Rijkom HM, Truin GJ, van 't Hof MA. A meta-analysis of clinical studies on the caries-inhibiting effect of fluoride gel treatment. Caries Research 1998;32:83-92.

\section{Whitford 1992}

Whitford GM. Acute and chronic fluoride toxicity. Journal of Dental Research 1992;71:1249-54.

* Indicates the major publication for the study

Abrams 1980

Methods

Stratified random allocation; double-blind (A); placebo-controlled; $48 \%$ drop out after 3 years (study duration $=3$ years). Reasons for high drop out described: change of residence, absenteeism, non-adherence to study protocol; no differential group losses.

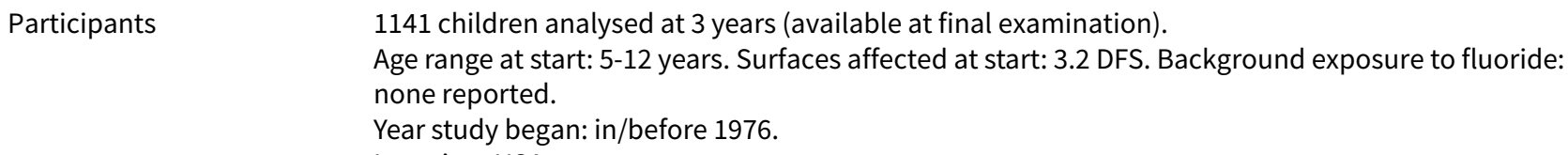

\begin{tabular}{l} 
Outcomes \\
Reported at 1,2 and 3 years follow ups. \\
DMFT. \\
DMFS. \\
DFT. \\
MD-DFS. \\
DFT rate. \\
DFS rate. \\
Participants randomised (N = 2210). \\
Baseline characteristics (DFS) 'balanced' . \\
Clinical (VT) caries assessment by two examiners, diagnostic threshold = CA. Radiographic assessment \\
(postBW) by two examiners; diagnostic threshold = ER. State of tooth eruption included = E/U. Intra- \\
\hline \multirow{2}{*}{ Notes }
\end{tabular}


Abrams 1980 (Continued)

and inter-examiner reproducibility of clinical caries diagnosis (DFS) assessed annually by duplicate examination of $10 \%$ random sample (\% of times diagnosis replicated in all 3 examinations ranged $42-97 \%$ and $77-92 \%$ for both examiners and for each respectively).

\section{Risk of bias}

\begin{tabular}{lll}
\hline Bias & Authors' judgement & Support for judgement \\
\hline $\begin{array}{l}\text { Allocation concealment } \\
\text { (selection bias) }\end{array}$ & Unclear risk & B - Unclear \\
\hline
\end{tabular}

\section{Andlaw 1975}

$\begin{array}{ll}\text { Methods } & \text { Stratified random allocation; double-blind (A); placebo-controlled; } 13 \% \text { drop out after } 3 \text { years (study } \\ \text { duration = } 3 \text { years). Main reasons for attrition described: moved away, absent at final examination; no } \\ \text { differential group losses. }\end{array}$

\begin{tabular}{|c|c|}
\hline Participants & $\begin{array}{l}740 \text { children analysed at } 3 \text { years (available at final examination). } \\
\text { Age range at start: } 11-12 \text { years. Surfaces affected at start: } 6.9 \text { DFS. } \\
\text { Background exposure to fluoride: none reported. } \\
\text { Year study began: } 1970 . \\
\text { Location: UK. }\end{array}$ \\
\hline Interventions & $\begin{array}{l}\text { FT versus PL } \\
\text { (SMFP group }=1000 \mathrm{ppm} F \text { ). } \\
\text { Home use/unsupervised, daily frequency assumed. } \\
\text { Abrasive system: Al oxide trihydrate. }\end{array}$ \\
\hline Outcomes & $\begin{array}{l}\text { 3yNetDFS increment - }(E+U)(C A) c l+(E R) \times r . \\
\text { Reported at } 3 \text { years follow up. } \\
\text { DMFS. } \\
\text { DFT. } \\
\text { DMFT. } \\
\text { PF-DMFS. } \\
\text { MD-BL-DMFS. } \\
\text { MD-DMFS. } \\
\text { O-DMFS. } \\
\text { ECSI. }\end{array}$ \\
\hline Notes & $\begin{array}{l}\text { Participants randomised ( } \mathrm{N}=846 \text { ). } \\
\text { Baseline characteristics (age, dental age, TAR, DFS, DMFS, DFT, DMFT, ECSI) 'balanced'. } \\
\text { Clinical (VT) caries assessment by two examiners; diagnostic threshold = CA. Radiographic assessment } \\
\text { ( } 2 \text { postBW) by two examiners; diagnostic threshold = ER. State of tooth eruption included = E/U. Repro- } \\
\text { ducibility ratio was less than } 0.22 \text { for intra-examiner reproducibility of clinical and radiographic caries } \\
\text { diagnosis; "significant differences between examiners could not have affected caries increment figures } \\
\text { since each examined same children annually". }\end{array}$ \\
\hline
\end{tabular}

\section{Risk of bias}

\begin{tabular}{lll} 
Bias & Authors' judgement & Support for judgement \\
\hline $\begin{array}{ll}\text { Allocation concealment } \\
\text { (selection bias) }\end{array}$ & Unclear risk & B - Unclear
\end{tabular}


Ashley 1977

Methods

Stratified random allocation; double-blind (A); placebo-controlled; $12 \%$ drop out (for all study groups combined) after 2 years (study duration $=2$ years). Natural losses; any differential group losses not assessable.

\begin{tabular}{|c|c|}
\hline Participants & $\begin{array}{l}489 \text { children analysed at } 2 \text { years (available at final examination). } \\
\text { Average age at start: } 12 \text { years. } \\
\text { Surfaces affected at start: } 9.1 \text { DFS. } \\
\text { Background exposure to fluoride: none. } \\
\text { Year study began: } 1973 . \\
\text { Location: UK. }\end{array}$ \\
\hline Interventions & $\begin{array}{l}\text { FT versus PL } \\
\text { (SMFP group = } 1000 \text { ppm F). } \\
\text { School use/supervised, daily, } 1 \mathrm{~g} \text { applied for } 1 \text { min, post-brushing water rinse done (non-fluoride tooth } \\
\text { paste provided to all for home use). } \\
\text { Abrasive system: IMP (main abrasive). }\end{array}$ \\
\hline Outcomes & $\begin{array}{l}\text { 2yNetDFS increment - }(E+U)(N C A) c l+(E R) \times r . \\
\text { Reported at } 2 \text { years follow up. } \\
\text { PF-DFS. } \\
\text { MD-BL-DFS. } \\
\text { MD-DFS. } \\
\text { DFS (U). }\end{array}$ \\
\hline Notes & $\begin{array}{l}\text { Participants randomised (numbers for relevant groups NR). } \\
\text { Baseline characteristics (age, DFS, DMFS, DMFT) 'balanced'. } \\
\text { Clinical (V) caries assessment by one examiner (FOTI used); diagnostic threshold = NCA. Radiograph- } \\
\text { ic assessment (postBW) by one examiner; diagnostic threshold = ER. State of tooth eruption included } \\
=\text { E/U. Intra-examiner reproducibility checks for incremental caries data (icc for clinical } 0.95 \text {, for radi- } \\
\text { ographic } 0.8 \text { ); reversal rate between } 12 \% \text { and } 7 \% \text { of observed DFS increment in study groups. }\end{array}$ \\
\hline
\end{tabular}

\section{Risk of bias}

\begin{tabular}{lll}
\hline Bias & Authors' judgement & Support for judgement \\
\hline $\begin{array}{l}\text { Allocation concealment } \\
\text { (selection bias) }\end{array}$ & Unclear risk & B - Unclear \\
\hline
\end{tabular}

\section{Blinkhorn 1983}

\begin{tabular}{ll}
\hline Methods & $\begin{array}{l}\text { Stratified random allocation; double-blind (A); placebo-controlled; 10\% drop out after } 3 \text { years (study } \\
\text { duration = } 3 \text { years). Reasons for attrition described with respective total numbers: } 57 \text { left school, } 12 \\
\text { withdrawn by parents, } 6 \text { absent at final examination; no differential group losses. }\end{array}$ \\
\hline Participants & 368 children analysed at 3 years (available at final examination). \\
& $\begin{array}{l}\text { Age range at start: } 11-12 \text { years. } \\
\text { Surfaces affected at start: } 8.2 \text { DMFS. } \\
\text { Background exposure to fluoride: none reported. } \\
\text { Year study began: } 1972 . \\
\text { Location: UK. }\end{array}$ \\
\hline Interventions & FT versus PL \\
& (SMFP group $=1000 \mathrm{ppm} \mathrm{F).}$
\end{tabular}


Blinkhorn 1983 (Continued)

School use/supervised, daily, for $1 \mathrm{~min}$, post-brushing water rinse done (appropriate toothpastes also provided for home use).

Abrasive system: IMP (main abrasive).

Outcomes
Reported at 3 years follow up.
PF-DFS.
MD-BL-DFS.
MD-DFS.
postMD-DFS.
DFS (U).
DMFT.
anterior DMFT.
posterior DMFT.
DMFT (U).
Participants randomised (N=410).
Baseline characteristics (DMFS, DMFT, SAR) 'balanced' (DFS baseline data NR).
Clinical (V) caries assessment by one examiner, diagnostic threshold = CA. Radiographic assessment (1
postBW) by one examiner; diagnostic threshold = DR. State of tooth eruption included = E/U. Intra-ex-
aminer reproducibility checks for incremental clinical and radiographic caries data in $10 \%$ sample (icc
score 0.9$)$.

\section{Risk of bias}

\begin{tabular}{lll}
\hline Bias & Authors' judgement & Support for judgement \\
\hline $\begin{array}{l}\text { Allocation concealment } \\
\text { (selection bias) }\end{array}$ & Unclear risk & B - Unclear \\
\hline
\end{tabular}

\section{Brudevold 1966}

$\begin{array}{ll}\text { Methods } & \text { Stratified random allocation; double-blind ('A'); placebo-controlled; } 25 \% \text { drop out (for all study groups } \\ \text { combined) after } 2 \text { years (study duration = } 2 \text { years). Reasons for attrition NR; any differential group loss- } \\ \text { es not assessable. }\end{array}$

Participants
Average age at start: 7-16 years (average =12).
Surfaces affected at start: 15.7 DFS.
Background exposure to fluoride: data not available for fluoridation status of site.
Year study began: 1961.
Location: USA.

$\begin{array}{ll}\text { Interventions } & \text { FT (3 groups) }{ }^{\star *} \text { versus 'PL' } \\ & (\text { both SnF2 groups }=1000 \mathrm{ppm} \mathrm{F,} \mathrm{APF} \mathrm{group}=1000 \mathrm{ppm} \mathrm{F}) .\end{array}$

Home use/unsupervised, daily frequency assumed.

Abrasive system: Ca pyrophosphate in one SnF2 toothpaste, IMP in the other SnF2 and in the APF toothpaste, control toothpaste abrasive NR.

2yDFS increment - cl+xr.
Reported at 2 years follow up.
DMFS.
DMFT.
DFT.


Brudevold 1966 (Continued)

Notes
Participants randomised (numbers for relevant groups NR).

Baseline characteristics (dental age, DFS, DFT, DMFS, DMFT, gender) 'balanced'.

Clinical (VT) caries assessment by two examiners; diagnostic threshold = CA. Radiographic assessment

(10 BW) by one examiner; diagnostic threshold NR. State of tooth eruption included NR. Diagnostic er-

rors NR.

${ }^{\star \star} \mathrm{NaF}$-secondary Ca phosphate toothpaste group not considered (abrasive system known to be incompatible with $\mathrm{NaF}$ ).

\section{Risk of bias}

\begin{tabular}{lll}
\hline Bias & Authors' judgement & Support for judgement \\
\hline $\begin{array}{l}\text { Allocation concealment } \\
\text { (selection bias) }\end{array}$ & Unclear risk & B - Unclear \\
\hline
\end{tabular}

Buhe 1984

$\begin{array}{ll}\text { Methods } & \text { Stratified random allocation; double-blind }(\mathrm{A}) \text {; placebo-controlled; } 18 \% \text { drop out after } 3 \text { years (study } \\ \text { duration }=3 \text { years). No differential group losses. }\end{array}$

Participants
Age range at start: $11-13$ years
(average $=12$ ).
Surfaces affected at start: 17.4 DMFS.
Background exposure to fluoride: data not obtained for fluoridation status of site.
Year study began: 1976.
Location: FRG.

\begin{tabular}{ll}
\hline Interventions & $\begin{array}{l}\text { FT (2 groups) versus PL } \\
\text { (SMFP groups = 1000 ppm F and }\end{array}$ \\
& $\begin{array}{l}\text { Home use/unsupervised, daily } \\
\text { Abrasive system: IMP. }\end{array}$ \\
\hline Outcomes & 3yNetDFS increment - cl+xr. \\
& Reported at 3 years follow up. \\
& DMFS. \\
& DMFS (U). \\
DMFT.
\end{tabular}

\begin{tabular}{ll}
\hline Notes & Participants randomised ( $N=1562)$. \\
& Baseline characteristics (age, TAR, DMFS) 'balanced' (DFS baseline data NR). \\
& Clinical (VT) caries assessment; diagnostic threshold NR; state of tooth eruption included E/U. Radi- \\
& ographic caries assessment; diagnostic threshold NR.
\end{tabular}

\section{Risk of bias}

\begin{tabular}{lll}
\hline Bias & Authors' judgement & Support for judgement \\
\hline $\begin{array}{l}\text { Allocation concealment } \\
\text { (selection bias) }\end{array}$ & Unclear risk & B - Unclear \\
\hline
\end{tabular}




\section{Cahen 1982}

\section{Methods}

Stratified random allocation; double-blind (A); placebo-controlled; $20 \%$ drop out after 3 years (study duration $=3$ years). Natural losses and exclusions based on presence in all follow-up examinations; any differential group losses not assessable.
2008 children analysed at 3 years (present for all examinations).

Age range at start: 6-8 years (average $=7$ ).

Surfaces affected at start: 1.4 DMFS (control group only).

Background exposure to fluoride: data not obtained for fluoridation status of site.

Year study began: 1977.

Location: France.

$\begin{array}{ll}\text { Interventions } & \text { FT (2 groups) versus PL } \\ & (\text { SMFP group }=1500 \mathrm{ppm} \mathrm{F,} \mathrm{AmF} \mathrm{group}=1500 \mathrm{ppm} \mathrm{F}) .\end{array}$

Home use/unsupervised, daily frequency assumed.

Abrasive system: IMP in the SMFP and placebo toothpaste, Ca carbonate/ Na and Al silicates in the AmF toothpaste.

\begin{tabular}{|c|c|}
\hline Outcomes & $\begin{array}{l}\text { 3yDMFS increment - cl+xr. } \\
\text { Reported at } 3 \text { years follow up. } \\
\text { DMFT. } \\
\text { df-rate. }\end{array}$ \\
\hline Notes & $\begin{array}{l}\text { Participants randomised ( } \mathrm{N}=2500) \text {; numbers by group NR. } \\
\text { Baseline characteristics (age, gender) 'balanced'. } \\
\text { Clinical (V) caries assessment by six examiners; diagnostic threshold = NR; state of tooth eruption in- } \\
\text { cluded NR. Radiographic assessment ( } 2 \text { postBW) by one examiner; diagnostic threshold NR; partial } \\
\text { recording. Inter- and intra-examiner reproducibility of clinical and radiographic caries diagnosis as- } \\
\text { sessed in 10\% sample ("good reproducibility, NS difference between or within examiners"). }\end{array}$ \\
\hline
\end{tabular}

\section{Risk of bias}

\section{Bias Authors' judgement Support for judgement}

Allocation concealment Unclear risk B-Unclear

(selection bias)

\section{Di Maggio 1980}

Methods Random allocation; double-blind (A); placebo-controlled; $16 \%$ drop out (for both study groups combined) after 2 years (study duration $=2$ years). Main reason for attrition described: left institution; any differential group losses not assessable.

Participants children analysed at 2 years (available at final examination).
Age range at start: $11-12$ years. Surfaces affected at start: 11.7 DMFS.
Background exposure to fluoride: data not obtained for fluoridation status of site.
Year study began: in/before 1977.
Location: Italy.

Interventions $\quad$ FT versus PL

(SMFP-NaF group $=2500 \mathrm{ppm}$ F).

Institution use/supervised, three times a day.

Abrasive system: not clearly specified. 
Di Maggio 1980 (Continued)

Outcomes
2yDMFS increment - $\mathrm{cl}$.

Reported at 1 and 2 years follow ups.

DMFT.
Participants randomised $(\mathrm{N}=50)$.

Baseline characteristics (DMFS, DMFT) 'balanced'.

Clinical caries assessment by two examiners; diagnostic threshold NR; state of tooth eruption included NR. Diagnostic errors NR.

\section{Risk of bias}

\begin{tabular}{lll}
\hline Bias & Authors' judgement & Support for judgement \\
\hline $\begin{array}{l}\text { Allocation concealment } \\
\text { (selection bias) }\end{array}$ & Unclear risk & B - Unclear \\
\hline
\end{tabular}

Dolles 1980

\begin{tabular}{ll}
\hline Methods & Stratified random allocation; double-blind (A); placebo-controlled; $22 \%$ natural drop out after 2 years \\
& (study duration $=2$ years). Reasons for attrition described with numbers by group: unacceptable stain- \\
& ing $(3,4)$, unacceptable taste $(2,0)$, change of residence $(0,2)$, other reasons/lack of co-operation $(1,1) ;$ \\
& exclusions based on presence in all follow-up examinations; no differential group losses.
\end{tabular}

Participants

47 children analysed at 2 years (present for all examinations).

Average age at start: 13 years. Surfaces affected at start: NR.

Background exposure to fluoride: none. Year study began: 1974 .

Location: Norway.

\begin{tabular}{|c|c|}
\hline Interventions & $\begin{array}{l}\mathrm{FT}(\mathrm{Chlor}) \text { versus } \mathrm{PL}(\mathrm{Chlor}){ }^{\star *} \\
(\mathrm{NaF} \text { toothpaste }=500 \mathrm{ppm} \mathrm{F}) \\
\text { Home use/unsupervised, daily frequency assumed (instructed to brush for } 2 \text { min twice a day). } \\
\text { Abrasive system: plastic particles. }\end{array}$ \\
\hline Outcomes & $\begin{array}{l}\text { 2yDS increment - }(C A) c l+(E R) x r . \\
\text { Reported at } 2 \text { years follow up. } \\
\text { Proportion of children with new carious surface. }\end{array}$ \\
\hline Notes & $\begin{array}{l}\text { Participants randomised }(\mathrm{N}=60) \text {. } \\
\text { Baseline characteristics NR. } \\
\text { Clinical (VT) caries assessment, diagnostic threshold = CA; state of tooth eruption included NR. Radi- } \\
\text { ographic assessment (postBW), diagnostic threshold = ER. Diagnostic errors NR. } \\
{ }^{\star *} \text { Chlorhexidine present in both, the fluoride and the non-fluoride toothpaste groups (other outcomes } \\
\text { measured, such as tooth staining, not considered relevant for the comparison of interest). }\end{array}$ \\
\hline
\end{tabular}

\section{Risk of bias}

\begin{tabular}{lll}
\hline Bias & Authors' judgement & Support for judgement \\
\hline $\begin{array}{l}\text { Allocation concealment } \\
\text { (selection bias) }\end{array}$ & Unclear risk & B - Unclear \\
\hline
\end{tabular}


Fanning 1968

\begin{tabular}{|c|c|}
\hline Methods & $\begin{array}{l}\text { Stratified random allocation; double-blind (A); placebo-controlled; } 22 \% \text { natural drop out after } 2 \text { years } \\
\text { (study duration = } 2 \text { years); no differential group losses ( } 46 \% \text { drop out based on analysis performed for } \\
\text { randomised block design). }\end{array}$ \\
\hline Participants & $\begin{array}{l}844 \text { children analysed at } 2 \text { years ( } 422 \text { complete replicates of each group available). } \\
\text { Age range at start: } 12-14 \text { years (average }=13 \text { ). Surfaces affected at start: } 17.7 \text { DMFS (from sample ran- } \\
\text { domised). Background exposure to fluoride: none. Year study began: } 1964 \text {. Location: Australia. }\end{array}$ \\
\hline Interventions & $\begin{array}{l}\mathrm{FT}^{\star \star} \text { versus } \mathrm{PL} \\
(\mathrm{SnF} 2 \text { group }=1000 \mathrm{ppm} \mathrm{F}) \\
\text { Home use/unsupervised, daily frequency assumed. } \\
\text { Abrasive system: IMP. }\end{array}$ \\
\hline Outcomes & $\begin{array}{l}\text { 2yDMFS increment }-(C A) c l+(E R) x r \\
\text { Reported at } 2 \text { years follow up. } \\
\text { Stain score. }\end{array}$ \\
\hline Notes & $\begin{array}{l}\text { Participants randomised ( } N=1576) \text {. } \\
\text { Baseline characteristics (DMFS, DMFT, SAR) 'balanced'. } \\
\text { Clinical (VT) caries assessment by two examiners; diagnostic threshold = CA. Radiographic assessment } \\
\text { ( } 5 \mathrm{BW} \text { ) by two examiners; diagnostic threshold = ER. State of tooth eruption included = E/U. Intra- and } \\
\text { inter-examiner reproducibility of clinical caries diagnosis (DFS) assessed annually by duplicate exami- } \\
\text { nation of } 10 \% \text { random sample ("error relatively small, NS difference between or within examiners"). } \\
{ }^{* \star N a ~ N-l a u r o y l ~ s a r c o s i n a t e / S M F P ~ t o o t h p a s t e ~ g r o u p ~ n o t ~ c o n s i d e r e d ~(a d d i t i o n a l ~ n o n-F ~ a c t i v e ~ a g e n t ~ u s e d ~} \\
\text { in this group only). }\end{array}$ \\
\hline
\end{tabular}

\section{Risk of bias}

\begin{tabular}{lll}
\hline Bias & Authors' judgement & Support for judgement \\
\hline $\begin{array}{l}\text { Allocation concealment } \\
\text { (selection bias) }\end{array}$ & Unclear risk & B - Unclear \\
\hline
\end{tabular}

\section{Fogels 1979}

$\begin{array}{ll}\text { Methods } & \text { Random allocation; double-blind (A); placebo-controlled; } 40 \% \text { drop out after } 3 \text { years (study duration = } \\ & \text { 3 years). Reasons for attrition described: graduations, change of residence/school, parental requests, } \\ & \text { and ortho treatment; no differential group losses. }\end{array}$

Participants
Age range at start: $6-11$ years (average $=9$ ).
Surfaces affected at start: 4.9 DFS. Background exposure to fluoride: none reported.
Year study began: 1972.
Location: USA.

Interventions

FT (2 groups) versus PL (both SnF2 groups $=1000$ ppm F).

Home use/unsupervised, daily frequency assumed.

Abrasive system: silica gel in one SnF2 and placebo toothpaste, Ca pyrophosphate in the other.

$\begin{array}{ll}\text { Outcomes } & \text { 3yNetDFS increment }-(C A) c l+(E R) x r . \\ \text { Reported at } 3 \text { years follow up. } \\ \text { MD-DFS. }\end{array}$


Fogels 1979 (Continued)

DFS (U).

DMFT.

Oral soft tissues lesions (data NR).

Proportion of children with tooth staining (data NR).

\begin{tabular}{ll}
\hline Notes & Participants randomised (N=2218). \\
& Baseline characteristics (DFS) 'balanced'. \\
& Clinical (VT) caries assessment by two examiners, diagnostic threshold = CA. Radiographic assessment \\
(postBW) by two examiners; diagnostic threshold = ER. State of tooth eruption included E/U. Results \\
shown for each examiner and for the pooled data from both (F-ratios less than unit for examiner by \\
treatment interactions); combined results considered.
\end{tabular}

\section{Risk of bias}

\begin{tabular}{lll}
\hline Bias & Authors' judgement & Support for judgement \\
\hline $\begin{array}{l}\text { Allocation concealment } \\
\text { (selection bias) }\end{array}$ & Unclear risk & B - Unclear \\
\hline
\end{tabular}

\section{Forsman 1974}

\section{Methods}

Random allocation; double-blind (A); placebo-controlled; $18 \%$ drop out after 2 years (study duration = 2 years). Reasons for attrition described with respective total numbers: change of residence/school, ortho treatment, did not wish to continue; no differential group losses reported (but not assessable).

Participants children analysed at 2 years (available at final examination).
Age range at start: $10-11$ years. Surfaces affected at start: 5.1 DMFS.
Background exposure to fluoride: mouthrinse.
Year study began: in/before 1970.
Location: Sweden.

\begin{tabular}{|c|c|}
\hline Interventions & $\begin{array}{l}\text { FT ( } 3 \text { groups) versus PL } \\
\text { (the NaF and one SMFP group = } 250 \text { ppm F, another SMFP group = } 1000 \text { ppm F). } \\
\text { Home use/unsupervised, daily frequency assumed. } \\
\text { Abrasive system: silica in all toothpastes. }\end{array}$ \\
\hline Outcomes & $\begin{array}{l}\text { 2yDMFS increment - (NCA)cl. } \\
\text { Reported at } 2 \text { years follow up. } \\
\text { BLMD-DFS (clin). } \\
\text { MD-DFS (x-ray). } \\
\text { Proportion of children with new smooth surface caries. }\end{array}$ \\
\hline Notes & $\begin{array}{l}\text { Participants randomised ( } \mathrm{N}=681 \text { ); numbers by group NR. } \\
\text { Baseline characteristics (dental age, DMFS) 'balanced'. } \\
\text { Clinical }(\mathrm{VT}) \text { caries assessment by one examiner, diagnostic threshold = NCA. Radiographic assessment } \\
\text { (postBW) by one examiner; diagnostic threshold = ER. State of tooth eruption included = NR. Diagnostic } \\
\text { errors NR. }\end{array}$ \\
\hline
\end{tabular}

\section{Risk of bias}


Forsman 1974 (Continued)

\begin{tabular}{l}
$\begin{array}{l}\text { Allocation concealment } \\
\text { (selection bias) }\end{array}$ Unclear risk $\quad$ B - Unclear \\
\hline
\end{tabular}

\section{Forsman 1974a}

Methods Random allocation; double-blind (A); placebo-controlled; $16 \%$ drop out after 2 years (study duration = 2 years). Reasons for attrition described with respective total numbers: change of residence/school, ortho treatment, did not wish to continue; no differential group losses reported (but not assessable).

Participants
Age range at start: 10-12 years.
Surfaces affected at start: 12.9 DMFS.
Background exposure to fluoride: mouthrinse.
Year study began: in/before 1970.
Location: Sweden.

\begin{tabular}{|c|c|}
\hline Interventions & $\begin{array}{l}\text { FT ( } 2 \text { groups) versus PL } \\
\text { (one SMFP group = } 250 \text { ppm F, another SMFP group = } 1000 \text { ppm F). } \\
\text { Home use/unsupervised, daily frequency assumed. } \\
\text { Abrasive system: Ca carbonate in all toothpastes. }\end{array}$ \\
\hline Outcomes & $\begin{array}{l}\text { 2yDMFS increment - (NCA)cl. } \\
\text { Reported at } 2 \text { years follow up. } \\
\text { BLMD-DFS (clin). } \\
\text { MD-DFS (x-ray). } \\
\text { Proportion of children with new smooth surface caries. }\end{array}$ \\
\hline Notes & $\begin{array}{l}\text { Participants randomised }(\mathrm{N}=469) \text {; numbers by group NR. } \\
\text { Baseline characteristics (dental age, DMFS) 'balanced'. } \\
\text { Clinical }(\mathrm{VT}) \text { caries assessment by one examiner, diagnostic threshold = NCA. Radiographic assessment } \\
\text { (postBW) by one examiner; diagnostic threshold = ER. State of tooth eruption included = NR. Diagnostic } \\
\text { errors NR. }\end{array}$ \\
\hline
\end{tabular}

\section{Risk of bias}

\begin{tabular}{lll}
\hline Bias & Authors' judgement & Support for judgement \\
\hline $\begin{array}{l}\text { Allocation concealment } \\
\text { (selection bias) }\end{array}$ & Unclear risk & B - Unclear \\
\hline
\end{tabular}

Gish 1966

Methods Stratified random allocation; double-blind (A); placebo-controlled; 34\% drop out after 3 years (study duration $=5$ years). Reasons for attrition NR; any differential group losses not assessable.

Participants 328 children analysed at 3 years (available at final examination).

Age range at start: $6-14$ years (average $=9$ ).

Surfaces affected at start: 3.9 DMFS.

Background exposure to fluoride: water.

Year study began: in/before 1963.

Location: USA. 
Gish 1966 (Continued)

\begin{tabular}{ll} 
Interventions & FT versus PL \\
& (SnF2 group = 1000 ppm F). \\
& Home use/unsupervised, daily frequency assumed. \\
& Abrasive system: Ca pyrophosphate. \\
\hline Outcomes & 3yDMFS increment - cl+xr. \\
& Reported at 1, 2, 3, 4 and 5 years follow ups. \\
& DMFT. \\
\hline Notes & Participants randomised ( $N=500)$; numbers by group NR. \\
& Baseline characteristics (age, DMFS) 'balanced'. \\
Clinical (VT) caries assessment by two examiners, diagnostic threshold = NR. Radiographic assessment \\
(5-7 BW); diagnostic threshold = NR. State of tooth eruption included = NR. Diagnostic errors NR.
\end{tabular}

\section{Risk of bias}

\begin{tabular}{lll}
\hline Bias & Authors' judgement & Support for judgement \\
\hline $\begin{array}{l}\text { Allocation concealment } \\
\text { (selection bias) }\end{array}$ & Unclear risk & B - Unclear \\
\hline
\end{tabular}

Glass 1978

Methods

Stratified random allocation; double-blind (A); placebo-controlled; 35\% drop out after 3 years (study duration $=3$ years). Natural losses, increased during 3rd year because an entire grade graduated; exclusions based on presence in all follow-up examinations; any differential group losses not assessable.

\begin{tabular}{|c|c|}
\hline Participants & $\begin{array}{l}346 \text { children analysed at } 3 \text { years (present for all examinations). } \\
\text { Age range at start: } 6 \text { - } 11 \text { years (average }=9 \text { ). } \\
\text { Surfaces affected at start: } 4.1 \text { DFS. } \\
\text { Background exposure to fluoride: none reported. } \\
\text { Year study began: in/before } 1974 \text {. } \\
\text { Location: USA. }\end{array}$ \\
\hline Interventions & $\begin{array}{l}\text { FT versus PL } \\
\text { (SMFP group = } 1000 \text { ppm F). } \\
\text { School use/supervised, } 1 \mathrm{~g} \text { applied daily (appropriate toothpastes and toothbrushes also provided for } \\
\text { home use). } \\
\text { Abrasive system: Ca carbonate. }\end{array}$ \\
\hline Outcomes & $\begin{array}{l}\text { 3yNetDFS increment - (CA)cl+(ER)xr. } \\
\text { Reported at } 1,2 \text { and } 3 \text { years follow ups. } \\
\text { MD-DFS. } \\
\text { O-BL-DFS. } \\
\text { DFT. } \\
\text { CIR. } \\
\text { O-BL-CIR. } \\
\text { MD-CIR. }\end{array}$ \\
\hline Notes & $\begin{array}{l}\text { Participants randomised ( } N=533) \text {; numbers by group NR. } \\
\text { Baseline characteristics (age, DFS, DFT, SAR, TAR) 'balanced'. } \\
\text { Clinical (VT) caries assessment (FOTI used) by one examiner; diagnostic threshold = CA; state of tooth } \\
\text { eruption included = E/U. Radiographic assessment ( } 2 \text { postBW) by one examiner; diagnostic threshold = }\end{array}$ \\
\hline
\end{tabular}


Glass 1978 (Continued)

ER. Reversals were small in both groups (about 6\% of DFS increments) and equally common (NS different).

\section{Risk of bias}

\begin{tabular}{lll}
\hline Bias & Authors' judgement & Support for judgement \\
\hline $\begin{array}{l}\text { Allocation concealment } \\
\text { (selection bias) }\end{array}$ & Unclear risk & D - Not used \\
\hline
\end{tabular}

Glass 1983

Methods Stratified random allocation; double-blind (A); placebo-controlled; $16 \%$ drop out after 2.5 years (study duration $=2.5$ years). Natural losses; no losses due to any adverse effects; any differential group losses not assessable.

\begin{tabular}{ll}
\hline Participants & 853 children analysed at 2.5 years (available at final examination). \\
Age range at start: $7-11$ years (average $=9)$. \\
Surfaces affected at start: 2.1 DFS. \\
Background exposure to fluoride: water. \\
Year study began: 1976. \\
Location: USA.
\end{tabular}

\begin{tabular}{|c|c|}
\hline \multirow[t]{2}{*}{ Interventions } & $\begin{array}{l}\text { FT ( } 2 \text { groups) versus } \mathrm{PL} \\
\text { (both SMFP groups }=1000 \mathrm{ppm} \mathrm{F).}\end{array}$ \\
\hline & $\begin{array}{l}\text { School use/supervised, daily (appropriate toothpastes and toothbrushes also provided for home use). } \\
\text { Abrasive system: IMP (main abrasive) in one SMFP and placebo toothpaste, Ca carbonate in the other } \\
\text { SMFP toothpaste. }\end{array}$ \\
\hline \multirow[t]{3}{*}{ Outcomes } & $\begin{array}{l}\text { 2.5yNetDFS increment - (CA)cl+(ER)xr. } \\
\text { Reported at } 2.5 \text { years follow up. }\end{array}$ \\
\hline & DFT. \\
\hline & CIR. \\
\hline \multirow[t]{3}{*}{ Notes } & Participants randomised ( $\mathrm{N}=1017$ ); numbers by group NR. \\
\hline & Baseline characteristics (age, DFS, DFT, SAR, TAR) 'balanced' (for DFT/DFS). \\
\hline & $\begin{array}{l}\text { Clinical (VT) caries assessment by two examiners (independently); diagnostic threshold = CA; state of } \\
\text { tooth eruption included = E/U. Radiographic assessment ( } 2 \text { postBW) by two examiners (independently); }\end{array}$ \\
\hline
\end{tabular}

\section{Risk of bias}

\begin{tabular}{lll}
\hline Bias & Authors' judgement & Support for judgement \\
\hline $\begin{array}{l}\text { Allocation concealment } \\
\text { (selection bias) }\end{array}$ & Unclear risk & B - Unclear \\
\hline
\end{tabular}

Hanachowicz 1984

$\begin{array}{ll}\text { Methods } & \text { Stratified random allocation; double-blind (A); placebo-controlled; } 28 \% \text { drop out after } 3 \text { years (study } \\ \text { duration = } 3 \text { years). Natural losses and exclusions based on compliance; no differential group losses. }\end{array}$


Hanachowicz 1984 (Continued)

Participants 945 children analysed at 3 years (available at final examination and cooperative).

Age range at start: $10-12$ years.

Surfaces affected at start: 5.4 DMFS.

Background exposure to fluoride: none reported.

Year study began: 1979.

Location: France.

\begin{tabular}{|c|c|}
\hline Interventions & $\begin{array}{l}\text { FT versus PL } \\
\text { (SMFP group = } 1500 \text { ppm F). } \\
\text { Home use/unsupervised, daily frequency assumed. } \\
\text { Abrasive system: Al oxide trihydrate. }\end{array}$ \\
\hline Outcomes & $\begin{array}{l}\text { 3yNetDMFS increment - }(E)(C A) c l+x r . \\
\text { Reported at } 3 \text { years follow up. } \\
\text { DMFT. } \\
\text { DMFS }(U) \text {. } \\
\text { O-DMFS. } \\
\text { MD-DMFS. } \\
\text { BL-DMFS. } \\
\text { premolarDMFT. } \\
\text { premolarDMFS. } \\
\text { Proportion of children with new caries. }\end{array}$ \\
\hline Notes & $\begin{array}{l}\text { Participants randomised }(\mathrm{N}=1318) \text {. } \\
\text { Baseline characteristics (DMFS) 'balanced'. } \\
\text { Clinical }(\mathrm{VT}) \text { caries assessment by two examiners; diagnostic threshold }=\mathrm{CA} \text {; radiographic assessment } \\
\text { ( } 2 \text { postBW) by one examiner; diagnostic threshold NR. State of tooth eruption included }=\mathrm{E} / \mathrm{U} \text {. Consis- } \\
\text { tency of clinical and } x \text {-ray diagnosis assessed by duplicate examinations of } 6 \% \text { sample (inter-examiner } \\
\text { reproducibility ratios } 0.24 \text { for clinical and } 0.13 \text { for } x \text {-ray; intra-examiner reproducibility } 0.27 \text { for clinical } \\
\text { and } 0.14 \text { for } x \text {-ray). }\end{array}$ \\
\hline
\end{tabular}

\section{Risk of bias}

\begin{tabular}{lll}
\hline Bias & Authors' judgement & Support for judgement \\
\hline $\begin{array}{l}\text { Allocation concealment } \\
\text { (selection bias) }\end{array}$ & Unclear risk & B - Unclear \\
\hline
\end{tabular}

\section{Hargreaves 1973}

$\begin{array}{ll}\text { Methods } & \text { Quasi-random allocation; double-blind (A); placebo-controlled; } 4 \% \text { drop out after } 3 \text { years (study dura- } \\ \text { tion = } 3 \text { years). Reasons for attrition NR; exclusions based on presence in all follow-up examinations; } \\ \text { any differential group losses not assessable. }\end{array}$

$\begin{array}{ll}\text { Participants } & 303 \text { children analysed at } 3 \text { years (present for all examinations). } \\ & \text { Age at start: } 6 \text { years. } \\ \text { Surfaces affected at start: } 13.9 \text { dfs (data for deciduous dentition only). } \\ \text { Background exposure to fluoride: none reported. } \\ \text { Year study began: } 1968 . \\ \text { Location: UK. }\end{array}$


Hargreaves 1973 (Continued)

Home use/unsupervised, daily frequency assumed.

Abrasive system: Al oxide trihydrate.

\begin{tabular}{|c|c|c|}
\hline Outcomes & \multicolumn{2}{|l|}{$\begin{array}{l}\text { DFT. } \\
\text { DMFS. } \\
\text { DMFT. } \\
\text { ECSI. }\end{array}$} \\
\hline Notes & \multicolumn{2}{|c|}{$\begin{array}{l}\text { Participants randomised ( } \mathrm{N}=316) \text {; numbers by group NR. } \\
\text { Baseline characteristics (age, tar, dfs, dmfs, dft, dmft, ecsi) 'balanced' (no DFS data at start). } \\
\text { Clinical }(\mathrm{VT}) \text { caries assessment by two examiners; diagnostic threshold = CA; radiographic assessment } \\
\text { ( } 2 \text { postBW) by two examiners; diagnostic threshold = ER. State of tooth eruption included = E/U. Diag- } \\
\text { nostic errors NR. }\end{array}$} \\
\hline \multicolumn{3}{|l|}{ Risk of bias } \\
\hline Bias & Authors' judgement & Support for judgement \\
\hline $\begin{array}{l}\text { Allocation concealment } \\
\text { (selection bias) }\end{array}$ & High risk & $\mathrm{C}$ - Inadequate \\
\hline
\end{tabular}

Hargreaves 1973a

Methods Quasi-random allocation; double-blind (A); placebo-controlled; $5 \%$ drop out after 3 years (study duration $=3$ years). Reasons for attrition NR; exclusions based on presence in all follow-up examinations; any differential group losses not assessable.

\begin{tabular}{ll}
\hline Participants & 284 children analysed at 3 years (present for all examinations). \\
& Age at start: 9 years. \\
Surfaces affected at start: 6.3 DFS. \\
Background exposure to fluoride: none reported. \\
Year study began: 1968. \\
Location: UK. \\
FT versus PL \\
(SMFP group = 2400 ppm F). \\
Home use/unsupervised, daily frequency assumed. \\
Abrasive system: Al oxide trihydrate. \\
3yNetDFS increment - (E+U)(CA)cl+(ER)xr. \\
Reported at 3 years follow up. \\
DFT. \\
DMFS. \\
DMFT. \\
ECSI. \\
Participants randomised (N = 298); numbers by group NR. \\
Baseline characteristics (age, TAR, DFS, DMFS, DFT, DMFT, ECSI) 'balanced'. \\
Clinical (VT) caries assessment by two examiners; diagnostic threshold = CA; radiographic assessment \\
(2 postBW) by two examiners; diagnostic threshold = ER. State of tooth eruption included = E/U. Diag- \\
nostic errors NR. \\
\hline Notes
\end{tabular}


Hargreaves 1973a (Continued)

Risk of bias

\begin{tabular}{lll}
\hline Bias & Authors' judgement & Support for judgement \\
\hline $\begin{array}{l}\text { Allocation concealment } \\
\text { (selection bias) }\end{array}$ & High risk & C-Inadequate \\
\hline
\end{tabular}

\section{Hargreaves 1973b}

$\begin{array}{ll}\text { Methods } & \text { Quasi-random allocation; double-blind (A); placebo-controlled; } 6 \% \text { drop out after } 3 \text { years (study dura- } \\ \text { tion }=3 \text { years). Reasons for attrition NR; exclusions based on presence in all follow-up examinations; } \\ \text { any differential group losses not assessable. }\end{array}$

Participants
Age at start: 12 years.
Surfaces affected at start: 9.2 DFS.
Background exposure to fluoride: none reported.
Year study began: 1968.
Location: UK.

\begin{tabular}{|c|c|}
\hline Interventions & $\begin{array}{l}\text { FT versus PL } \\
\text { (SMFP group }=2400 \mathrm{ppm} F \text { ). } \\
\text { Home use/unsupervised, daily frequency assumed. } \\
\text { Abrasive system: Al oxide trihydrate. }\end{array}$ \\
\hline Outcomes & $\begin{array}{l}\text { 3yNetDFS increment - }(E+U)(C A) c l+(E R) x r . \\
\text { Reported at } 3 \text { years follow up. } \\
\text { DFT. } \\
\text { DMFS. } \\
\text { DMFT. } \\
\text { ECSI. }\end{array}$ \\
\hline Notes & $\begin{array}{l}\text { Participants randomised ( } \mathrm{N}=317 \text { ); numbers by group NR. } \\
\text { Baseline characteristics (age, TAR, DFS, DMFS, DFT, DMFT, ECSI) 'balanced'. } \\
\text { Clinical }(\mathrm{VT}) \text { caries assessment by two examiners; diagnostic threshold = CA; radiographic assessment } \\
\text { ( } 2 \text { postBW) by two examiners; diagnostic threshold = ER. State of tooth eruption included = E/U. Diag- } \\
\text { nostic errors NR. }\end{array}$ \\
\hline
\end{tabular}

\section{Risk of bias}

\begin{tabular}{lll}
\hline Bias & Authors' judgement & Support for judgement \\
\hline $\begin{array}{l}\text { Allocation concealment } \\
\text { (selection bias) }\end{array}$ & High risk & C - Inadequate \\
\hline
\end{tabular}

\section{Held 1968}

$\begin{array}{ll}\text { Methods } & \text { Stratified random allocation; double-blind (A); placebo-controlled; } 65 \% \text { drop out after } 3 \text { years (study } \\ \text { duration = } 3 \text { years). Reasons for high drop out due to age range at which many leave the institutions; no } \\ \text { differential group losses. }\end{array}$


Held 1968 (Continued)

Age range at start: $15-16$ years.

Surfaces affected at start: 14.3 DMFS.

Background exposure to fluoride: data not available for fluoridation status of site.

Year study began: 1962.

Location: France.

\begin{tabular}{ll}
\hline Interventions & $\begin{array}{l}\text { FT versus PL } \\
\text { (NaF-SnF2 group = } 1000 \text { ppm F). }\end{array}$ \\
& $\begin{array}{l}\text { Institution use/supervised, twice a day. } \\
\text { Abrasive system: not clearly specified (silica used). }\end{array}$ \\
\hline Outcomes & $\begin{array}{l}\text { 3yDMFS increment - (E) cl. } \\
\text { Reported at 3 years follow up. } \\
\text { DMFT. } \\
\text { Annual CAR. }\end{array}$ \\
\hline Notes & $\begin{array}{l}\text { Participants randomised (N = 178). } \\
\text { Baseline characteristics (DMFS, DMFT) not balanced. } \\
\text { Clinical (VT) caries assessment by one examiner; diagnostic threshold NR; state of tooth eruption in- } \\
\text { cluded = E. Intra-examiner reproducibility checks done. }\end{array}$ \\
\hline Risk of bias & Authors' judgement Support for judgement \\
\hline Bias & Unclear risk $\quad$ B - Unclear \\
\hline (selection bias)
\end{tabular}

Held 1968a

Methods Stratified random allocation; double-blind (A); placebo-controlled; 64\% drop out after 3 years (study duration $=3$ years). Reasons for high drop out due to age range at which many leave the institutions; no differential group losses.

\begin{tabular}{ll}
\hline Participants & 36 children analysed at 3 years (available at final examination). \\
& Age range at start: 15-16 years. \\
Surfaces affected at start: 9.6 DMFS. \\
Background exposure to fluoride: data not available for fluoridation status of site. \\
Year study began: 1961. \\
Location: France.
\end{tabular}

\begin{tabular}{ll}
\hline Notes & Participants randomised ( $N=101)$. \\
& Baseline characteristics (DMFS, DMFT) not balanced.
\end{tabular}


Held 1968a (Continued)

Clinical (VT) caries assessment by one examiner; diagnostic threshold NR; state of tooth eruption included $=$ E. Intra-examiner reproducibility checks done.

\section{Risk of bias}

\begin{tabular}{lll}
\hline Bias & Authors' judgement & Support for judgement \\
\hline $\begin{array}{l}\text { Allocation concealment } \\
\text { (selection bias) }\end{array}$ & Unclear risk & B - Unclear \\
\hline
\end{tabular}

Held 1968b

Methods Stratified random allocation; double-blind (A); placebo-controlled; 62\% drop out after 2 years (study duration $=3$ years). Reasons for high drop out due to age range at which many leave the institutions; no differential group losses.

Participants children analysed at $2^{\star}$ years (available at final examination).
Average age at start: 15 years.
Surfaces affected at start: 10.2 DMFS.
Background exposure to fluoride: data not available for fluoridation status of site.
Year study began: 1961.
Location: France.

\begin{tabular}{|c|c|}
\hline Interventions & $\begin{array}{l}\text { FT versus } P L \\
\text { (NaF group = } 500 \text { ppm F). } \\
\text { Institution use/supervised, twice a day. } \\
\text { Abrasive system: not clearly specified (silica used). }\end{array}$ \\
\hline Outcomes & $\begin{array}{l}2 \mathrm{y}^{\star} \text { DMFS increment }-(\mathrm{E}) \mathrm{cl} \text {. } \\
\text { Reported at } 2 \text { and } 3 \text { years follow ups. } \\
\text { DMFT. } \\
\text { Annual CAR. }\end{array}$ \\
\hline Notes & $\begin{array}{l}\text { Participants randomised ( } N=85 \text { ). } \\
\text { Baseline characteristics (DMFS, DMFT) not balanced. } \\
\text { Clinical (VT) caries assessment by one examiner; diagnostic threshold NR; state of tooth eruption in- } \\
\text { cluded = E. Intra-examiner reproducibility checks done. } \\
{ }^{*} \text { Results for } 3 \text { years follow up not considered due to very high drop out rate. }\end{array}$ \\
\hline
\end{tabular}

\section{Risk of bias}

\begin{tabular}{lll}
\hline Bias & Authors' judgement & Support for judgement \\
\hline $\begin{array}{l}\text { Allocation concealment } \\
\text { (selection bias) }\end{array}$ & Unclear risk & B - Unclear \\
\hline
\end{tabular}

\section{Hodge 1980}

$\begin{array}{ll}\text { Methods } & \text { Stratified random allocation; double-blind (A); placebo-controlled; } 18 \% \text { drop out after } 3 \text { years (study } \\ \text { duration = } 3 \text { years). Reasons for attrition described with respective total numbers: } 158 \text { left school, } 14 \\ \text { withdrawn by own choice, } 8 \text { lack of co-operation; any differential group losses not assessable. }\end{array}$

Participants 799 children analysed at 3 years (available at final examination).


Hodge 1980 (Continued)

Age range at start: 11-12 years.

Surfaces affected at start: 7.3 DMFS.

Background exposure to fluoride: none reported.

Year study began: in/before 1976.

Location: UK.

\begin{tabular}{|c|c|}
\hline Interventions & $\begin{array}{l}\text { FT ( } 3 \text { groups) versus PL } \\
\text { (SMFP group = } 1000 \mathrm{ppm} \text { F, both SMFP-NaF groups = } 1450 \mathrm{ppm} \text { F). } \\
\text { School use/supervised, daily, for } 1 \text { min (appropriate toothpastes also provided for home use). } \\
\text { Abrasive system: alumina (in placebo toothpaste, SMFP and in one SMFP-NaF toothpaste), dicalcium } \\
\text { phosphate (in another SMFP-NaF toothpaste). }\end{array}$ \\
\hline Outcomes & $\begin{array}{l}\text { 3yNetDFS increment - (E) (CA)cl+(DR)xr. } \\
\text { Reported at } 3 \text { years follow up. } \\
\text { DMFT. }\end{array}$ \\
\hline Notes & $\begin{array}{l}\text { Participants randomised ( } N=979) \text {; numbers by group NR. } \\
\text { Baseline characteristics (DMFS, DMFT, SAR) 'balanced' (DFS baseline data NR). } \\
\text { Clinical (VT) caries assessment by one examiner; diagnostic threshold = CA; state of tooth eruption in- } \\
\text { cluded = E/U; radiographic assessment ( } 2 \text { postBW) by one examiner; diagnostic threshold = DR. Repro- } \\
\text { ducibility checks done in } 10 \% \text { sample clinically and radiographically (icc of incremental data between } \\
0.92 \text { and } 0.97 \text { ). }\end{array}$ \\
\hline
\end{tabular}

\section{Risk of bias}

\begin{tabular}{lll}
\hline Bias & Authors' judgement & Support for judgement \\
\hline $\begin{array}{l}\text { Allocation concealment } \\
\text { (selection bias) }\end{array}$ & Unclear risk & B - Unclear \\
\hline
\end{tabular}

Homan 1969

Methods Stratified random allocation; double-blind (A); placebo-controlled; $19 \%$ drop out after 1.7 years (study duration $=1.7$ years). Reasons for attrition not described; any differential group losses not assessable.

\begin{tabular}{ll}
\hline Participants & $\begin{array}{l}\text { 1874 children analysed at } 1.7 \text { years. } \\
\text { Age range at start: } 7-13 \text { years. } \\
\text { Surfaces affected at start: data not available nor obtainable. } \\
\text { Background exposure to fluoride: none. } \\
\text { Year study began: } 1965 . \\
\text { Location: Australia. }\end{array}$ \\
\hline Interventions & (SnF2 and APF toothpaste concentrations NR nor obtainable). \\
& $\begin{array}{l}\text { Home use/unsupervised, daily frequency assumed. } \\
\text { Abrasive system: Ca pyrophosphate in one SnF2 toothpaste, calcium-free abrasive in the other SnF2 } \\
\text { toothpaste and in the APF toothpaste; abrasive in placebo toothpaste NR. }\end{array}$ \\
\hline Outcomes & $\begin{array}{l}\text { Caries increment data NR (not obtainable). } \\
\text { Percentage DFS reductions by gender and age groups } \\
\text { reported at } 1.7 \text { years follow up. }\end{array}$ \\
\hline Notes & Participants randomised ( $=2317) ;$ numbers by group NR. \\
& Baseline characteristics NR.
\end{tabular}


Homan 1969 (Continued)

Clinical (VT) caries assessment by two examiners; diagnostic threshold = CA; state of tooth eruption included = E; radiographic assessment; diagnostic threshold = DR. Diagnostic errors NR.

\section{Risk of bias}

\begin{tabular}{lll}
\hline Bias & Authors' judgement & Support for judgement \\
\hline $\begin{array}{l}\text { Allocation concealment } \\
\text { (selection bias) }\end{array}$ & Low risk & A - Adequate \\
\hline
\end{tabular}

Horowitz 1966

$\begin{array}{ll}\text { Methods } & \begin{array}{l}\text { Quasi-random allocation; double-blind (A); placebo-controlled; } 40 \% \text { drop-out rate after } 3 \text { years (study } \\ \text { duration = } 3 \text { years). Natural losses; no differential group losses. }\end{array}\end{array}$

\begin{tabular}{|c|c|}
\hline Participants & $\begin{array}{l}638 \text { children analysed at } 3 \text { years (available at final examination). } \\
\text { Age range at start: } 6-10 \text { years. } \\
\text { Surfaces affected at start: } 2.08 \text { DMFS. } \\
\text { Background exposure to fluoride: none reported. } \\
\text { Year study began: } 1961 . \\
\text { Location: USA. }\end{array}$ \\
\hline Interventions & $\begin{array}{l}\text { FT versus } \mathrm{PL}^{\star \star} \\
\text { (SnF2 group }=1000 \mathrm{ppm} \mathrm{F} \text { ). } \\
\text { Home use/unsupervised, daily frequency assumed. } \\
\text { Abrasive system: Ca pyrophosphate. }\end{array}$ \\
\hline Outcomes & $\begin{array}{l}\text { 3yNetDMFS increment - }(\mathrm{E}+\mathrm{U})(\mathrm{CA}) \mathrm{cl} \text {. } \\
\text { Reported at 1, 2, and } 3 \text { years follow ups. } \\
\text { DMFT. }\end{array}$ \\
\hline Notes & 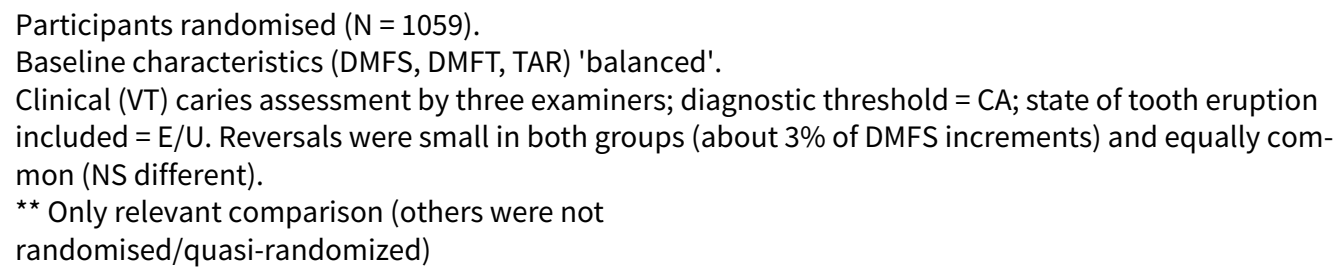 \\
\hline
\end{tabular}

\section{Risk of bias}

\begin{tabular}{lll}
\hline Bias & Authors' judgement & Support for judgement \\
\hline $\begin{array}{l}\text { Allocation concealment } \\
\text { (selection bias) }\end{array}$ & High risk & C - Inadequate \\
\hline
\end{tabular}

\section{Howat 1978}

Random allocation; double-blind (A); placebo-controlled; $12 \%$ drop out after 3 years (study duration =
3 years). Reasons for attrition described with respective total numbers ( 56 left school, 7 withdrawn by
own choice, 2 lack of co-operation); any differential group losses not assessable.

Participants 495 children analysed at 3 years (available at final examination).


Howat 1978 (Continued)

Age range at start: $11-12$ years.

Surfaces affected at start: 7.4 DMFS.

Background exposure to fluoride: none reported.

Year study began: in/before 1974.

Location: UK.

\begin{tabular}{|c|c|}
\hline Interventions & $\begin{array}{l}\text { FT versus PL } \\
\text { (SMFP group = } 1000 \text { ppm F). } \\
\text { School use/supervised, daily, for } 1 \text { min (appropriate toothpastes also provided for home use). } \\
\text { Abrasive system: silica zerogel. }\end{array}$ \\
\hline Outcomes & $\begin{array}{l}\text { 3yNetDMFS increment - }(\mathrm{E})(\mathrm{CA}) \mathrm{cl}+(\mathrm{DR}) \mathrm{xr} \text {. } \\
\text { Reported at } 3 \text { years follow up. } \\
\text { antDMFS. } \\
\text { postDMFS. } \\
\text { PF-DMFS. } \\
\text { MD-DMFS. } \\
\text { MD-BL-DMFS. } \\
\text { DMFT. }\end{array}$ \\
\hline Notes & $\begin{array}{l}\text { Participants randomised ( } N=560) \text {; numbers by group NR. } \\
\text { Baseline characteristics (DMFS, DMFT, SAR) 'balanced'. } \\
\text { Clinical (VT) caries assessment by one examiner; diagnostic threshold = CA; state of tooth eruption in- } \\
\text { cluded = E/U; radiographic assessment ( } 2 \text { postBW) by one examiner; diagnostic threshold = DR. Repro- } \\
\text { ducibility checks done in } 10 \% \text { sample clinically and radiographically (icc of incremental data between } \\
0.96 \text { and } 0.99 \text { ). }\end{array}$ \\
\hline
\end{tabular}

\section{Risk of bias}

\begin{tabular}{lll}
\hline Bias & Authors' judgement & Support for judgement \\
\hline $\begin{array}{l}\text { Allocation concealment } \\
\text { (selection bias) }\end{array}$ & Unclear risk & B - Unclear \\
\hline
\end{tabular}

\section{Jackson 1967}

\section{Methods}

Quasi-random allocation; double-blind (A); placebo-controlled; $12 \%$ drop-out rate after 3 years (study duration $=3$ years). Natural losses; no differential group losses.

Participants children analysed at 3 years
(available at final examination).
Age range at start: $11-12$ years. Surfaces affected at start: 8.7 DMFS.
Background exposure to fluoride: none reported.
Year study began: 1962.
Location: UK.

\begin{tabular}{ll}
\hline Interventions & FT versus PL \\
& $($ SnF2 group $=1000 \mathrm{ppm} \mathrm{F})$.
\end{tabular}

Home use/unsupervised, daily frequency assumed.

Abrasive system: dicalcium pyrophosphate.

$\begin{array}{ll}\text { Outcomes } & \text { 3yDMFS increment }-(E+U)(C A) c l . \\ \text { Reported at 3 years follow up. } \\ \text { DMFT. }\end{array}$


Proportion of children who complained of tooth staining.

Notes $\quad$ Participants randomised ( $N=986)$.

Baseline characteristics (age, DMFS, DMFT, TAR, level of treatment, staining) 'balanced'.

Clinical (VT) caries assessment by one examiner; diagnostic threshold = CA; state of tooth eruption included $=\mathrm{E} / \mathrm{U}$. Consistency of clinical diagnosis maintained by re-examination of $10 \%$ sample and calibration checks made against reserve examiner.

\section{Risk of bias}

\begin{tabular}{lll}
\hline Bias & Authors' judgement & Support for judgement \\
\hline $\begin{array}{l}\text { Allocation concealment } \\
\text { (selection bias) }\end{array}$ & High risk & C-Inadequate \\
\hline
\end{tabular}

\section{James 1967}

$\begin{array}{ll}\text { Methods } & \text { Random allocation; double-blind (A); placebo-controlled; 23\% drop out rate after } 3 \text { years (study dura- } \\ \text { tion }=3 \text { years). Reasons for drop out described with respective total numbers: moved away, unco-op- } \\ \text { erative, not present on examination day, disliked toothpaste, staining of teeth, others; no differential } \\ \text { group losses. }\end{array}$

Participants
(available at final examination).
Age range at start: $11-12$ years. Surfaces affected at start: 11 DFS.
Background exposure to fluoride: data not available for fluoridation status of site.
Year study began: 1962.
Location: UK.

\begin{tabular}{ll}
\hline Interventions & FT versus PL \\
(SnF2 group $=1000 \mathrm{ppm} F)$. \\
Home use/unsupervised, daily frequency assumed. \\
Abrasive system: dicalcium pyrophosphate. \\
\hline Outcomes \\
(CA)cl+(ER)xr. \\
Reported at 3 years follow up. \\
DMFS. \\
DFT. \\
DMFT. \\
postMD-DFS. \\
Proportion of children with tooth staining. \\
Participants randomised (N = 1043). \\
Baseline characteristics (age, DFS, DFT, DMFS, DMFT) 'balanced'. \\
Clinical (VT) caries assessment by one examiner; diagnostic threshold = CA; state of tooth eruption in- \\
cluded = E/U. Radiographic assessment (2 postBW) by one examiner; diagnostic threshold = ER. Diag- \\
nostic errors NR.
\end{tabular}

\section{Risk of bias}


James 1967 (Continued)

\begin{tabular}{l}
$\begin{array}{l}\text { Allocation concealment } \\
\text { (selection bias) }\end{array}$ Unclear risk $\quad$ B - Unclear \\
\hline
\end{tabular}

James 1977

Methods Stratified random allocation; double-blind (A); placebo-controlled; $19 \%$ drop out after 3 years (study duration $=3$ years). Reasons for attrition NR; exclusions based on presence in all follow-up examinations; any differential group losses not assessable.

Participants

782 children analysed at 3 years (present for all examinations).

Age range at start: $11-12$ years.

Surfaces affected at start: 11.2 DMFS.

Background exposure to fluoride: data not available for fluoridation status of site.

Year study began: 1970 .

Location: UK.

\begin{tabular}{ll}
\hline Interventions & FT versus PL \\
& (SMFP group $=2400 \mathrm{ppm} F)$. \\
& Home use/unsupervised, daily frequency assumed. \\
& Abrasive system: Al oxide trihydrate. \\
\hline Outcomes & 3yDMFS increment - (CA)cl+(ER)xr. \\
Reported at 3 years follow up. & postMD-DMFS. \\
O-DMFS. & BL-DMFS. \\
O-BL-MDDMFS. \\
antDMFS. \\
Participants randomised ( $\mathrm{N}=964)$; numbers by group NR. \\
Baseline characteristics (age, gender, DMFS) 'balanced'. \\
Clinical (VT) caries assessment by two examiners; diagnostic threshold = CA; radiographic assessment \\
(2 postBW); state of tooth eruption included NR. Inter- and intra- examiner reliability for clinical and ra- \\
diographic diagnosis revealed by re-examination of 10\% sample.
\end{tabular}

\section{Risk of bias}

\begin{tabular}{lll}
\hline Bias & Authors' judgement & Support for judgement \\
\hline $\begin{array}{l}\text { Allocation concealment } \\
\text { (selection bias) }\end{array}$ & Unclear risk & B - Unclear \\
\hline
\end{tabular}

\section{Kinkel 1972}

Methods Random allocation; double-blind (A); placebo-controlled; 25\% drop-out rate after 3 years (study dura-
tion $=7$ years). Reasons for drop out not described; any differential group losses not assessable.

Participants 699 children analysed at 3 years.

Average age at start: 10 years. Surfaces affected at start: 2.2 DMFS.

Background exposure to fluoride: data not available.

Year study began: in/before 1969.

Location: Switzerland. 
Kinkel 1972 (Continued)

$\begin{array}{ll}\text { Interventions } & \text { FT versus PL } \\ \text { (SMFP group F concentration NR). } \\ \text { Home use/unsupervised, daily frequency assumed. } \\ \text { Abrasive system: NR. }\end{array}$

\begin{tabular}{ll}
\hline Outcomes & 3yDMFS increment $-(\mathrm{CA}) \mathrm{cl}+(\mathrm{DR}) \mathrm{xr}$. \\
& Reported at $1,2,3,4,5$ and 7 years follow ups. \\
\hline Notes & Participants randomised ( $\mathrm{N}=927)$; numbers by group NR. \\
& Baseline characteristics (DMFS) 'balanced'. \\
& Clinical (V) caries assessment; diagnostic threshold = CA and NCA; state of tooth eruption included NR. \\
& Radiographic assessment (2 postBW); diagnostic threshold = DR and ER.
\end{tabular}

\section{Risk of bias}

\begin{tabular}{lll}
\hline Bias & Authors' judgement & Support for judgement \\
\hline $\begin{array}{l}\text { Allocation concealment } \\
\text { (selection bias) }\end{array}$ & Unclear risk & B - Unclear \\
\hline
\end{tabular}

Kleber 1996

Methods Stratified random allocation; double-blind (A); placebo-controlled; $10 \%$ drop out after 1 year (study duration $=1$ year). Main reasons for attrition: changes in residence, few exclusions for initiation of ortho treatment; no differential group losses.

\begin{tabular}{|c|c|}
\hline Participants & $\begin{array}{l}156 \text { children analysed at } 1 \text { year (available at final examination). } \\
\text { Age range at start: } 10-11 \text { years (average = 10.7). } \\
\text { Surfaces affected at start: } 4.2 \text { DMFS. } \\
\text { Background exposure to fluoride: none reported. } \\
\text { Year study began: in/before } 1994 . \\
\text { Location: USA. }\end{array}$ \\
\hline Interventions & $\begin{array}{l}\mathrm{FT}(+ \text { Alrins) versus } \mathrm{PL}(+ \text { Alrins) } \\
(\text { NaF toothpaste }=1100 \mathrm{ppm} \mathrm{F}) \\
\text { Home use/unsupervised, daily frequency assumed. } \\
\text { Abrasive system: silica. }\end{array}$ \\
\hline Outcomes & $\begin{array}{l}\text { 1yDMFS increment - }(\mathrm{CA}) \mathrm{cl}+(\mathrm{ER}) \mathrm{xr} \text {. } \\
\text { Reported at } 0.6 \text { and } 1 \text { year follow ups. } \\
\text { DMFT. } \\
\text { Proportion of children remaining caries-free. } \\
\text { Proportion of children with new DMFS. } \\
\text { Oral soft tissues lesions. }\end{array}$ \\
\hline Notes & $\begin{array}{l}\text { Participants randomised ( } \mathrm{N}=174) \text {. } \\
\text { Baseline characteristics (age, gender DMFS, DMFT) 'balanced'. } \\
\text { Clinical }(\mathrm{VT}) \text { caries assessment by two examiners; diagnostic threshold = CA; state of tooth eruption in- } \\
\text { cluded = E/U. Radiographic assessment (postBW) by two examiners (independently); diagnostic thresh- } \\
\text { old = ER. } \\
\text { Reversals were small in both groups and equally common. Results of one examiner chosen (findings } \\
\text { consistent throughout). }\end{array}$ \\
\hline
\end{tabular}


Kleber 1996 (Continued)

**Rinsing with 500 ppm Al solutions performed daily at school in both relevant groups compared.

\section{Risk of bias}

\begin{tabular}{lll}
\hline Bias & Authors' judgement & Support for judgement \\
\hline $\begin{array}{l}\text { Allocation concealment } \\
\text { (selection bias) }\end{array}$ & Unclear risk & B - Unclear \\
\hline
\end{tabular}

\section{Koch 1967}

$\begin{array}{ll}\text { Methods } & \begin{array}{l}\text { Stratified random allocation } \\ \text { duration }=3 \text { years }+2 \text { years post-intervention period). Natural losses; no differential group losses. }\end{array}\end{array}$

Participants
Age range at start: 8-10 years (average $=9)$.
Surfaces affected at start: 11.3 DFS.
Background exposure to fluoride: none reported.
Year study began: 1962.
Location: Sweden.

\begin{tabular}{ll}
\hline Interventions & FT versus PL \\
& $($ NaF group $=1000 \mathrm{ppm} \mathrm{F})$. \\
& School use/supervised, daily, $1 \mathrm{~g}$ applied for 2 min (non-fluoride toothpaste provided to all for home \\
use). & Abrasive system: methacrylate polymer (acrylic).
\end{tabular}

Outcomes
Reported at 1 and 3 years follow ups (and 2 years post-treatment).
DFT.
O-DFS.
MD-DFS.
BL-DFS.
Annual CAR.
Secondary caries.
Participants randomised (N = 153).
Baseline characteristics (DFS, DFT, SAR) 'balanced'.
Clinical (VT) caries assessment by one examiner; diagnostic threshold = CA; radiographic assessment (2
postBW) used as an aid but not reported; state of tooth eruption included = E.
Intra-examiner reproducibility checks for DFS in 10\% sample (icc over 0.98); reversals very small in
both groups and equally common.
$\star * \star A l l o c a t i o n$ concealment considered adequate by consensus.

\section{Risk of bias}

\begin{tabular}{lll}
\hline Bias & Authors' judgement & Support for judgement \\
\hline $\begin{array}{l}\text { Allocation concealment } \\
\text { (selection bias) }\end{array}$ & Low risk & A - Adequate \\
\hline
\end{tabular}


Koch 1967a

Methods

\section{Participants}

Stratified random allocation ${ }^{\star \star \star}$; double-blind (A); placebo-controlled; $18 \%$ drop out after 3 years (study duration $=3$ years +2 years post-intervention period). Natural losses; no differential group losses.

\begin{tabular}{|c|c|}
\hline & $\begin{array}{l}\text { Age range at start: } 11-12 \text { years (average = 11). } \\
\text { Surfaces affected at start: } 19.7 \text { DFS. } \\
\text { Background exposure to fluoride: none reported. } \\
\text { Year study began: } 1962 \text {. } \\
\text { Location: Sweden. }\end{array}$ \\
\hline Interventions & $\begin{array}{l}\text { FT versus PL } \\
\text { (NaF group = } 1000 \text { ppm F). } \\
\text { School use/supervised, daily, } 1 \mathrm{~g} \text { applied for } 2 \text { min (non-fluoride toothpaste provided to all for home } \\
\text { use). } \\
\text { Abrasive system: methacrylate polymer (acrylic). }\end{array}$ \\
\hline Outcomes & $\begin{array}{l}\text { 3yDFS increment }-\mathrm{cl}(\mathrm{CA})(\mathrm{E}) \text {. } \\
\text { Reported at } 1 \text { and } 3 \text { years follow ups (and } 2 \text { years post-treatment). } \\
\text { DFT. } \\
\text { O-DFS. } \\
\text { MD-DFS. } \\
\text { BL-DFS. } \\
\text { Annual CAR. } \\
\text { Secondary caries. }\end{array}$ \\
\hline Notes & $\begin{array}{l}\text { Participants randomised ( } N=146) \text {. } \\
\text { Baseline characteristics (DFS, DFT, SAR, TAR) 'balanced'. } \\
\text { Clinical (VT) caries assessment by one examiner; diagnostic threshold = CA; radiographic assessment ( } 2 \\
\text { postBW) used as an aid but not reported; state of tooth eruption included = E. } \\
\text { Intra-examiner reproducibility checks for DFS in } 10 \% \text { sample (icc over } 0.98) \text {; reversals very small in } \\
\text { both groups and equally common. } \\
\star * * \text { Allocation concealment considered adequate by consensus. }\end{array}$ \\
\hline
\end{tabular}

\section{Risk of bias}

\begin{tabular}{lll}
\hline Bias & Authors' judgement & Support for judgement \\
\hline $\begin{array}{l}\text { Allocation concealment } \\
\text { (selection bias) }\end{array}$ & Low risk & A - Adequate \\
\hline
\end{tabular}

\section{Koch 1967b}

Methods Stratified random allocation ${ }^{\star \star \star}$; double-blind (A); placebo-controlled; $19 \%$ drop out after 2 years (study
duration $=2$ years). Natural losses; any differential group losses not assessable.

$\begin{array}{ll}\text { Participants } & 70 \text { children analysed at } 2 \text { years (present for entire trial period). } \\ & \text { Age range at start: } 13-14 \text { years. } \\ \text { Surfaces affected at start: } 30.1 \text { DFS. } \\ \text { Background exposure to fluoride: none reported. } \\ \text { Year study began: } 1963 . \\ \text { Location: Sweden. }\end{array}$


Koch 1967b (Continued)

Home use/unsupervised, twice a day instructed frequency but daily frequency assumed, for $2 \mathrm{~min}$.

Abrasive system: methacrylate polymer (acrylic).

\begin{tabular}{ll}
\hline Outcomes & 2yDFS increment $-\mathrm{cl}(\mathrm{CA})(\mathrm{E})$. \\
& Reported at 2 years follow up. \\
& DFT. \\
O-DFS. \\
MD-DFS. \\
BL-DFS. \\
Annual CAR. \\
Secondary caries. \\
Participants randomised ( $N=86)$; numbers by group NR. \\
Baseline characteristics (FS, FT, SAR, TAR) 'balanced'. \\
Clinical (VT) caries assessment by one examiner; diagnostic threshold = CA; radiographic assessment (2 \\
postBW) used as an aid but not reported; state of tooth eruption included = E. Diagnostic errors NR. \\
$\star * \star A l l o c a t i o n$ concealment considered adequate by consensus. \\
\hline
\end{tabular}

\section{Risk of bias}

\begin{tabular}{lll}
\hline Bias & Authors' judgement & Support for judgement \\
\hline $\begin{array}{l}\text { Allocation concealment } \\
\text { (selection bias) }\end{array}$ & Low risk & A - Adequate \\
\hline
\end{tabular}

\section{Koch 1967 c}

\begin{tabular}{|c|c|}
\hline Methods & $\begin{array}{l}\text { Stratified random allocation }{ }^{\star \star \star} \text {; double-blind (A); placebo-controlled; } 19 \% \text { drop out after } 3 \text { years (study } \\
\text { duration = } 3 \text { years). Natural losses; no differential group losses. }\end{array}$ \\
\hline Participants & $\begin{array}{l}255 \text { children analysed at } 3 \text { years (present for entire trial period). } \\
\text { Age range at start: } 7-10 \text { years. Surfaces affected at start: } 7.9 \text { DFS. } \\
\text { Background exposure to fluoride: none reported. } \\
\text { Year study began: } 1962 \text {. } \\
\text { Location: Sweden. }\end{array}$ \\
\hline Interventions & $\begin{array}{l}\text { FT versus PL } \\
\text { (NaF group = } 1000 \mathrm{ppm} F) \text {. } \\
\text { School clinic/supervised, } 3 \text { times a year, } 1 \mathrm{~g} \text { applied for } 2 \mathrm{~min} \text { (no provision of any toothpaste reported } \\
\text { for home use). } \\
\text { Abrasive system: methacrylate polymer (acrylic). }\end{array}$ \\
\hline Outcomes & $\begin{array}{l}\text { 3yDFS increment }-\mathrm{cl}(\mathrm{CA})(\mathrm{E}) \text {. } \\
\text { Reported at } 1 \text { and } 3 \text { years follow ups. } \\
\text { DFT. } \\
\text { Annual CAR. } \\
\text { Secondary caries. }\end{array}$ \\
\hline Notes & $\begin{array}{l}\text { Participants randomised }(\mathrm{N}=316) \text {. } \\
\text { Baseline characteristics (FS, FT, SAR, TAR) 'balanced'. } \\
\text { Clinical }(\mathrm{VT}) \text { caries assessment by one examiner; diagnostic threshold = CA; radiographic assessment ( } 2 \\
\text { postBW) used as an aid but not reported; state of tooth eruption included = E. Diagnostic errors NR. } \\
{ }_{\star \star \star} \text { Allocation concealment considered adequate by consensus. }\end{array}$ \\
\hline
\end{tabular}


Koch 1967c (Continued)

Risk of bias

\begin{tabular}{lll}
\hline Bias & Authors' judgement & Support for judgement \\
\hline $\begin{array}{l}\text { Allocation concealment } \\
\text { (selection bias) }\end{array}$ & Low risk & A - Adequate \\
\hline
\end{tabular}

Lind 1974

Methods Stratified random allocation; double-blind (A); placebo-controlled; $17 \%$ drop-out rate after 3 years (study duration = 3 years). Main reasons for drop out: moved away, sickness; exclusions based on presence in one interim examination; no differential group losses.

\begin{tabular}{|c|c|}
\hline Participants & $\begin{array}{l}1167 \text { children analysed at } 3 \text { years (available at intermediate and final examination). } \\
\text { Age range at start: } 7-12 \text { years (average = 10). } \\
\text { Surfaces affected at start: } 5.1 \text { DMFS. } \\
\text { Background exposure to fluoride: water. } \\
\text { Year study began: } 1970 . \\
\text { Location: Denmark. }\end{array}$ \\
\hline Interventions & $\begin{array}{l}\text { FT versus PL } \\
\text { (SMFP group }=2400 \text { ppm F). } \\
\text { Home use/unsupervised, daily frequency assumed. } \\
\text { Abrasive system: Al oxide trihydrate. }\end{array}$ \\
\hline Outcomes & $\begin{array}{l}\text { 3yNetDMFS increment }-(\mathrm{E}+\mathrm{U})(\mathrm{CA}) \mathrm{cl}+(\mathrm{DR}) \mathrm{xr} \text {. } \\
\text { Reported at } 1,2 \text {, and } 3 \text { years follow ups. } \\
\text { DMFT. } \\
\text { ECSI. }\end{array}$ \\
\hline Notes & $\begin{array}{l}\text { Participants randomised ( } \mathrm{N}=1407) \text {. } \\
\text { Baseline characteristics (age, DMFS, DMFT) 'balanced'. } \\
\text { Clinical }(\mathrm{VT}) \text { caries assessment by two examiners; diagnostic threshold = CA/NCA; radiographic assess- } \\
\text { ment ( } 2 \text { postBW) by two examiners; diagnostic threshold = ER/DR; state of tooth eruption included = E/ } \\
\text { U. Inter-examiner diagnostic error reported to have no effect on results; reversal rates small and similar } \\
\text { in both groups. }\end{array}$ \\
\hline
\end{tabular}

\section{Risk of bias}

\begin{tabular}{lll}
\hline Bias & Authors' judgement & Support for judgement \\
\hline $\begin{array}{l}\text { Allocation concealment } \\
\text { (selection bias) }\end{array}$ & Unclear risk & B - Unclear \\
\hline
\end{tabular}

\section{Mainwaring 1978}

\begin{tabular}{ll}
\hline Methods & $\begin{array}{l}\text { Stratified random allocation; double-blind (A); placebo-controlled; } \\
\text { combined) after } 3 \text { years (study duration = } 3 \text { years). Natural losses; } \\
\text { sessable. }\end{array}$ \\
\hline Participants & $\begin{array}{l}1107 \text { children analysed at } 3 \text { years (available at final examination). } \\
\text { Age range at start: } 11-12 \text { years. }\end{array}$
\end{tabular}


Mainwaring 1978 (Continued)

Surfaces affected at start: 7.9 DFS.

Background exposure to fluoride: none reported.

Year study began: in/before 1974 .

Location: UK.

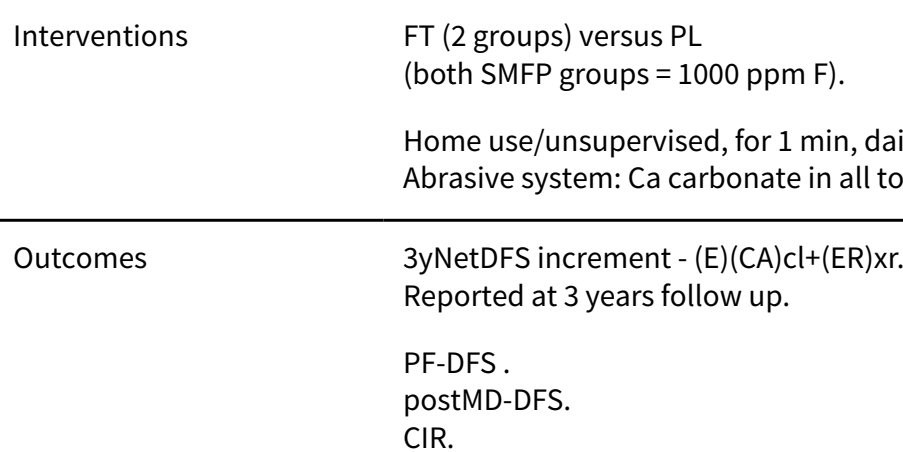

Notes Participants randomised (numbers for relevant groups NR).

Baseline characteristics (age, SAR, DFS) 'balanced'.

Clinical (VT) caries assessment by one examiner; diagnostic threshold = CA; state of tooth eruption included $=$ E. Radiographic assessment ( 2 postBW) by one examiner; diagnostic threshold = ER. Intra-examiner reproducibility checks for DFS in $10 \%$ sample (icc for VT/XR over 0.95 ); error variance less than $5 \%$ of total variance; reversal rate less than $5 \%$ of observed DFS increment in all groups.

\section{Risk of bias}

\begin{tabular}{lll}
\hline Bias & Authors' judgement & Support for judgement \\
\hline $\begin{array}{l}\text { Allocation concealment } \\
\text { (selection bias) }\end{array}$ & Unclear risk & B - Unclear \\
\hline
\end{tabular}

Mainwaring 1983

$\begin{array}{ll}\text { Methods } & \text { Stratified random allocation; double-blind (A); placebo-controlled; } 19 \% \text { drop out (for all study groups } \\ \text { combined) after } 4 \text { years (study duration }=4 \text { years). Natural losses, no losses due to any adverse effects; } \\ \text { any differential group losses not assessable. }\end{array}$

Participants
Age range at start: $11-12$ years.
Surfaces affected at start: 6.9 DFS.
Background exposure to fluoride: none reported.
Year study began: in/before 1978.
Location: UK.

Interventions

FT (2 groups) ${ }^{\star \star}$ versus PL

$($ SMFP group $=1000$ ppm F, SMFP-NaF group $=1000 \mathrm{ppm} \mathrm{F})$.

Home use/unsupervised, daily frequency assumed.

Abrasive system: Ca carbonate in all toothpastes.

$\begin{array}{ll}\text { Outcomes } & \text { 4yNetDFS increment }-(C A) c l+(E R) x r . \\ & \text { Reported at } 4 \text { years follow up. } \\ & \text { O-DFS. } \\ \text { MD-DFS. } \\ \text { postMD-DFS. }\end{array}$


Mainwaring 1983 (Continued)

MD-BL-DFS.

Notes Participants randomised (numbers for relevant groups NR).

Baseline characteristics (age, SAR, DFS, FS) 'balanced'.

Clinical (VT) caries assessment (FOTI used) by one examiner; diagnostic threshold = CA; state of tooth eruption included NR. Radiographic assessment ( 2 postBW) by one examiner; diagnostic threshold = ER. Intra-examiner reproducibility checks for DFS in $10 \%$ sample (icc for VT/XR over 0.95 ).

${ }^{\star \star} \mathrm{Ca}$ glycerophosphate/SMFP toothpaste group not considered (additional non-F active agent in this group only).

\section{Risk of bias}

\begin{tabular}{lll}
\hline Bias & Authors' judgement & Support for judgement \\
\hline $\begin{array}{l}\text { Allocation concealment } \\
\text { (selection bias) }\end{array}$ & Unclear risk & B - Unclear \\
\hline
\end{tabular}

\section{Marthaler 1965}

$\begin{array}{ll}\text { Methods } & \text { Random allocation; double-blind (A); } \\ & \text { placebo-controlled; } 43 \% \text { drop out (for all study groups combined) after } 3 \text { years (study duration }=7 \\ & \text { years). Exclusions based on variation in toothpaste provision and presence in follow-up examinations; } \\ & \text { any differential group losses not assessable. }\end{array}$

Participants 269 children analysed at 3 years (present for all examinations).
Age range at start: 6-9 years (average = 8).
Surfaces affected at start: 3.3 DMFS.
Background exposure to fluoride: salt (suboptimal).
Year study began: 1958.
Location: Switzerland.

\begin{tabular}{ll}
\hline Interventions & FT versus PL \\
& $($ AmF group $=1250 \mathrm{ppm} \mathrm{F})$.
\end{tabular}

Home use/unsupervised, daily frequency assumed.

Abrasive system: IMP.

\begin{tabular}{l} 
Outcomes \\
Reported at $1.5,3,5$ and 7 years follow ups. \\
postMD-DFS. \\
antMD-DFS. \\
BL-DFS. \\
O-DFS. \\
DMFT. \\
FT. \\
FS. \\
MT. \\
Participants randomised (numbers for relevant groups NR). \\
Baseline characteristics (age, DMFS, DMFT) 'balanced' (DFS baseline data NR). \\
Clinical (V) caries assessment by one examiner; diagnostic threshold = CA and NCA; state of tooth erup- \\
tion included NR. Radiographic assessment (2 postBW) by one examiner; diagnostic threshold = DR and \\
ER; partial recording. Diagnostic errors NR. \\
\hline Notes
\end{tabular}

\section{Risk of bias}


Marthaler 1965 (Continued)

\begin{tabular}{lll} 
Bias & Authors' judgement & Support for judgement \\
\hline $\begin{array}{l}\text { Allocation concealment } \\
\text { (selection bias) }\end{array}$ & Low risk & A-Adequate \\
\hline
\end{tabular}

Marthaler 1965a

\begin{tabular}{ll}
\hline Methods & Random allocation; double-blind $(\mathrm{A}) ;$ \\
& placebo-controlled; $66 \%$ drop out (for all study groups combined) after 3 years (study duration $=3$ \\
& years). Main reason for high drop out: children leaving public school on completion of last compulso- \\
& ry year; exclusions based on variation in toothpaste provision and presence in follow-up examinations; \\
& any differential group losses not assessable.
\end{tabular}

\begin{tabular}{|c|c|}
\hline Participants & $\begin{array}{l}74 \text { children analysed at } 3 \text { years (present for all examinations). } \\
\text { Age range at start: } 11-14 \text { years (average = 13). } \\
\text { Surfaces affected at start: } 18.9 \text { DMFS. } \\
\text { Background exposure to fluoride: salt (suboptimal). } \\
\text { Year study began: } 1958 . \\
\text { Location: Switzerland. }\end{array}$ \\
\hline Interventions & $\begin{array}{l}\text { FT versus PL } \\
\text { (AmF group = } 1250 \mathrm{ppm} F) \\
\text { Home use/unsupervised, daily frequency assumed. } \\
\text { Abrasive system: IMP. }\end{array}$ \\
\hline Outcomes & $\begin{array}{l}\text { 3yNetDFS increment - (CA)cl+(DR)xr. } \\
\text { Reported at } 3 \text { years follow up. } \\
\text { postMD-DFS. } \\
\text { antMD-DFS. } \\
\text { BL-DFS. } \\
\text { O-DFS. } \\
\text { DMFT. } \\
\text { FT. } \\
\text { FS. } \\
\text { MT. }\end{array}$ \\
\hline Notes & $\begin{array}{l}\text { Participants randomised (numbers for relevant groups NR). } \\
\text { Baseline characteristics (age, DMFS, DMFT) 'balanced' (DFS baseline data NR). } \\
\text { Clinical (V) caries assessment by one examiner; diagnostic threshold = CA and NCA; state of tooth erup- } \\
\text { tion included NR. Radiographic assessment ( } 2 \text { postBW) by one examiner; diagnostic threshold = DR and } \\
\text { ER; partial recording. Diagnostic errors NR. }\end{array}$ \\
\hline
\end{tabular}

\section{Risk of bias}

\begin{tabular}{lll}
\hline Bias & Authors' judgement & Support for judgement \\
\hline $\begin{array}{l}\text { Allocation concealment } \\
\text { (selection bias) }\end{array}$ & Low risk & A - Adequate \\
\hline
\end{tabular}


Marthaler 1970

$\begin{array}{ll}\text { Methods } & \text { Random allocation; indication of blind caries assessment (C); placebo-controlled; } 18 \% \text { drop out (for all } \\ \text { study groups combined) after } 3 \text { years (study duration = } 3 \text { years). Exclusions based on use of orthodontic } \\ \text { bands and presence in all follow-up examinations; any differential group losses not assessable. }\end{array}$

\begin{tabular}{|c|c|c|}
\hline Participants & \multicolumn{2}{|c|}{$\begin{array}{l}100 \text { children analysed at } 3 \text { years (present for all examinations). } \\
\text { Age range at start: } 6-7 \text { years (average }=7 \text { ). } \\
\text { Surfaces affected at start: } 1 \text { DMFS. } \\
\text { Background exposure to fluoride: salt (suboptimal). } \\
\text { Year study began: } 1966 . \\
\text { Location: Switzerland. }\end{array}$} \\
\hline Interventions & \multicolumn{2}{|c|}{$\begin{array}{l}\text { FT versus PL } \\
(\text { AmF group }=1250 \mathrm{ppm} F) \\
\text { Home use/unsupervised, twice/three times a day/680 times a year estimated. } \\
\text { Abrasive system: IMP. }\end{array}$} \\
\hline Outcomes & \multicolumn{2}{|c|}{$\begin{array}{l}\text { 3yNetDFS increment - (CA)cl+(DR)xr. } \\
\text { Reported at } 1 \text { and } 3 \text { years follow ups. }\end{array}$} \\
\hline Notes & \multicolumn{2}{|c|}{$\begin{array}{l}\text { Participants randomised (numbers for relevant groups NR). } \\
\text { Baseline characteristics (age, DMFS, 1stmDMFS) 'balanced' (DFS baseline data NR). } \\
\text { Clinical (V) caries assessment by two examiners; diagnostic threshold = CA and NCA; state of tooth } \\
\text { eruption included NR. Radiographic assessment ( } 2 \text { postBW) by two examiners; diagnostic threshold = } \\
\text { DR and ER; partial recording. "Sufficient agreement of the two examiners known from earlier work". }\end{array}$} \\
\hline \multicolumn{3}{|l|}{ Risk of bias } \\
\hline Bias & Authors' judgement & Support for judgement \\
\hline $\begin{array}{l}\text { Allocation concealment } \\
\text { (selection bias) }\end{array}$ & Unclear risk & B - Unclear \\
\hline
\end{tabular}

\section{Marthaler 1970a}

$\begin{array}{ll}\text { Rethods } & \text { Random allocation; indication of blind caries assessment (C); placebo-controlled; } 30 \% \text { drop out (for all } \\ \text { study groups combined) after } 4 \text { years (study duration = } 4 \text { years). Exclusions based on: use of orthodon- } \\ \text { tic bands, and presence in all follow-up examinations; any differential group losses not assessable. }\end{array}$

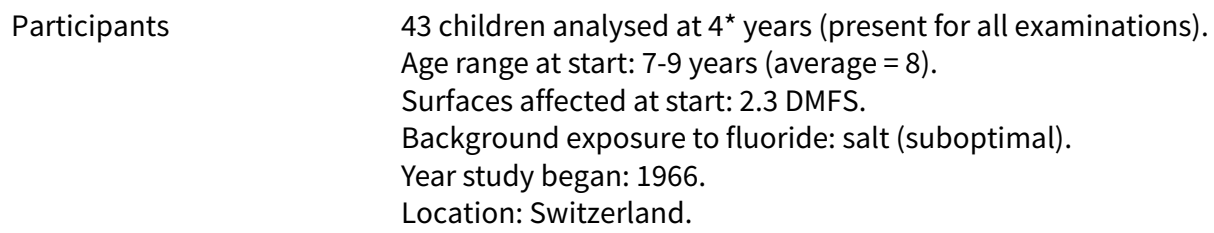

\begin{tabular}{ll}
\hline Interventions & $\begin{array}{l}\text { FT versus PL } \\
\text { (AmF group }=1250 \mathrm{ppm} \mathrm{F}) . \\
\text { Home use/unsupervised, twice/three } \\
\text { Abrasive system: IMP. }\end{array}$ \\
\hline Outcomes & $\begin{array}{l}2 y^{*} \text { NetDFS increment }-(C A) c l+(D R) x r . \\
\text { Reported at } 2 \text { and } 4 \text { years follow ups. }\end{array}$
\end{tabular}


Marthaler 1970a (Continued)

1stmPF-DFS.

1stmMD-DFS.

\begin{tabular}{ll}
\hline Notes & Participants randomised (numbers for relevant groups NR). \\
& Baseline characteristics (age, DMFS, 1stmDMFS) 'balanced' (DFS baseline data NR). \\
& Clinical (V) caries assessment by two examiners; diagnostic threshold = CA and NCA; state of tooth \\
eruption included NR. Radiographic assessment (2 postBW) by two examiners; diagnostic threshold = \\
DR and ER; partial recording. "Sufficient agreement of examiners known from earlier work". \\
*F solution used by all children after 2 years (final 4 years results not considered).
\end{tabular}

\section{Risk of bias}

\begin{tabular}{lll}
\hline Bias & Authors' judgement & Support for judgement \\
\hline $\begin{array}{l}\text { Allocation concealment } \\
\text { (selection bias) }\end{array}$ & Unclear risk & B - Unclear \\
\hline
\end{tabular}

Marthaler 1974

\begin{tabular}{ll}
\hline Methods & $\begin{array}{l}\text { Random allocation; double-blind (A); placebo-controlled; } 32 \% \text { drop out after } 6 \text { years (study duration }= \\
6 \text { years). Exclusions based on presence in all follow-up examinations; no differential group losses. }\end{array}$ \\
\hline Participants & 109 children analysed at $6^{\star}$ years (present for all examinations). \\
& Age range at start: $6-9$ years (average $=7.5)$. \\
& Surfaces affected at start: 2.6 DMFS. \\
& Background exposure to fluoride: in solution/salt (suboptimal). \\
& Year study began: 1966. \\
& Location: Switzerland.
\end{tabular}

\begin{tabular}{|c|c|}
\hline Interventions & $\begin{array}{l}\text { FT versus PL } \\
(\text { AmF group }=1250 \mathrm{ppm} F) \\
\text { Home use/unsupervised, daily frequency assumed. } \\
\text { Abrasive system: IMP. }\end{array}$ \\
\hline Outcomes & $\begin{array}{l}6 y^{\star} \text { NetDFS increment - (E) (CA)cl+(DR)xr. } \\
\text { Reported at } 2 \text { and } 6 \text { years follow ups. } \\
\text { PF-DFS. } \\
\text { postMD-DFS. } \\
\text { antMD-B-DFS. } \\
\text { DFT. } \\
\text { Proportion of children with new DFS. }\end{array}$ \\
\hline Notes & $\begin{array}{l}\text { Participants randomised ( } N=161) \text {. } \\
\text { Baseline characteristics (DMFS, DMFT, FS, FT, TAR) 'balanced' (DFS baseline data NR). } \\
\text { Clinical }(\mathrm{V}) \text { caries assessment by two examiners; diagnostic threshold = CA and NCA; state of tooth } \\
\text { eruption included = E. Radiographic assessment ( } 2 \text { postBW) by two examiners; diagnostic threshold = } \\
\text { DR and ER; partial recording. "Sufficient agreement of examiners known from earlier work". } \\
\text { *Results at } 6 \text { years follow up chosen (reported for all outcomes). }\end{array}$ \\
\hline
\end{tabular}

\section{Risk of bias}


Marthaler 1974 (Continued)

\begin{tabular}{l}
$\begin{array}{l}\text { Allocation concealment } \\
\text { (selection bias) }\end{array}$ \\
\hline
\end{tabular}

\section{Mergele 1968}

Methods Stratified random allocation; double-blind ('A'); placebo-controlled; $22 \%$ drop out (for all study groups combined) after 3 years (study duration $=3$ years). Reasons for attrition: natural losses to follow up; any differential group losses not assessable.

Participants
Age range at start: $10-13$ years (average =11).
Surfaces affected at start: 6.5 DMFS.
Background exposure to fluoride: water.
Year study began: in/before 1964.
Location: USA.

\begin{tabular}{|c|c|}
\hline Interventions & $\begin{array}{l}\mathrm{FT}^{\star \star} \text { versus 'PL' } \\
(\mathrm{SnF} 2 \text { group }=1000 \mathrm{ppm} \mathrm{F}) \text {. } \\
\text { Home use/unsupervised, daily frequency assumed. } \\
\text { Abrasive system: Ca pyrophosphate in fluoride toothpaste, IMP in control toothpaste. }\end{array}$ \\
\hline Outcomes & $\begin{array}{l}\text { 3yNetDMFS increment - cl. } \\
\text { Reported at } 3 \text { years follow up. } \\
\text { DMFT. }\end{array}$ \\
\hline Notes & $\begin{array}{l}\text { Participants randomised (numbers for relevant groups NR). } \\
\text { Baseline characteristics (age, SAR, DMFS, DMFT) 'balanced'. } \\
\text { Clinical (VT) caries assessment by one examiner, diagnostic threshold = NR. State of tooth eruption in- } \\
\text { cluded = NR. Diagnostic errors NR. } \\
{ }^{\star * N a ~ N-l a u r o y l ~ s a r c o s i n a t e / S M F P ~ t o o t h p a s t e ~ g r o u p s ~ n o t ~ c o n s i d e r e d ~(a d d i t i o n a l ~ n o n-F ~ a c t i v e ~ a g e n t ~} \\
\text { used in this group only). }\end{array}$ \\
\hline
\end{tabular}

\section{Risk of bias}

\begin{tabular}{lll}
\hline Bias & Authors' judgement & Support for judgement \\
\hline $\begin{array}{l}\text { Allocation concealment } \\
\text { (selection bias) }\end{array}$ & Unclear risk & B - Unclear \\
\hline
\end{tabular}

\section{Muhler 1955}

Methods Stratified random allocation; double-blind (A); placebo-controlled; 22\% drop out after 1 year (study duration $=1$ year). Reasons for attrition NR; differential group losses.

\begin{tabular}{ll}
\hline Participants & 444 children analysed at 1 year (available at final examination). \\
& Age range at start: $6-16$ years. Surfaces affected at start: 9.3 DMFS. \\
& Background exposure to fluoride: data not available for fluoridation status of site. \\
& Year study began: in/before 1954. \\
& Location: USA. \\
\hline Interventions & $\mathrm{FT}^{\star \star}$ versus PL \\
& $(\mathrm{SnF} 2$ group $=1000 \mathrm{ppm}$ F).
\end{tabular}


Muhler 1955 (Continued)

Home use/unsupervised, daily frequency assumed.

Abrasive system: heat-treated Ca orthophosphate.

\begin{tabular}{ll}
\hline Outcomes & 1yDMFS increment $-\mathrm{cl}+\mathrm{xr}$. \\
& Reported at $6 \mathrm{~m}$ and 1 year follow ups. \\
& DMFT. \\
\hline Notes & Participants randomised ( $=568)$. \\
& Baseline characteristics (DMFS) 'balanced'. \\
& Clinical (VT) caries assessment by one examiner, diagnostic threshold = NR. Radiographic assessment \\
& by one examiner; diagnostic threshold = NR. State of tooth eruption included = NR. Criteria for caries di- \\
& agnosis reported to have been carefully standardised, diagnostic errors NR. \\
& i*NaF-heat treated Ca orthophosphate toothpaste group not considered (abrasive system known to be \\
& incompatible with NaF).
\end{tabular}

\section{Risk of bias}

\begin{tabular}{lll}
\hline Bias & Authors' judgement & Support for judgement \\
\hline $\begin{array}{l}\text { Allocation concealment } \\
\text { (selection bias) }\end{array}$ & Unclear risk & B - Unclear \\
\hline
\end{tabular}

\section{Muhler 1970}

$\begin{array}{ll}\text { Methods } & \text { Stratified random allocation; double-blind (A); placebo-controlled; } 15 \% \text { drop out after } 1 \text { year (study du- } \\ \text { ration = } 1 \text { year). Reasons for attrition NR; differential group losses. }\end{array}$

\begin{tabular}{|c|c|}
\hline Participants & $\begin{array}{l}436 \text { children analysed at } 1 \text { year (available at final examination). } \\
\text { Age range at start: } 5-16 \text { years (average }=10) \text {. } \\
\text { Surfaces affected at start: } 10.3 \text { DMFS. } \\
\text { Background exposure to fluoride: data not available for fluoridation status of site. } \\
\text { Year study began: in/before } 1967 . \\
\text { Location: USA. }\end{array}$ \\
\hline Interventions & $\begin{array}{l}\mathrm{FT}^{\star \star} \text { versus } \mathrm{PL} \\
(\mathrm{SnF} 2 \text { group }=1000 \mathrm{ppm} \mathrm{F}) \\
\text { Home use/unsupervised, daily frequency assumed. } \\
\text { Abrasive system: Ca pyrophosphate. }\end{array}$ \\
\hline Outcomes & $\begin{array}{l}\text { 1yDMFS increment - } \mathrm{cl}+\mathrm{xr} \text {. } \\
\text { Reported at } 6 \mathrm{~m} \text { and } 1 \text { year follow ups. } \\
\text { DMFT. }\end{array}$ \\
\hline Notes & $\begin{array}{l}\text { Participants randomised ( } N=510) \text {. } \\
\text { Baseline characteristics (age, gender, DMFS) with some imbalance. } \\
\text { Clinical (VT) caries assessment by one examiner, diagnostic threshold = NR. Radiographic assessment } \\
\text { (5-7 BW) by one examiner; diagnostic threshold = NR. State of tooth eruption included = NR. Diagnostic } \\
\text { errors NR. } \\
{ }^{\star \star} \text { Na N-lauroyl sarcosinate/SMFP toothpaste group not considered (additional non-F active agent used } \\
\text { in this group only). }\end{array}$ \\
\hline
\end{tabular}

\section{Risk of bias}


Muhler 1970 (Continued)
Allocation concealment
Unclear risk
B - Unclear
(selection bias)

\section{Murray 1980}

$\begin{array}{ll}\text { Methods } & \text { Stratified random allocation; double-blind (A); placebo-controlled; } 23 \% \text { drop out after } 3 \text { years (study } \\ \text { duration = } 3 \text { years). Natural losses; exclusions based on presence in all follow-up examinations; no dif- } \\ \text { ferential group losses. }\end{array}$

Participants
Age range at start: $11-13$ years (average $=11.9$ ). Surfaces affected at start: 9.9 DMFS.
Background exposure to fluoride: data not available for fluoridation status of site.
Year study began: 1974.
Location: UK.

\begin{tabular}{|c|c|}
\hline Interventions & $\begin{array}{l}\text { FT ( } 2 \text { groups) versus PL } \\
\text { (both SMFP groups = } 1000 \text { ppm F). } \\
\text { Home use/unsupervised, daily frequency assumed. } \\
\text { Abrasive system: Al oxide trihydrate (low and normal abrasivity). }\end{array}$ \\
\hline Outcomes & $\begin{array}{l}\text { 3yNetDMFS increment - } \mathrm{cl}+\mathrm{xr} \text {. } \\
\text { Reported at } 3 \text { years follow up. } \\
\text { DMFS (U). }\end{array}$ \\
\hline Notes & $\begin{array}{l}\text { Participants randomised ( } N=1431) \text {. } \\
\text { Baseline characteristics (age, DMFS, TAR) 'balanced'. } \\
\text { Clinical }(V T) \text { caries assessment by two examiners; diagnostic threshold = NR; radiographic assessment } \\
\text { ( } 2 \text { postBW) by two examiners; diagnostic threshold = NR; state of tooth eruption included = E/U. } \\
\text { Reproducibility ratios were less than } 0.23 \text { for intra-examiner reproducibility for clinical caries diagnosis } \\
\text { and less than } 0.16 \text { for radiographic caries diagnosis; inter-examiner reproducibility ratios was } 0.26 \text { and } \\
0.1 \text { respectively. }\end{array}$ \\
\hline
\end{tabular}

\section{Risk of bias}

\begin{tabular}{lll}
\hline Bias & Authors' judgement & Support for judgement \\
\hline $\begin{array}{l}\text { Allocation concealment } \\
\text { (selection bias) }\end{array}$ & Low risk & A - Adequate \\
\hline
\end{tabular}

Naylor 1967

Methods Stratified random allocation; double-blind (A); placebo-controlled; $17 \%$ drop out (for all study groups combined) after 3 years (study duration $=3$ years). Natural losses; any differential group losses not assessable.

Participants children analysed at 3 years (available at final examination).
Age range at start: $11-12$ years.
Surfaces affected at start: 9.5 DMFS.
Background exposure to fluoride: none reported.
Year study began: 1961.
Location: UK.


Naylor 1967 (Continued)

$\begin{array}{ll}\text { Interventions } & \mathrm{FT}^{\star \star} \text { versus } \mathrm{PL} \\ & (\mathrm{SnF} 2 \text { group }=1000 \mathrm{ppm} \mathrm{F}) .\end{array}$

Home use/unsupervised, daily frequency assumed.

Abrasive system: IMP (main abrasive) in fluoride toothpaste, dicalcium phosphate (dihydrate) in placebo toothpaste.

Outcomes
Reported at 3 years follow up.
DMFT.
DMFS.
postMD-DFS.
1stmoMD-DFS.
Proportion of children with tooth staining.
Participants randomised (numbers for relevant groups NR).
Baseline characteristics (age, gender, SAR, DMFS, DMFT, postMD-DFS) 'balanced'.
Clinical (VT) caries assessment by one examiner; diagnostic threshold = CA; state of tooth eruption in-
cluded = E/U. Radiographic assessment (2 postBW) by one examiner; diagnostic threshold = ER. Rever-
sal rate less than $4 \%$ of observed DFS increment in all groups. High accuracy of diagnosis revealed by
10\% sample checks (clinically and radiographically).
$\star \star * N a$ N-lauroyl sarcosinate/SMFP toothpaste group not considered (additional non-F active agent used
in this group only).

\section{Risk of bias}

\begin{tabular}{lll}
\hline Bias & Authors' judgement & Support for judgement \\
\hline $\begin{array}{l}\text { Allocation concealment } \\
\text { (selection bias) }\end{array}$ & Low risk & A - Adequate \\
\hline
\end{tabular}

Naylor 1979

Methods Stratified random allocation; double-blind (A); placebo-controlled; $20 \%$ drop out (for all study groups combined) after 3 years (study duration $=3$ years). Natural losses; any differential group losses not assessable.

\begin{tabular}{|c|c|}
\hline Participants & $\begin{array}{l}625 \text { children analysed at } 3 \text { years (ava } \\
\text { Age range at start: } 11-12 \text { years. Surfa } \\
\text { Background exposure to fluoride: no } \\
\text { Year study began: } 1973 . \\
\text { Location: UK. }\end{array}$ \\
\hline Interventions & $\begin{array}{l}\mathrm{FT}^{\star \star} \text { versus } \mathrm{PL} \\
\text { (SMFP group = } 1000 \text { ppm F). } \\
\text { Home use/unsupervised, daily freque } \\
\text { Abrasive system: Ca carbonate. }\end{array}$ \\
\hline Outcomes & $\begin{array}{l}\text { 3yDFS increment - (E) (CA)cl+(ER)xr. } \\
\text { Reported at } 3 \text { years follow up. } \\
\text { DFT. } \\
\text { DFT (U). } \\
\text { O-BL-DFS. } \\
\text { MD-DFS. }\end{array}$ \\
\hline
\end{tabular}


Naylor 1979 (Continued)

CIR.

Notes Participants randomised (numbers for relevant groups NR).

Baseline characteristics (age, SAR, TAR, DFS, DFT) 'balanced'.

Clinical (VT) caries assessment (FOTI used) by two examiners (independently); diagnostic threshold = CA; state of tooth eruption included = E/U. Radiographic assessment ( 2 postBW) by two examiners (independently); diagnostic threshold = ER. Results of one examiner chosen (findings consistent throughout) .

${ }^{\star \star}$ Ca glycerophosphate/SMFP toothpaste group not considered (additional non-F active agent used in this group only).

\section{Risk of bias}

\begin{tabular}{lll}
\hline Bias & Authors' judgement & Support for judgement \\
\hline $\begin{array}{l}\text { Allocation concealment } \\
\text { (selection bias) }\end{array}$ & Unclear risk & B - Unclear \\
\hline
\end{tabular}

\section{Peterson 1967}

Methods Stratified random allocation; double-blind ('A'); placebo-controlled; $16 \%$ drop out after 2 years (study duration $=3$ years). Reasons for attrition not described; any differential group losses not assessable.

Participants children analysed at 2 years (available at this examination).
Age range at start: 9-15 years.
Surfaces affected at start: 14.3 DMFS.
Background exposure to fluoride: data not available for fluoridation status of site.
Year study began: in/before 1964.
Location: USA.

\begin{tabular}{|c|c|}
\hline Interventions & $\begin{array}{l}\text { FT ( } 2 \text { groups) versus 'PL' } \\
\text { (SnF2 group }=1000 \text { ppm F, APF group }=1000 \text { ppm F). } \\
\text { Home use/unsupervised, daily frequency assumed. } \\
\text { Abrasive system: Ca pyrophosphate in SnF2 toothpaste, IMP in APF toothpaste, control toothpaste } \\
\text { abrasive NR. }\end{array}$ \\
\hline Outcomes & $\begin{array}{l}2 y^{\star} \text { DMFS increment }-\mathrm{cl}+\mathrm{xr} \text {. } \\
\text { Reported at } 1,2 \text { and } 3 \text { years follow ups. } \\
\text { DMFT. } \\
\text { O-DMFS. } \\
\text { BL-DMFS. } \\
\text { MD-DMFS. }\end{array}$ \\
\hline Notes & $\begin{array}{l}\text { Participants randomised ( } N=1136) \text {; numbers by group NR. } \\
\text { Baseline characteristics (DMFS, DMFT, dental age) 'balanced'. } \\
\text { Clinical (VT) caries assessment by one examiner; diagnostic threshold NR; state of tooth eruption in- } \\
\text { cluded NR; radiographic assessment ( } 3 \mathrm{BW} \text { ) by one examiner; diagnostic threshold NR. Diagnostic er- } \\
\text { rors NR. } \\
\text { `Results for } 3 \text { years follow up not considered (not fully reported). }\end{array}$ \\
\hline
\end{tabular}

\section{Risk of bias}

Bias Authors' judgement Support for judgement


Peterson 1967 (Continued)

Allocation concealment Low risk
(selection bias)

\section{Peterson 1979}

Methods Stratified random allocation; double-blind (A); placebo-controlled; 25\% drop out after 2.5 years (study duration $=2.5$ years). Natural losses; exclusions based on presence in all follow-up examinations; any differential group losses not assessable.

Participants
Age range at start: $8-12$ years (average =10).
Surfaces affected at start: 2.9 DFS.
Background exposure to fluoride: water.
Year study began: 1971.
Location: USA.

\begin{tabular}{|c|c|}
\hline Interventions & $\begin{array}{l}\text { FT ( } 2 \text { groups) versus PL } \\
\text { (both SMFP groups = } 1000 \text { ppm F). } \\
\text { School use/supervised, daily, (appropriate toothpastes also provided for home use). } \\
\text { Abrasive system: Ca carbonate in one toothpaste and in placebo toothpaste, IMP in the other SMFP } \\
\text { toothpaste. }\end{array}$ \\
\hline Outcomes & $\begin{array}{l}\text { 2.5yDFS increment }-\mathrm{cl}+\mathrm{xr} \text {. } \\
\text { Reported at } 2.5 \text { years follow up. } \\
\text { DMFT. } \\
\text { MD-DFS. }\end{array}$ \\
\hline Notes & $\begin{array}{l}\text { Participants randomised (N=950); numbers by group NR. } \\
\text { Baseline characteristics (DFS, MD-DFS, DFT) 'balanced'. } \\
\text { Clinical (VT) caries assessment (FOTI used) by one examiner; diagnostic threshold = CA; state of tooth } \\
\text { eruption included NR; radiographic assessment (postBW) by one examiner; diagnostic threshold = ER. } \\
\text { Diagnostic errors NR. }\end{array}$ \\
\hline
\end{tabular}

\section{Risk of bias}

\begin{tabular}{lll}
\hline Bias & Authors' judgement & Support for judgement \\
\hline $\begin{array}{l}\text { Allocation concealment } \\
\text { (selection bias) }\end{array}$ & Unclear risk & B - Unclear \\
\hline
\end{tabular}

\section{Powell 1981}

$\begin{array}{ll}\text { Methods } & \begin{array}{l}\text { Stratified random allocation; double-blind (A); placebo-controlled; drop-out rate NR nor obtainable } \\ \text { (study duration = } 4 \text { years). Reasons for attrition NR; any differential group losses not assessable. }\end{array}\end{array}$
(study duration $=4$ years). Reasons for attrition NR; any differential group losses not assessable.

Participants
Age range at start: $12-14$ years.
Surfaces affected at start: 21.4 DMFS (from sample above).
Background exposure to fluoride: none reported.
Year study began: 1963.
Location: Australia.


Powell 1981 (Continued)

Interventions

$\mathrm{FT}$ (pp/Plsol) versus PL(pp/Plsol) ${ }^{\star \star}(\mathrm{SnF} 2$ group $=1000 \mathrm{ppm} \mathrm{F})$.

Home use/unsupervised, daily frequency assumed.

Abrasive system: Ca pyrophosphate.

Caries increment data NR (not obtainable).

Progression rate of initial carious lesions in MD surfaces of permanent posterior teeth at annual intervals (for 4 years).

Notes

Participants randomised (numbers NR).

Baseline characteristics (age, gender, DMFS) 'balanced'.

Radiographic (post BW) enamel caries progression assessment by one examiner; state of tooth erup-

tion included $=\mathrm{E}$.

High reproducibility of radiographic diagnosis

(icc $=0.91)$.

${ }^{\star \star}$ Prior prophylaxis with lava pumice followed by professional application of placebo solution per-

formed every six months for 2 years in both relevant groups compared.

\section{Risk of bias}

\begin{tabular}{lll}
\hline Bias & Authors' judgement & Support for judgement \\
\hline $\begin{array}{l}\text { Allocation concealment } \\
\text { (selection bias) }\end{array}$ & Unclear risk & B - Unclear \\
\hline
\end{tabular}

Ran 1991

$\begin{array}{ll}\text { Methods } & \text { Random allocation; double-blind (A); placebo-controlled; } 20 \% \text { drop out (for all study groups com- } \\ \text { bined) after } 1.5 \text { years (study duration }=1.5 \text { years }+0.5 \text { year post-intervention period). Reasons for attri- } \\ \text { tion/handling of exclusions NR; any differential group losses not assessable. }\end{array}$
tion/handling of exclusions NR; any differential group losses not assessable.

\begin{tabular}{|c|c|}
\hline Participants & $\begin{array}{l}55 \text { children analysed at } 1.5 \text { years; all male. } \\
\text { Average age at start: } 13 \text { years. } \\
\text { Surfaces affected at start: } 6.4 \text { DMFS. } \\
\text { Background exposure to other fluoride: data not obtained for home use of toothpaste. } \\
\text { Year study began: in/before } 1989 . \\
\text { Location: Israel. }\end{array}$ \\
\hline Interventions & $\begin{array}{l}\text { FT versus PL } \\
\text { (AmF group = } 1250 \text { ppm F). } \\
\text { School use/supervised, fortnightly/20 times a year, } \\
1 \mathrm{~g} \text { applied for } 4 \text { minutes, no post-brushing rinse done (no provision of any toothpaste reported for } \\
\text { home use). } \\
\text { Abrasive system: NR. }\end{array}$ \\
\hline Outcomes & $\begin{array}{l}\text { 1.5yNetDMFS increment - (CA). } \\
\text { Reported at } 0.5 \text { and } 1.5 \text { years follow ups (and } 0.5 \text { year post-treatment). }\end{array}$ \\
\hline Notes & $\begin{array}{l}\text { Participants randomised (numbers for relevant groups NR). } \\
\text { Baseline characteristics (DMFS) with some imbalance (reported as NS difference). Clinical (VT) caries } \\
\text { assessment by one examiner; diagnostic threshold = CA; state of tooth eruption included NR. Intra-ex- } \\
\text { aminer reproducibility checks for DMFS (icc reaching 0.97). }\end{array}$ \\
\hline
\end{tabular}

\section{Risk of bias}

Fluoride toothpastes for preventing dental caries in children and adolescents (Review)

Copyright @ 2016 The Cochrane Collaboration. Published by John Wiley \& Sons, Ltd. 
Ran 1991 (Continued)

\begin{tabular}{lll} 
Bias & Authors' judgement & Support for judgement \\
\hline $\begin{array}{l}\text { Allocation concealment } \\
\text { (selection bias) }\end{array}$ & Unclear risk & B - Unclear \\
\hline
\end{tabular}

Reed 1973

Methods Stratified random allocation; double-blind (A); placebo-controlled; $28 \%$ drop out after 2 years (study duration $=2$ years). Reasons for attrition not described; no differential group losses.

Participants
Age range at start: 6-13 years (average =9).
Surfaces affected at start: 3.3 DMFS.
Background exposure to fluoride: none reported.
Year study began: in/before 1970.
Location: USA.

\begin{tabular}{|c|c|}
\hline Interventions & $\begin{array}{l}\text { FT ( } 3 \text { groups) versus PL } \\
\text { (NaF groups = } 1000 \text { ppm F, } 500 \text { ppm F, } 250 \text { ppm F). } \\
\text { Home use/unsupervised, daily frequency assumed. } \\
\text { Abrasive system: Ca pyrophosphate. }\end{array}$ \\
\hline Outcomes & $\begin{array}{l}\text { 2yDMFS increment - } \mathrm{cl}+\mathrm{xr} \text {. } \\
\text { Reported at } 1 \text { and } 2 \text { years follow ups. } \\
\text { DMFT. }\end{array}$ \\
\hline Notes & $\begin{array}{l}\text { Participants randomised ( } \mathrm{N}=2104) \text {. } \\
\text { Baseline characteristics (age, gender, DMFS, DMFT) 'balanced' . } \\
\text { Clinical (VT) caries assessment by one examiner; diagnostic threshold NR; state of tooth eruption in- } \\
\text { cluded NR. Radiographic assessment (up to } 7 \mathrm{BW} \text { ) by one examiner; diagnostic threshold NR. Diagnos- } \\
\text { tic errors NR. }\end{array}$ \\
\hline
\end{tabular}

\section{Risk of bias}

\begin{tabular}{lll}
\hline Bias & Authors' judgement & Support for judgement \\
\hline $\begin{array}{l}\text { Allocation concealment } \\
\text { (selection bias) }\end{array}$ & Unclear risk & B - Unclear \\
\hline
\end{tabular}

Reed 1975

$\begin{array}{ll}\text { Methods } & \begin{array}{l}\text { Stratified random allocation; double-blind (A); placebo-controlled; } 39 \% \text { drop out after } 2 \text { years (study } \\ \text { duration = } 2 \text { years). Reasons for high drop out not described; no differential group losses. }\end{array}\end{array}$

Participants

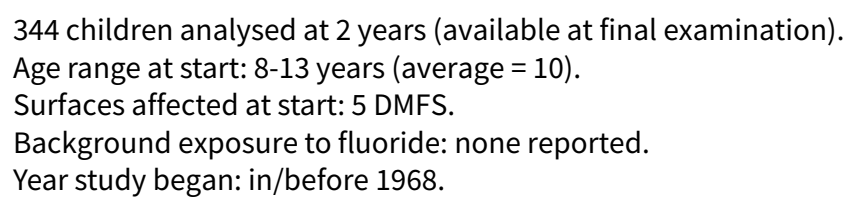

Interventions $\quad$ FT versus PL


Reed 1975 (Continued)

$(\mathrm{NaF}$ group $=1000 \mathrm{ppm} \mathrm{F})$.

Home use/unsupervised, daily frequency assumed.

Abrasive system: Ca pyrophosphate.

\begin{tabular}{|c|c|}
\hline Outcomes & $\begin{array}{l}\text { 2yDMFS increment - } \mathrm{cl}+\mathrm{xr} \text {. } \\
\text { Reported at } 1 \text { and } 2 \text { years follow ups. } \\
\text { DMFT. }\end{array}$ \\
\hline Notes & $\begin{array}{l}\text { Participants randomised ( } \mathrm{N}=567 \text { ). } \\
\text { Baseline characteristics (age, gender, DMFS, DMFT) with some imbalance. } \\
\text { Clinical (VT) caries assessment by one examiner; diagnostic threshold NR; state of tooth eruption in- } \\
\text { cluded NR. Radiographic assessment (up to } 7 \text { BW) by one examiner; diagnostic threshold NR. Diagnos- } \\
\text { tic errors NR. }\end{array}$ \\
\hline
\end{tabular}

\section{Risk of bias}

\begin{tabular}{lll}
\hline Bias & Authors' judgement & Support for judgement \\
\hline $\begin{array}{l}\text { Allocation concealment } \\
\text { (selection bias) }\end{array}$ & Unclear risk & B - Unclear \\
\hline
\end{tabular}

Ringelberg 1979

Methods Stratified random allocation; double-blind (A); placebo-controlled; $37 \%$ drop out after 2.5 years (study
duration $=2.5$ years). Reasons for attrition not described; no differential group losses.

\begin{tabular}{|c|c|}
\hline Participants & $\begin{array}{l}556 \text { children analysed at } 2.5 \text { years (available at final examination). } \\
\text { Average age at start: } 11 \text { years. } \\
\text { Surfaces affected at start: } 4.2 \text { DMFS. } \\
\text { Background exposure to fluoride: none reported. } \\
\text { Year study began: } 1973 . \\
\text { Location: USA. }\end{array}$ \\
\hline Interventions & $\begin{array}{l}\text { FT ( } 2 \text { groups) versus PL(2 groups) (AmF group }=1250 \text { ppm F, SnF2 group = } 1000 \text { ppm F). } \\
\text { Home use/unsupervised, daily frequency assumed. } \\
\text { Abrasive system: Ca pyrophosphate in SnF2 toothpaste and its placebo, NR for AmF and its placebo. }\end{array}$ \\
\hline Outcomes & $\begin{array}{l}\text { 2.5yNetDMFS increment }-(C A) c l+(D R) x r \text {. } \\
\text { Reported at } 2.5 \text { years follow up. } \\
\text { DMFT. } \\
\text { Stain score. }\end{array}$ \\
\hline Notes & $\begin{array}{l}\text { Participants randomised ( } N=888 \text { ). } \\
\text { Baseline characteristics (DMFS, DMFT) 'balanced'. } \\
\text { Clinical (VT) caries assessment by two examiners, diagnostic threshold = CA. Radiographic assessment } \\
\text { ( } 5 \text { BW) by two examiners; diagnostic threshold = DR. State of tooth eruption included NR. Reversal rate } \\
\text { between } 4 \text { and } 9 \% \text { of observed caries increment in the groups. }\end{array}$ \\
\hline
\end{tabular}

\section{Risk of bias}


Ringelberg 1979 (Continued)
Allocation concealment
Unclear risk
B - Unclear
(selection bias)

Rule 1984

$\begin{array}{ll}\text { Methods } & \begin{array}{l}\text { Stratified random allocation; double-blind (A); placebo-controlled; } 24 \% \text { drop out after } 2 \text { years (study } \\ \text { duration = } 2 \text { years). Reasons for attrition not described; exclusions based on presence in all follow-up } \\ \text { examinations; no differential group losses. }\end{array}\end{array}$

\begin{tabular}{ll}
\hline Participants & 876 children analysed at 2 years (present for all examinations). \\
Age range at start: $9-12$ years (average $=11)$. \\
Surfaces affected at start: 8.6 DMFS. \\
Background exposure to fluoride: none reported. \\
Year study began: 1977. \\
Location: USA.
\end{tabular}

\begin{tabular}{ll}
\hline Interventions & FT versus PL \\
& (SMFP group $=1000 \mathrm{ppm}$ F). \\
& $\begin{array}{l}\text { School use/supervised, daily, for } 1 \text { min (appropriate toothpastes also provided for home use). } \\
\text { Abrasive system: silica zerogel. }\end{array}$ \\
\hline Outcomes & 2yDFS increment - (E+U) (CA)cl+(ER)xr. \\
Reported at 1 and 2 years follow ups. \\
DFT. \\
DMFS. \\
DMFT. \\
O-DFS. \\
MD-DFS. \\
Oral soft tissue lesions. \\
Participants randomised ( $N=1154)$. \\
Baseline characteristics (age, gender, TAR, DMFS, DMFT, DS, DT) 'balanced' (DFS baseline data NR). \\
Clinical (VT) caries assessment (FOTI used) by one examiner; diagnostic threshold = CA; state of tooth \\
eruption included = E/U. Radiographic assessment (2 postBW) by one examiner; diagnostic threshold = \\
ER. Reproducibility checks done in 10\% sample clinically and radiographically.
\end{tabular}

\section{Risk of bias}

\begin{tabular}{lll}
\hline Bias & Authors' judgement & Support for judgement \\
\hline $\begin{array}{l}\text { Allocation concealment } \\
\text { (selection bias) }\end{array}$ & Unclear risk & B - Unclear \\
\hline
\end{tabular}

Segal 1967

$\begin{array}{ll}\text { Methods } & \text { Stratified random allocation; double-blind (A); placebo-controlled; } 23 \% \text { drop out after } 2 \text { years (study } \\ \text { duration = } 2 \text { years). Reasons for attrition NR; differential group losses. }\end{array}$

Participants
Age range at start: $7-12$ years. Surfaces affected at start: NR.
Background exposure to fluoride: none reported.
Year study began: in/before 1964 .


Segal 1967 (Continued)

Location: USA.

\begin{tabular}{|c|c|}
\hline Interventions & $\begin{array}{l}\text { FT versus PL } \\
\text { (SnF2 group = } 1000 \text { ppm F). } \\
\text { School use/supervised, daily, (appropriate toothpastes also provided for home use). } \\
\text { Abrasive system: IMP (mainly). }\end{array}$ \\
\hline Outcomes & $\begin{array}{l}\text { 2yDFS increment - }(\mathrm{CA}) \mathrm{cl}+\mathrm{xr} \text {. } \\
\text { Reported at } 1 \text { and } 2 \text { years follow ups. } \\
\text { DFS (U). }\end{array}$ \\
\hline Notes & $\begin{array}{l}\text { Participants randomised }(\mathrm{N}=845) \text {. } \\
\text { Baseline characteristics (SAR) 'balanced'. } \\
\text { Clinical (VT) caries assessment by two examiners, diagnostic threshold = CA. Radiographic assessment } \\
\text { as a supplementary aid; diagnostic threshold = NR. State of tooth eruption included E/U. Inter- and in- } \\
\text { tra-examiner reproducibility checks done. }\end{array}$ \\
\hline
\end{tabular}

\section{Risk of bias}

\begin{tabular}{lll}
\hline Bias & Authors' judgement & Support for judgement \\
\hline $\begin{array}{l}\text { Allocation concealment } \\
\text { (selection bias) }\end{array}$ & Unclear risk & B - Unclear \\
\hline
\end{tabular}

\section{Slack 1964}

$\begin{array}{ll}\text { Methods } & \text { Random allocation; double-blind (A); placebo-controlled; 32\% drop-out rate after } 2 \text { years (study dura- } \\ \text { tion = } 2 \text { years). Natural losses and other reasons; exclusions based on presence in all follow-up exami- } \\ \text { nations; no differential group losses. }\end{array}$

$\begin{array}{ll}\text { Participants } & 719 \text { children analysed at } 2 \text { years } \\ \text { (present for all examinations). } \\ \text { Age range at start: } 11-13 \text { years. Surfaces affected at start: NR. } \\ \text { Background exposure to fluoride: none reported. } \\ \text { Year study began: } 1962 . \\ \text { Location: UK. }\end{array}$

\begin{tabular}{|c|c|}
\hline Interventions & $\begin{array}{l}\text { FT versus PL } \\
(\text { SnF2 group = } 1000 \text { ppm F). } \\
\text { Home use/unsupervised, } 3 \text { times/day instructed but daily frequency assumed. } \\
\text { Abrasive system: IMP in fluoride toothpaste, dicalcium phosphate (dihydrate) in placebo toothpaste. }\end{array}$ \\
\hline Outcomes & $\begin{array}{l}\text { Caries increment data NR (not obtainable). } \\
\text { Proportion of carious teeth/surfaces (by tooth type) } \\
\text { reported at } 1 \text { and } 2 \text { years follow ups. } \\
\text { Proportion of caries-free teeth/surfaces (by tooth type) which developed caries after each year. } \\
\text { Proportion of children with tooth staining. }\end{array}$ \\
\hline Notes & $\begin{array}{l}\text { Participants randomised ( } \mathrm{N}=1059) \text {. } \\
\text { Baseline characteristics 'balanced'. } \\
\text { Clinical }(V T) \text { caries assessment by one examiner; diagnostic threshold = CA; state of tooth eruption in- } \\
\text { cluded NR. Diagnostic errors NR. }\end{array}$ \\
\hline
\end{tabular}


Slack 1964 (Continued)

Risk of bias

\begin{tabular}{lll}
\hline Bias & Authors' judgement & Support for judgement \\
\hline $\begin{array}{l}\text { Allocation concealment } \\
\text { (selection bias) }\end{array}$ & Unclear risk & B - Unclear \\
\hline
\end{tabular}

\section{Slack 1967}

$\begin{array}{ll}\text { Methods } & \text { Random allocation; double-blind (A); placebo-controlled; } 21 \% \text { drop-out rate after } 3 \text { years (study du- } \\ \text { ration }=3 \text { years). Reasons for drop out described with numbers: left school, moved away, staining of } \\ \text { teeth, on parents request; exclusions based on presence in all follow-up examinations; no differential } \\ \text { group losses. }\end{array}$

\begin{tabular}{|c|c|}
\hline Participants & $\begin{array}{l}696 \text { children analysed at } 3 \text { years, all female } \\
\text { (present for all examinations). } \\
\text { Average age at start: } 11 \text { years. Surfaces affected at start: } 8.9 \text { DFS. Background exposure to fluoride: } \\
\text { none reported. } \\
\text { Year study began: } 1963 \text {. } \\
\text { Location: UK. }\end{array}$ \\
\hline Interventions & $\begin{array}{l}\text { FT versus PL } \\
\text { (SnF2 group = } 1000 \text { ppm F). } \\
\text { Home use/unsupervised, daily frequency assumed. } \\
\text { Abrasive system: IMP (dicalcium phosphate (dihydrate) in placebo toothpaste also). }\end{array}$ \\
\hline Outcomes & $\begin{array}{l}\text { 3yNetDFS increment - }(E)(C A) c l . \\
\text { Reported at } 3 \text { years follow up. } \\
\text { DFT. } \\
\text { DMFS. } \\
\text { DMFT. } \\
\text { postMD-DFS. } \\
\text { Proportion of children with tooth staining. }\end{array}$ \\
\hline Notes & $\begin{array}{l}\text { Participants randomised ( } \mathrm{N}=886 \text { ). } \\
\text { Baseline characteristics (age, dental age, DFS, DFT, DMFS, DMFT, TAR) 'balanced'. } \\
\text { Clinical }(\mathrm{VT}) \text { caries assessment by one examiner; diagnostic threshold = CA; state of tooth eruption in- } \\
\text { cluded = E/U. Radiographic assessment ( } 2 \text { postBW) by one examiner; diagnostic threshold = ER. Consis- } \\
\text { tency of clinical diagnosis maintained by re-examination of } 10 \% \text { sample and calibration checks made } \\
\text { against reserve examiner. }\end{array}$ \\
\hline
\end{tabular}

\section{Risk of bias}

\begin{tabular}{lll}
\hline Bias & Authors' judgement & Support for judgement \\
\hline $\begin{array}{l}\text { Allocation concealment } \\
\text { (selection bias) }\end{array}$ & Unclear risk & B - Unclear \\
\hline
\end{tabular}

\section{Slack 1967a}

\section{Methods}

Random allocation; double-blind (A); placebo-controlled; $21 \%$ drop-out rate after 3 years (study duration $=3$ years). Reasons for drop out described with numbers: left school, moved away, staining of 
Slack 1967a (Continued)

teeth, on parents request; exclusions based on presence in all follow-up examinations; no differential group losses.

\begin{tabular}{|c|c|c|}
\hline Participants & \multicolumn{2}{|c|}{$\begin{array}{l}757 \text { children analysed at } 3 \text { years, all female } \\
\text { (present for all examinations). } \\
\text { Age range at start: } 11-12 \text { years. Surfaces affected at start: } 7 \text { DFS. } \\
\text { Background exposure to fluoride: none reported. } \\
\text { Year study began: } 1962 . \\
\text { Location: UK. }\end{array}$} \\
\hline Interventions & \multicolumn{2}{|c|}{$\begin{array}{l}\text { FT versus PL } \\
\text { (SnF2 group = } 1000 \text { ppm F). } \\
\text { Home use/unsupervised, daily frequency assumed. } \\
\text { Abrasive system: dicalcium pyrophosphate. }\end{array}$} \\
\hline Outcomes & \multicolumn{2}{|l|}{$\begin{array}{l}\text { DFT. } \\
\text { DMFS. } \\
\text { DMFT. } \\
\text { postMD-DFS. }\end{array}$} \\
\hline Notes & \multicolumn{2}{|c|}{$\begin{array}{l}\text { Participants randomised ( } \mathrm{N}=961 \text { ). } \\
\text { Baseline characteristics (age, dental age, DFS, DFT, DMFS, DMFT, TAR) 'balanced'. } \\
\text { Clinical }(\mathrm{VT}) \text { caries assessment by one examiner; diagnostic threshold = CA; state of tooth eruption in- } \\
\text { cluded = E/U. Radiographic assessment ( } 2 \text { postBW) by one examiner; diagnostic threshold = ER. Consis- } \\
\text { tency of clinical diagnosis maintained by re-examination of } 10 \% \text { sample and calibration checks made } \\
\text { against reserve examiner. }\end{array}$} \\
\hline \multicolumn{3}{|l|}{ Risk of bias } \\
\hline Bias & Authors' judgement & Support for judgement \\
\hline $\begin{array}{l}\text { Allocation concealment } \\
\text { (selection bias) }\end{array}$ & Unclear risk & B - Unclear \\
\hline
\end{tabular}

\section{Slack 1971}

Methods Random allocation; double-blind ('A'); placebo-controlled; 33\% drop-out rate after 3 years (study duration $=3$ years). Main reasons for drop out: moved away, left school, away on examination day, disliked toothpaste taste, brown staining of teeth; no differential group losses.

$\begin{array}{ll}\text { Participants } & 1110 \text { children analysed at } 3 \text { years (available at final examination). } \\ \text { Age range at start: } 11-12 \text { years. Surfaces affected at start: 11.6 DMFS. } \\ \text { Background exposure to fluoride: none reported. } \\ \text { Year study began: } 1965 . \\ \text { Location: UK. }\end{array}$

Interventions

FT (3 groups) versus 'PL'

(Both SnF2 groups $=1000$ ppm F, APF group $=1000$ ppm F).

Home use/unsupervised, daily frequency assumed. 
Slack 1971 (Continued)

Abrasive system: IMP in one SnF2 toothpaste and in APF toothpaste, dicalcium pyrophosphate in another SnF2 toothpaste; control toothpaste abrasive NR.

\begin{tabular}{ll}
\hline Outcomes & 3yCrudeDMFS increment - (CA)cl+(ER)xr. \\
& Reported at 3 years follow up. \\
\hline Notes & Participants randomised ( $\mathrm{N}=1665)$. \\
& Baseline characteristics (age, gender, DMFS, previous F toothpaste use) 'balanced'. \\
& Clinical (VT) caries assessment by one examiner; diagnostic threshold = CA; state of tooth eruption in- \\
& cluded = NR. Radiographic assessment (2 postBW) by one examiner; diagnostic threshold = ER. Consis- \\
& tency of clinical diagnosis revealed by $10 \%$ sample checks at each examination. \\
\hline
\end{tabular}

\section{Risk of bias}

\begin{tabular}{lll}
\hline Bias & Authors' judgement & Support for judgement \\
\hline $\begin{array}{l}\text { Allocation concealment } \\
\text { (selection bias) }\end{array}$ & Unclear risk & B - Unclear \\
\hline
\end{tabular}

\section{Thomas 1966}

\begin{tabular}{|c|c|}
\hline Methods & $\begin{array}{l}\text { Stratified random allocation; double-blind (A); placebo-controlled; } 32 \% \text { drop out after } 2 \text { years (study } \\
\text { duration = } 2 \text { years). Reasons for attrition NR; no differential group losses. }\end{array}$ \\
\hline Participants & $\begin{array}{l}464 \text { children analysed at } 2 \text { years (present for the entire study period). } \\
\text { Average age at start: } 7-16 \text { years (average }=12 \text { ). } \\
\text { Surfaces affected at start: } 10.7 \text { DFS. Background exposure to fluoride: none reported. } \\
\text { Year study began: } 1961 . \\
\text { Location: USA. }\end{array}$ \\
\hline Interventions & $\begin{array}{l}\text { FT ( } 2 \text { groups) versus PL } \\
\text { (Both SnF2 groups = } 1000 \text { ppm F). } \\
\text { Institution use/supervised, twice a day. } \\
\text { Abrasive system: IMP in one SnF2 and placebo toothpaste, Ca pyrophosphate in another SnF2 tooth- } \\
\text { paste. }\end{array}$ \\
\hline Outcomes & $\begin{array}{l}\text { 2yDFS increment - } \mathrm{cl}+\mathrm{xr} \text {. } \\
\text { Reported at } 6 \mathrm{~m}, 1,1.5 \text { and } 2 \text { years follow ups. } \\
\text { DFT. }\end{array}$ \\
\hline Notes & $\begin{array}{l}\text { Participants randomised ( } N=679) \text {. } \\
\text { Baseline characteristics (DFS, DFT, TAR) 'balanced'. } \\
\text { Clinical (VT) caries assessment by one examiner, diagnostic threshold = NR. Radiographic assessment } \\
\text { (10 BW) by one examiner; diagnostic threshold = NR. State of tooth eruption included = NR. Check of di- } \\
\text { agnostic errors done. }\end{array}$ \\
\hline
\end{tabular}

\section{Risk of bias}

\begin{tabular}{lll}
\hline Bias & Authors' judgement & Support for judgement \\
\hline $\begin{array}{l}\text { Allocation concealment } \\
\text { (selection bias) }\end{array}$ & Low risk & A - Adequate \\
\hline
\end{tabular}


Torell 1965

\begin{tabular}{|c|c|}
\hline Methods & $\begin{array}{l}\text { Random allocation; double-blind (A); placebo-controlled; } 13 \% \text { drop-out rate after } 2 \text { years (study dura- } \\
\text { tion = } 2 \text { years). Natural losses mainly; no differential group losses. }\end{array}$ \\
\hline Participants & $\begin{array}{l}668 \text { children analysed at } 2 \text { years (available at final examination). } \\
\text { Average age at start: } 10 \text { years. Surfaces affected at start: } 14.5 \text { DMFS (from sample randomised). } \\
\text { Background exposure to fluoride: none reported. } \\
\text { Year study began: } 1962 . \\
\text { Location: Sweden. }\end{array}$ \\
\hline Interventions & $\begin{array}{l}\text { FT ( } 2 \text { groups) versus PL( } 2 \text { groups) ( } \mathrm{SnF} 2 \text { group }=1000 \mathrm{ppm} F, \mathrm{NaF} \text { group }=1100 \mathrm{ppm} \mathrm{F} \text { ). } \\
\text { Home use/unsupervised, twice a day instructed but daily frequency assumed, post-brushing water } \\
\text { rinse instructed. } \\
\text { Abrasive system: Ca pyrophosphate in SnF2 toothpaste and its placebo, Na bicarbonate in NaF tooth- } \\
\text { paste and its placebo. }\end{array}$ \\
\hline Outcomes & $\begin{array}{l}\text { 2yDMFS increment - (CA)cl. } \\
\text { Reported at } 1 \text { and } 2 \text { years follow ups. } \\
\text { MD-DMFS. } \\
\text { FS. } \\
\text { Proportion of children with new carious lesions (U)xr. }\end{array}$ \\
\hline Notes & $\begin{array}{l}\text { Participants randomised ( } N=766 \text { ). } \\
\text { Baseline characteristics (DMFS, MD-DMFS) 'balanced'. } \\
\text { Clinical (VT) caries assessment by two examiners, diagnostic threshold = CA; radiographic assessment } \\
\text { (BW) by two examiners; diagnostic threshold = DR. State of tooth eruption included NR. Inter- and in- } \\
\text { tra-examiner reproducibility checks done for clinical caries in } 4 \text { and } 2 \% \text { sample respectively; duplicate } \\
\text { examination of } x \text {-rays records done and any discrepancies discussed before final diagnosis. }\end{array}$ \\
\hline
\end{tabular}

\section{Risk of bias}

\begin{tabular}{lll}
\hline Bias & Authors' judgement & Support for judgement \\
\hline $\begin{array}{l}\text { Allocation concealment } \\
\text { (selection bias) }\end{array}$ & Unclear risk & B - Unclear \\
\hline
\end{tabular}

\section{Torell 1965a}

$\begin{array}{ll}\text { Methods } & \text { Random allocation; double-blind (A); placebo-controlled; } 20 \% \text { drop-out rate after } 2 \text { years (study dura- } \\ \text { tion = } 2 \text { years). Natural losses mainly; differential group losses. }\end{array}$

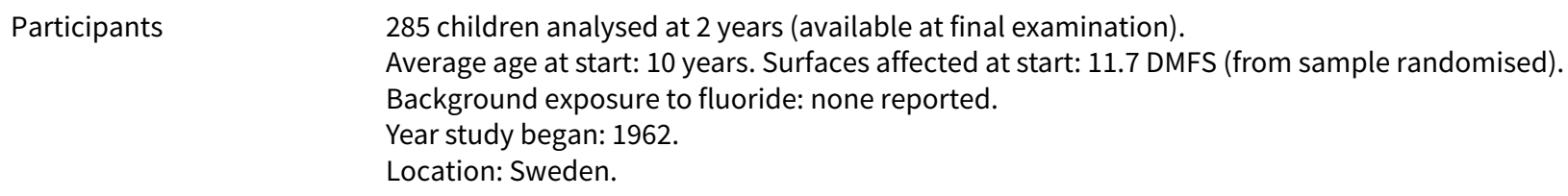

Participants 285 children analysed at 2 years (available at final examination). Average age at start: 10 years. Surfaces affected at start: 11.7 DMFS (from sample randomised). Background exposure to fluoride: none reported. 
Torell 1965a (Continued)

Outcomes
2yDMFS increment - (CA)cl.

Reported at 2 years follow up.

MD-DMFS.

FS.

Participants randomised ( $N=357)$.
Baseline characteristics (DMFS, MD-DMFS) 'balanced'.
Clinical (VT) caries assessment by one examiner, diagnostic threshold = CA; radiographic assessment
(BW) by two examiners; diagnostic threshold = DR. State of tooth eruption included NR. Intra-examiner
reproducibility check done for clinical caries in a sample; duplicate examination of $x$-rays records done
and any discrepancies discussed before final diagnosis.

\section{Risk of bias}

\begin{tabular}{lll}
\hline Bias & Authors' judgement & Support for judgement \\
\hline $\begin{array}{l}\text { Allocation concealment } \\
\text { (selection bias) }\end{array}$ & Unclear risk & B - Unclear \\
\hline
\end{tabular}

\section{Torell 1965b}

\begin{tabular}{|c|c|}
\hline Methods & $\begin{array}{l}\text { Random allocation; double-blind (A); placebo-controlled; } 15 \% \text { drop-out rate after } 2 \text { years (study dura- } \\
\text { tion = } 2 \text { years). Natural losses mainly; differential group losses. }\end{array}$ \\
\hline Participants & $\begin{array}{l}368 \text { children analysed at } 2 \text { years (available at final examination). } \\
\text { Average age at start: } 11 \text { years. Surfaces affected at start: } 15 \text { DMFS (from sample randomised). } \\
\text { Background exposure to fluoride: none reported. } \\
\text { Year study began: } 1962 . \\
\text { Location: Sweden. }\end{array}$ \\
\hline Interventions & $\begin{array}{l}\text { FT versus PL } \\
\text { (SMFP group = } 1000 \text { ppm F). } \\
\text { Home use/unsupervised, twice a day instructed but daily frequency assumed, post-brushing water } \\
\text { rinse instructed. } \\
\text { Abrasive system: Ca carbonate. }\end{array}$ \\
\hline Outcomes & $\begin{array}{l}\text { 2yDMFS increment - (CA)cl. } \\
\text { Reported at } 2 \text { years follow up. } \\
\text { MD-DMFS. } \\
\text { FS. }\end{array}$ \\
\hline Notes & $\begin{array}{l}\text { Participants randomised ( } N=432 \text { ). } \\
\text { Baseline characteristics (DMFS, MD-DMFS) 'balanced'. } \\
\text { Clinical (VT) caries assessment by one examiner, diagnostic threshold = CA; radiographic assessment } \\
\text { (BW) by two examiners; diagnostic threshold = DR. State of tooth eruption included NR. Intra-examiner } \\
\text { reproducibility check done for clinical caries in a sample; duplicate examination of } x \text {-rays records done } \\
\text { and any discrepancies discussed before final diagnosis. }\end{array}$ \\
\hline
\end{tabular}

\section{Risk of bias}

\section{Bias} Authors' judgement Support for judgement 
Torell 1965b (Continued)
Allocation concealment
Unclear risk
B - Unclear
(selection bias)

\section{Weisenstein 1972}

$\begin{array}{ll}\text { Methods } & \begin{array}{l}\text { Stratified random allocation; double-blind (A); placebo-controlled; } 42 \% \text { drop out after } 1.8 \text { years (study } \\ \text { duration }=1.8 \text { years). Reasons for high drop out described: change of residence, absent on examination } \\ \text { day; no differential group losses. }\end{array}\end{array}$

day; no differential group losses.

Participants children analysed at 1.8 years (available at final examination).
Age range at start: 5-15 years (average =9.5).
Surfaces affected at start: 6.8 DMFS.
Background exposure to fluoride: none reported.
Year study began: in/before 1969.
Location: USA.

\begin{tabular}{|c|c|}
\hline Interventions & $\begin{array}{l}\text { FT versus PL } \\
(\text { NaF group }=1000 \text { ppm F). } \\
\text { Home use/unsupervised, daily frequency assumed. } \\
\text { Abrasive system: Ca pyrophosphate. }\end{array}$ \\
\hline Outcomes & $\begin{array}{l}\text { 1.8yDMFS increment - } \mathrm{cl}+\mathrm{xr} \text {. } \\
\text { Reported at } 9 \mathrm{~m}, 1.4 \text { and } 1.8 \text { years follow ups. } \\
\text { DMFT. }\end{array}$ \\
\hline Notes & $\begin{array}{l}\text { Participants randomised }(\mathrm{N}=694) \text {. } \\
\text { Baseline characteristics (age, gender, DMFS, DMFT) 'balanced'. } \\
\text { Clinical (VT) caries assessment by two examiners, diagnostic threshold = NR. Radiographic assessment } \\
\text { ( } 7 \text { BW) by two examiners; diagnostic threshold = NR. State of tooth eruption included = NR. Diagnostic } \\
\text { errors NR. Results of one examiner chosen. }\end{array}$ \\
\hline
\end{tabular}

\section{Risk of bias}

Bias Authors' judgement Support for judgement

Allocation concealment Unclear risk B-Unclear

(selection bias)

\section{Zacherl 1970}

\begin{tabular}{ll}
\hline Methods & $\begin{array}{l}\text { Stratified random allocation; double-blind (A); placebo-controlled; 43\% drop out after 2.5 years (study } \\
\text { duration }=2.5 \text { years). Reasons for high drop out NR; no differential group losses. }\end{array}$ \\
\hline Participants & 512 children analysed at 2.5 years (available at final examination). \\
& $\begin{array}{l}\text { Age range at start: 6-9 years. Surfaces affected at start: 4.6 DMFS. } \\
\text { Background exposure to fluoride: none reported. } \\
\text { Year study began: in/before 1963. } \\
\text { Location: USA. }\end{array}$ \\
\hline Interventions & FT versus PL \\
& (SnF2 group = 1000 ppm F). \\
& Home use/unsupervised, daily frequency assumed. \\
\hline
\end{tabular}


Zacherl 1970 (Continued)

Abrasive system: Ca pyrophosphate.

$\begin{array}{ll}\text { Outcomes } & \text { 2.5yDMFS increment }-\mathrm{cl}+\mathrm{xr} . \\ \text { Reported at } 10 \mathrm{~m}, 1.5 \text { and } 2.5 \text { years follow ups. } \\ \text { DMFT. }\end{array}$

Notes $\quad$ Participants randomised ( $N=902)$.

Baseline characteristics (dental age, gender, DMFS, DMFT, oral hygiene) 'balanced'.

Clinical (VT) caries assessment by one examiner, diagnostic threshold = NR. Radiographic assessment

$(5-10$ BW $)$ by one examiner; diagnostic threshold $=$ NR. State of tooth eruption included $=$ NR. Diagnostic errors NR.

\section{Risk of bias}

\begin{tabular}{lll}
\hline Bias & Authors' judgement & Support for judgement \\
\hline $\begin{array}{l}\text { Allocation concealment } \\
\text { (selection bias) }\end{array}$ & High risk & C-Inadequate \\
\hline
\end{tabular}

\section{Zacherl 1970a}

Methods

Stratified random allocation; double-blind (A); placebo-controlled; 35\% drop out after 2.5 years (study duration $=2.5$ years). Reasons for attrition NR; no differential group losses.

Participants children analysed at 2.5 years (available at final examination).
Age range at start: 13-14 years. Surfaces affected at start: 23.5 DMFS.
Background exposure to fluoride: none reported.
Year study began: in/before 1963.
Location: USA.

\begin{tabular}{|c|c|c|}
\hline Interventions & \multicolumn{2}{|c|}{$\begin{array}{l}\text { FT versus } P L \\
\text { (SnF2 group = } 1000 \text { ppm F). } \\
\text { Home use/unsupervised, daily frequency assumed. } \\
\text { Abrasive system: Ca pyrophosphate. }\end{array}$} \\
\hline Outcomes & \multicolumn{2}{|c|}{$\begin{array}{l}\text { 2.5yDMFS increment - } \mathrm{cl}+\mathrm{xr} \text {. } \\
\text { Reported at } 10 \mathrm{~m}, 1.5 \text { and } 2.5 \text { years follow ups. }\end{array}$} \\
\hline Notes & \multicolumn{2}{|c|}{$\begin{array}{l}\text { Participants randomised }(\mathrm{N}=811) \text {. } \\
\text { Baseline characteristics (dental age, gender, DMFS, DMFT, oral hygiene) 'balanced'. } \\
\text { Clinical }(\mathrm{VT}) \text { caries assessment by one examiner, diagnostic threshold = NR. Radiographic assessment } \\
(5-10 \mathrm{BW}) \text { by one examiner; diagnostic threshold = NR. State of tooth eruption included = NR. Diagnos- } \\
\text { tic errors NR. }\end{array}$} \\
\hline \multicolumn{3}{|l|}{ Risk of bias } \\
\hline Bias & Authors' judgement & Support for judgement \\
\hline $\begin{array}{l}\text { Allocation concealment } \\
\text { (selection bias) }\end{array}$ & High risk & C - Inadequate \\
\hline
\end{tabular}


Zacherl 1972

\begin{tabular}{|c|c|}
\hline Methods & $\begin{array}{l}\text { Stratified random allocation; double-blind (A); placebo-controlled; } 34 \% \text { drop out after } 2 \text { years (study } \\
\text { duration = } 2 \text { years). } \\
\text { Reasons for attrition NR; no differential group losses. }\end{array}$ \\
\hline Participants & $\begin{array}{l}447 \text { children analysed at } 2 \text { years (available at final examination). } \\
\text { Age range at start: } 6 \text { - } 15 \text { years (average = 10). } \\
\text { Surfaces affected at start: } 11.7 \text { DMFS. } \\
\text { Background exposure to fluoride: none reported. } \\
\text { Year study began: in/before } 1969 . \\
\text { Location: Canada. }\end{array}$ \\
\hline Interventions & $\begin{array}{l}\text { FT versus PL } \\
\text { (SnF2 group = } 1000 \text { ppm F). } \\
\text { Home use/unsupervised, daily frequency assumed. } \\
\text { Abrasive system: Ca pyrophosphate in SnF2 toothpaste, placebo toothpaste abrasive NR. }\end{array}$ \\
\hline Outcomes & $\begin{array}{l}\text { 2yDMFS increment - cl+xr. } \\
\text { Reported at } 1 \text { and } 2 \text { years follow ups. } \\
\text { DMFT. }\end{array}$ \\
\hline Notes & $\begin{array}{l}\text { Participants randomised ( } N=677 \text { ). } \\
\text { Baseline characteristics (age, gender, DMFS, DMFT) 'balanced'. } \\
\text { Clinical }(V T) \text { caries assessment by one examiner, diagnostic threshold = NR. Radiographic assessment } \\
\text { (5-10 BW) by one examiner; diagnostic threshold = NR. State of tooth eruption included = NR. Diagnos- } \\
\text { tic errors NR. }\end{array}$ \\
\hline \multicolumn{2}{|l|}{ Risk of bias } \\
\hline Bias & Support for judgement \\
\hline $\begin{array}{l}\text { Allocation concealment } \\
\text { (selection bias) }\end{array}$ & Unclear risk \\
\hline
\end{tabular}

\section{Zacherl 1972a}

Methods Stratified random allocation; double-blind (A); placebo-controlled; $36 \%$ drop out after 1.7 years (study duration $=1.7$ years). Reasons for high drop out NR; exclusions based on presence in both examinations; no differential group losses.

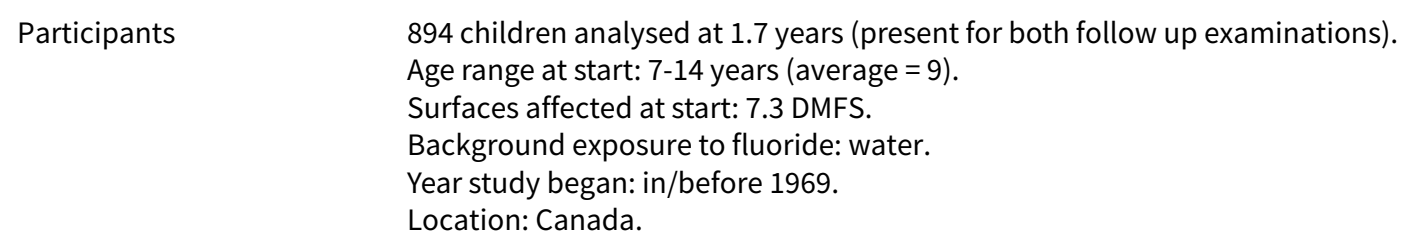


Zacherl 1972a (Continued)

DMFT.

Notes $\quad$ Participants randomised $(\mathrm{N}=1405)$.

Baseline characteristics (age, gender, DMFS, DMFT) 'balanced'.

Clinical (VT) caries assessment by one examiner, diagnostic threshold = NR. Radiographic assessment

$(5-10$ BW $)$ by one examiner; diagnostic threshold = NR. State of tooth eruption included $=$ NR. Diagnostic errors NR.

\section{Risk of bias}

\begin{tabular}{lll}
\hline Bias & Authors' judgement & Support for judgement \\
\hline $\begin{array}{l}\text { Allocation concealment } \\
\text { (selection bias) }\end{array}$ & Unclear risk & B - Unclear \\
\hline
\end{tabular}

\section{Zacherl 1973}

$\begin{array}{ll}\text { Methods } & \begin{array}{l}\text { Stratified random allocation; double-blind (A); placebo-controlled; } 34 \% \text { drop out after } 2 \text { years (study } \\ \text { duration = } 2 \text { years). Reasons for attrition NR; no differential group losses. }\end{array}\end{array}$
duration $=2$ years). Reasons for attrition NR; no differential group losses.

\begin{tabular}{|c|c|}
\hline Participants & $\begin{array}{l}444 \text { children analysed at } 2 \text { years (available at final examination). } \\
\text { Age range at start: } 5-12 \text { years (average }=9 \text { ). } \\
\text { Surfaces affected at start: } 8.5 \text { DMFS. } \\
\text { Background exposure to fluoride: none reported. } \\
\text { Year study began: in/before } 1970 . \\
\text { Location: USA. }\end{array}$ \\
\hline Interventions & $\begin{array}{l}\mathrm{FT}^{\star \star} \text { versus } \mathrm{PL} \\
(\mathrm{SnF} 2 \text { group }=1000 \mathrm{ppm} \mathrm{F}) \text {. } \\
\text { Home use/unsupervised, daily frequency assumed. } \\
\text { Abrasive system: Ca pyrophosphate in SnF2 toothpaste, placebo toothpaste abrasive NR. }\end{array}$ \\
\hline Outcomes & $\begin{array}{l}\text { 2yDMFS increment - cl+xr. } \\
\text { Reported at } 1 \text { and } 2 \text { years follow ups. } \\
\text { DMFT. }\end{array}$ \\
\hline Notes & $\begin{array}{l}\text { Participants randomised ( } \mathrm{N}=677 \text { ). } \\
\text { Baseline characteristics (age, DMFS, DMFT) 'balanced'. } \\
\text { Clinical (VT) caries assessment by one examiner, diagnostic threshold = NR. Radiographic assessment } \\
\text { (5-10 BW) by one examiner; diagnostic threshold = NR. State of tooth eruption included = NR. Diagnos- } \\
\text { tic errors NR. } \\
{ }^{\star *} \text { Na N-lauroyl sarcosinate/SMFP toothpaste group not considered (additional non-F active agent used } \\
\text { in this group only). }\end{array}$ \\
\hline
\end{tabular}

\section{Risk of bias}

\begin{tabular}{lll}
\hline Bias & Authors' judgement & Support for judgement \\
\hline $\begin{array}{l}\text { Allocation concealment } \\
\text { (selection bias) }\end{array}$ & Unclear risk & B - Unclear \\
\hline
\end{tabular}


Zacherl 1981

$\begin{array}{ll}\text { Methods } & \text { Stratified random allocation; double-blind (A); placebo-controlled; } 43 \% \text { drop out after } 3 \text { years (study } \\ \text { duration }=3 \text { years). Reasons for attrition described: change of residence, absent on examination day, } \\ \text { poor quality of } x \text {-rays; no differential group losses. }\end{array}$

\begin{tabular}{ll}
\hline Participants & 1754 children analysed at 3 years (available at final examination). \\
& Age range at start: $6-13$ years (average =9). \\
& Surfaces affected at start: 5.8 DMFS. \\
& Background exposure to fluoride: none reported. \\
Year study began: in/before 1977. & \\
Location: USA.
\end{tabular}

Location: USA.

$\begin{array}{ll}\text { Interventions } & \text { FT (2 groups) versus PL } \\ & (\text { SnF2 group }=1000 \mathrm{ppm} \mathrm{F,} \mathrm{NaF} \mathrm{group}=1100 \mathrm{ppm} \mathrm{F}) .\end{array}$

Home use/unsupervised, daily frequency assumed.

Abrasive system: Ca pyrophosphate in SnF2 and placebo toothpastes, silica in NaF toothpaste.

\begin{tabular}{ll}
\hline Outcomes & 3yDMFS increment $-(\mathrm{CA}) \mathrm{cl}+(\mathrm{ER}) \mathrm{xr}$. \\
& Reported at 1,2 and 3 years follow ups. \\
& DMFT. \\
\hline Notes & Participants randomised (N=3093). \\
& Baseline characteristics (DMFS, DMFT) 'balanced'. \\
& Clinical (VT) caries assessment (FOTI used) by one examiner, diagnostic threshold = CA. Radiographic \\
& assessment (postBW) by one examiner; diagnostic threshold = ER. State of tooth eruption included = \\
& NR. Intra-examiner reproducibility checks for incremental clinical and radiographic caries data in $10 \%$ \\
& sample (icc score 0.9 ). Reversal rate very low and similar among groups.
\end{tabular}

\section{Risk of bias}

\begin{tabular}{lll}
\hline Bias & Authors' judgement & Support for judgement \\
\hline $\begin{array}{l}\text { Allocation concealment } \\
\text { (selection bias) }\end{array}$ & Unclear risk & B - Unclear \\
\hline
\end{tabular}

Drop-out rate based only on groups relevant to review, on relevant follow ups, unless otherwise stated. Baseline caries experience averaged among relevant study arms, and based on the study sample analysed at the end of study period (final sample), unless otherwise stated. Age range (average age when reported) at the time the study started based on all study participants (or on groups relevant to the review when data were available).

$1 \mathrm{stm}$ = first permanent molar; 'A' = classified as double-blind but participants may not be blind (as a 'PL' was used); $A \mathrm{l}=$ aluminium; Alumina = Al oxide trihydrate (Al2O3); $\mathrm{AmF}=$ amine fluoride; $\mathrm{APF}=$ acidulated phosphate fluoride; $\mathrm{Ca}=\mathrm{calcium} ; \mathrm{Ca} \mathrm{carbonate}=\mathrm{CaCO} ; \mathrm{CA}$ $=$ lesions showing loss of enamel continuity that can be recorded clinically (undermined enamel, softened floor/walls) or showing frank cavitation; $\mathrm{CAR}=$ caries attack rate; $\mathrm{CIR}=$ caries incidence rate; $\mathrm{Chlor}=$ chlorhexidine diguclonate; $\mathrm{cl}=\mathrm{clinical}$ examination; $\mathrm{d}(\mathrm{e}) \mathrm{ft} / \mathrm{s}=$ decayed, (extracted) and filled deciduous teeth or surface; $\mathrm{dmft} / \mathrm{s}=$ decayed, missing (or extracted) and filled deciduous teeth or surface; $\mathrm{D}(\mathrm{M}) \mathrm{FS} / \mathrm{T}$ = decayed, (missing) and filled permanent surfaces or teeth; $\mathrm{DR}=$ radiolucency into dentin; $\mathrm{E}=$ teeth erupted at baseline; $\mathrm{ECSI}=$ Extrapolated Caries Surface Index (assesses caries progression into enamel/dentin/pulp); ER = any radiolucency in enamel/enamel-dentin junction; $\mathrm{F}$ = fluoride; $\mathrm{FR}$ = fluoride mouthrinse; $\mathrm{FT}$ = fluoride toothpaste; icc = intra-class correlation coefficient (for inter-rater reliability); IMP = insoluble Na metaphosphate; $\mathrm{M}=$ missing permanent teeth; $\mathrm{MD}=$ mesio and distal surfaces; $\mathrm{N}=$ numbers; $\mathrm{Na}=$ sodium; $\mathrm{NaF}=$ sodium fluoride; $\mathrm{Na}$ bicarbonate = NaHCO3; NCA = non-cavitated enamel lesions visible as white spots or discoloured fissures; NR = not reported; $\mathrm{NS}$ = not significant; $\mathrm{O}$ = occlusal surfaces; $\mathrm{PF}=$ pit and fissure surfaces; $\mathrm{PL}$ = placebo toothpaste; 'PL' = fluoride-free toothpaste but not a true placebo (e.g. different in taste or colour from test toothpaste(s)); post BW = posterior bite-wing $\mathrm{x}$-ray assessment; $\mathrm{ppm} \mathrm{F}=$ parts per million of fluoride; $\mathrm{ptc}=$ prior tooth-cleaning performed with or without a non-fluoride paste; Silica = silicon dioxide $(\mathrm{SiO} 2 ; \mathrm{SMFP}=$ sodium monofluorophosphate; $\mathrm{SnF} 2$ = stannous fluoride; $\mathrm{U}=$ teeth unerupted at baseline; $\mathrm{VT}$ = visual-tactile assessment; $\mathrm{xr}=$ radiographic examination.

Characteristics of excluded studies [ordered by study ID] 


\begin{tabular}{|c|c|}
\hline Study & Reason for exclusion \\
\hline Antia 1974 & Random or quasi-random allocation not stated. \\
\hline Axelsson 1976 & $\begin{array}{l}\text { Additional fluoride-based intervention associated to fluoride toothpaste. Blind outcome assess- } \\
\text { ment not stated. }\end{array}$ \\
\hline Bibby 1945 & $\begin{array}{l}\text { Random or quasi-random allocation not stated or indicated. Blind outcome assessment not stated } \\
\text { or indicated. }\end{array}$ \\
\hline Bixler 1962 & $\begin{array}{l}\text { Group of participants more than } 16 \text { years old selected. Random or quasi-random allocation not } \\
\text { stated. }\end{array}$ \\
\hline Bixler 1966 & Group of young adults selected. \\
\hline Bixler 1966a & $\begin{array}{l}\text { Additional fluoride-based intervention associated to fluoride toothpaste. Group of participants } \\
\text { more than } 16 \text { years old selected. Blind outcome assessment not stated. }\end{array}$ \\
\hline Downer 1976 & Additional fluoride-based intervention associated to fluoride toothpaste. \\
\hline Ennever 1980 & Random or quasi-random allocation not stated or indicated. \\
\hline Finn 1963 & Medically compromised group of institutionalised children selected. \\
\hline Gish 1965 & $\begin{array}{l}\text { Additional fluoride-based intervention associated to fluoride toothpaste. Blind outcome assess- } \\
\text { ment not stated. }\end{array}$ \\
\hline Gutherz 1968 & $\begin{array}{l}\text { Random or quasi-random allocation not stated or indicated. Blind outcome assessment not stated } \\
\text { or indicated. }\end{array}$ \\
\hline Halikis 1966 & Random or quasi-random allocation not stated or indicated. \\
\hline Hill 1959 & $\begin{array}{l}\text { Random or quasi-random allocation not stated or indicated. Blind outcome assessment not stated } \\
\text { or indicated. }\end{array}$ \\
\hline Jiraskova 1965 & $\begin{array}{l}\text { Random or quasi-random allocation not stated or indicated. Blind outcome assessment not stated } \\
\text { or indicated. }\end{array}$ \\
\hline Jordan 1959 & Only two clusters (schools), each randomised to one of the two interventions compared. \\
\hline Kunzel 1977 & Additional fluoride-based intervention associated to fluoride toothpaste. \\
\hline Lehnhoff 1966 & Participants more than 16 years old selected. \\
\hline Lu 1985 & Additional active agent associated to fluoride in toothpaste. \\
\hline Luoma 1978 & Additional fluoride-based intervention associated to fluoride toothpaste. \\
\hline Mergele 1968a & Medically compromised group of institutionalised young adults and children selected. \\
\hline Moller 1968 & Additional active agent associated to fluoride in test toothpaste. \\
\hline Muhler 1955a & Random or quasi-random allocation not stated. \\
\hline Muhler 1957 & Random or quasi-random allocation not stated. \\
\hline Muhler 1958 & Participants more than 16 years old selected. Random or quasi-random allocation not stated. \\
\hline
\end{tabular}




\begin{tabular}{|c|c|}
\hline Study & Reason for exclusion \\
\hline Muhler 1960 & $\begin{array}{l}\text { Participants more than } 16 \text { years old selected. Random or quasi-random allocation not stated. Blind } \\
\text { outcome assessment not stated. }\end{array}$ \\
\hline Muhler 1962 & Participants more than 16 years old selected. \\
\hline Niwa 1975 & $\begin{array}{l}\text { Random or quasi-random allocation not stated or indicated. Blind outcome assessment not stated } \\
\text { or indicated. }\end{array}$ \\
\hline Onisi 1970 & $\begin{array}{l}\text { Random or quasi-random allocation not stated or indicated. Blind outcome assessment not stated } \\
\text { or indicated. }\end{array}$ \\
\hline Onisi 1974 & $\begin{array}{l}\text { Additional active agent associated to fluoride in toothpaste. Only two clusters (villages), each as- } \\
\text { signed to one of the two interventions compared. }\end{array}$ \\
\hline Patz 1970 & Participants more than 16 years old selected. Blind outcome assessment not stated. \\
\hline Peffley 1960 & $\begin{array}{l}\text { Participants more than } 16 \text { years old selected. Random or quasi-random allocation not stated. Blind } \\
\text { outcome assessment not stated. }\end{array}$ \\
\hline Piccione 1979 & Blind outcome assessment not stated or indicated. \\
\hline Riethe 1975 & Blind outcome assessment not stated or indicated. \\
\hline Stookey 1975 & Random or quasi-random allocation not stated. \\
\hline Wrinkler 1953 & $\begin{array}{l}\text { Random or quasi-random allocation clearly not used (non-random concurrent control: by match- } \\
\text { ing procedure). }\end{array}$ \\
\hline Zickert 1982 & Additional fluoride-based intervention associated to fluoride toothpaste. \\
\hline
\end{tabular}

DATA AND ANALYSES

\section{Comparison 1. Fluoride toothpaste versus placebo}

\begin{tabular}{|c|c|c|c|c|}
\hline Outcome or subgroup title & No. of studies & $\begin{array}{l}\text { No. of partici- } \\
\text { pants }\end{array}$ & Statistical method & Effect size \\
\hline $\begin{array}{l}1 \mathrm{D}(\mathrm{M}) \mathrm{FS} \text { increment (prevented fraction) - } \\
\text { nearest to } 3 \text { years ( } 70 \text { trials) }\end{array}$ & & & Other data & No numeric data \\
\hline $\begin{array}{l}2 \mathrm{D}(\mathrm{M}) \mathrm{FT} \text { increment (prevented fraction) - } \\
\text { nearest to } 3 \text { years ( } 53 \text { trials) }\end{array}$ & & & Other data & No numeric data \\
\hline $\begin{array}{l}3 \mathrm{D}(\mathrm{M}) \mathrm{FS} \text { increment (SMD) - nearest to } 3 \\
\text { years ( } 70 \text { trials) }\end{array}$ & 70 & 42300 & $\begin{array}{l}\text { Std. Mean Difference (IV, } \\
\text { Random, } 95 \% \mathrm{CI} \text { ) }\end{array}$ & $\begin{array}{l}-0.31[-0.35 \\
-0.27]\end{array}$ \\
\hline $\begin{array}{l}4 \mathrm{D}(\mathrm{M}) \mathrm{FT} \text { increment }(\mathrm{SMD}) \text { - nearest to } 3 \\
\text { years (53 trials) }\end{array}$ & 53 & 32371 & $\begin{array}{l}\text { Std. Mean Difference (IV, } \\
\text { Random, } 95 \% \mathrm{CI} \text { ) }\end{array}$ & $\begin{array}{l}-0.28[-0.33 \\
-0.23]\end{array}$ \\
\hline $\begin{array}{l}5 \text { Developing one or more new caries ( } 6 \text { tri- } \\
\text { als) }\end{array}$ & 7 & 2878 & $\begin{array}{l}\text { Risk Ratio (M-H, Ran- } \\
\text { dom, } 95 \% \mathrm{Cl})\end{array}$ & $0.91[0.80,1.04]$ \\
\hline
\end{tabular}




\begin{tabular}{lllll}
\hline Outcome or subgroup title & No. of studies & $\begin{array}{l}\text { No. of partici- } \\
\text { pants }\end{array}$ & Statistical method & Effect size \\
\hline 6 Acquiring extrinsic tooth staining (5 trials) & 5 & 3948 & $\begin{array}{l}\text { Risk Difference (M- H, } \\
\text { Random, 95\% Cl) }\end{array}$ & $0.24[0.19,0.30]$ \\
\hline
\end{tabular}

\section{Analysis 1.1. Comparison 1 Fluoride toothpaste versus placebo, Outcome} $1 \mathrm{D}$ (M)FS increment (prevented fraction) - nearest to 3 years ( 70 trials).

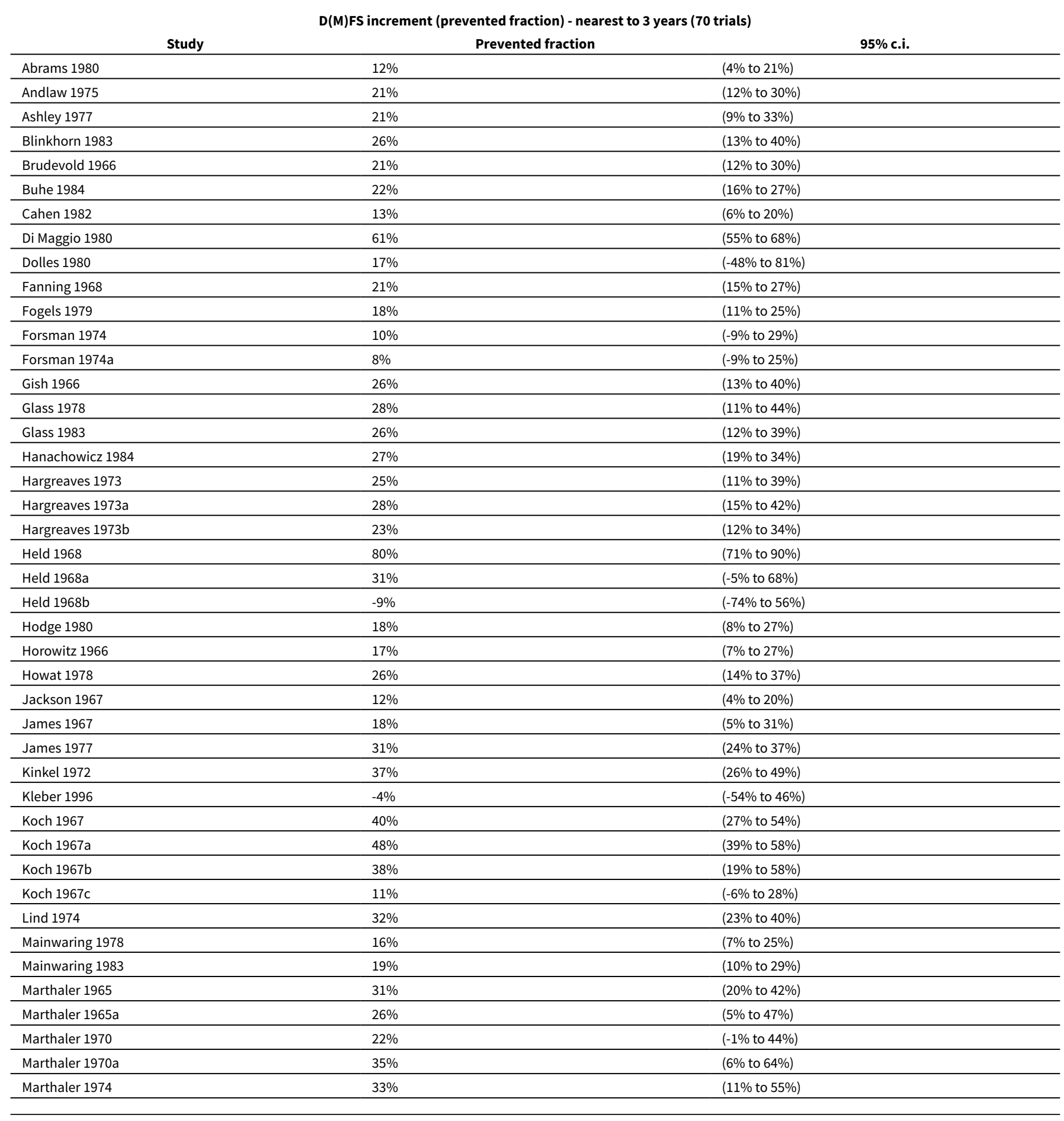


$D$ (M)FS increment (prevented fraction) - nearest to 3 years (70 trials)

\begin{tabular}{|c|c|c|}
\hline Study & Prevented fraction & 95\% c.i. \\
\hline Mergele 1968 & $13 \%$ & (1\% to $26 \%)$ \\
\hline Muhler 1955 & $36 \%$ & (19\% to $53 \%)$ \\
\hline Muhler 1970 & $29 \%$ & (14\% to $44 \%)$ \\
\hline Murray 1980 & $30 \%$ & ( $21 \%$ to $39 \%)$ \\
\hline Naylor 1967 & $14 \%$ & (7\% to $21 \%)$ \\
\hline Naylor 1979 & $22 \%$ & (14\% to $31 \%)$ \\
\hline Peterson 1979 & $10 \%$ & (-7\% to $27 \%)$ \\
\hline Reed 1973 & $12 \%$ & (1\% to $23 \%)$ \\
\hline Reed 1975 & $30 \%$ & (15\% to $45 \%)$ \\
\hline Ringelberg 1979 & $18 \%$ & (1\% to $35 \%)$ \\
\hline Rule 1984 & $29 \%$ & (20\% to $37 \%)$ \\
\hline Segal 1967 & $19 \%$ & (5\% to $34 \%)$ \\
\hline Slack 1967a & $5 \%$ & (-7\% to $17 \%)$ \\
\hline Slack 1971 & $17 \%$ & (9\% to $24 \%)$ \\
\hline Thomas 1966 & $30 \%$ & (17\% to $44 \%)$ \\
\hline Torell 1965 & $20 \%$ & (11\% to $29 \%)$ \\
\hline Torell 1965a & $6 \%$ & $(-5 \%$ to $18 \%)$ \\
\hline Torell 1965b & $15 \%$ & (5\% to $26 \%)$ \\
\hline Weisenstein 1972 & $11 \%$ & (-3\% to $25 \%)$ \\
\hline Zacherl 1970 & $40 \%$ & (32\% to $49 \%)$ \\
\hline Zacherl 1970a & $43 \%$ & (37\% to $50 \%)$ \\
\hline Zacherl 1972 & $22 \%$ & (11\% to $34 \%)$ \\
\hline Zacherl 1972a & $23 \%$ & (12\% to $35 \%)$ \\
\hline Zacherl 1973 & $30 \%$ & (10\% to $49 \%)$ \\
\hline Zacherl 1981 & $32 \%$ & (20\% to $44 \%$ \\
\hline
\end{tabular}

Analysis 1.2. Comparison 1 Fluoride toothpaste versus placebo, Outcome $2 \mathrm{D}(\mathrm{M}) \mathrm{FT}$ increment (prevented fraction) - nearest to 3 years (53 trials).

\begin{tabular}{|c|c|c|}
\hline \multicolumn{3}{|c|}{$D(M) F T$ increment (prevented fraction) - nearest to 3 years (53 trials) } \\
\hline Study & Prevented fraction & 95\% c.i. \\
\hline Abrams 1980 & $15 \%$ & ( $4 \%$ to $26 \%)$ \\
\hline Andlaw 1975 & $18 \%$ & $(10 \%$ to $26 \%)$ \\
\hline Blinkhorn 1983 & $30 \%$ & $(18 \%$ to $43 \%)$ \\
\hline Brudevold 1966 & $22 \%$ & $(13 \%$ to $31 \%)$ \\
\hline Buhe 1984 & $17 \%$ & $(11 \%$ to $23 \%)$ \\
\hline Cahen 1982 & $15 \%$ & (9\% to $20 \%)$ \\
\hline Di Maggio 1980 & $51 \%$ & $(45 \%$ to $56 \%)$ \\
\hline Fogels 1979 & $12 \%$ & ( $2 \%$ to $21 \%)$ \\
\hline Gish 1966 & $14 \%$ & $(-1 \%$ to $29 \%)$ \\
\hline Glass 1978 & $25 \%$ & $(11 \%$ to $40 \%)$ \\
\hline Glass 1983 & $28 \%$ & (16\% to $39 \%)$ \\
\hline Hanachowicz 1984 & $26 \%$ & $(19 \%$ to $33 \%)$ \\
\hline Hargreaves 1973 & $17 \%$ & $(-3 \%$ to $38 \%)$ \\
\hline Hargreaves 1973a & $29 \%$ & (14\% to $4 \%)$ \\
\hline Hargreaves 1973b & $11 \%$ & (-4\% to $26 \%)$ \\
\hline Held 1968 & $93 \%$ & (85\% to $101 \%)$ \\
\hline Held 1968a & $40 \%$ & $(-4 \%$ to $83 \%)$ \\
\hline Held 1968b & $59 \%$ & (10\% to $109 \%)$ \\
\hline Hodge 1980 & $22 \%$ & (14\% to $30 \%)$ \\
\hline Horowitz 1966 & $17 \%$ & (6\% to $27 \%$ ) \\
\hline
\end{tabular}


D(M)FT increment (prevented fraction) - nearest to 3 years (53 trials)

\begin{tabular}{|c|c|c|}
\hline Study & Prevented fraction & 95\% c.i. \\
\hline Howat 1978 & $27 \%$ & (17\% to $37 \%)$ \\
\hline Jackson 1967 & $10 \%$ & (3\% to $18 \%)$ \\
\hline James 1967 & $11 \%$ & $(-2 \%$ to $24 \%)$ \\
\hline Kleber 1996 & $-2 \%$ & (-50\% to $47 \%)$ \\
\hline Koch 1967 & $35 \%$ & ( $24 \%$ to $46 \%)$ \\
\hline Koch 1967a & $30 \%$ & (17\% to $43 \%)$ \\
\hline Koch 1967c & $5 \%$ & (-14\% to $24 \%)$ \\
\hline Lind 1974 & $31 \%$ & ( $23 \%$ to $38 \%$ ) \\
\hline Marthaler 1965 & $33 \%$ & (20\% to $45 \%)$ \\
\hline Marthaler 1965a & $16 \%$ & $(-5 \%$ to $37 \%)$ \\
\hline Marthaler 1974 & $33 \%$ & (15\% to $52 \%)$ \\
\hline Mergele 1968 & $6 \%$ & $(-5 \%$ to $18 \%)$ \\
\hline Muhler 1970 & $32 \%$ & (16\% to $49 \%)$ \\
\hline Naylor 1967 & $8 \%$ & (1\% to $15 \%)$ \\
\hline Naylor 1979 & $20 \%$ & (12\% to $27 \%)$ \\
\hline Peterson 1967 & $14 \%$ & (5\% to $23 \%)$ \\
\hline Peterson 1979 & $10 \%$ & $(-7 \%$ to $26 \%)$ \\
\hline Reed 1973 & $18 \%$ & (8\% to $28 \%)$ \\
\hline Reed 1975 & $26 \%$ & (10\% to $41 \%)$ \\
\hline Ringelberg 1979 & $15 \%$ & (1\% to $30 \%)$ \\
\hline Rule 1984 & $24 \%$ & (14\% to $34 \%)$ \\
\hline Slack 1967 & $-2 \%$ & $(-14 \%$ to $11 \%)$ \\
\hline Slack 1967a & $4 \%$ & (-7\% to $14 \%)$ \\
\hline Thomas 1966 & $31 \%$ & (15\% to $47 \%)$ \\
\hline Weisenstein 1972 & $15 \%$ & (1\% to $28 \%)$ \\
\hline Zacherl 1972 & $20 \%$ & (6\% to $34 \%)$ \\
\hline Zacherl 1972a & $21 \%$ & (8\% to $33 \%)$ \\
\hline Zacherl 1973 & $35 \%$ & (18\% to $53 \%)$ \\
\hline Zacherl 1981 & $31 \%$ & ( $20 \%$ to $42 \%)$ \\
\hline
\end{tabular}

Analysis 1.3. Comparison 1 Fluoride toothpaste versus placebo, Outcome 3 D(M)FS increment (SMD) - nearest to 3 years (70 trials).

\begin{tabular}{|c|c|c|c|c|c|c|c|c|}
\hline \multirow{3}{*}{$\begin{array}{l}\text { Study or subgroup } \\
\text { Mainwaring } 1983\end{array}$} & \multicolumn{2}{|c|}{$\begin{array}{l}\text { Fluoride } \\
\text { Toothpaste }\end{array}$} & \multicolumn{2}{|c|}{ Placebo } & \multirow{2}{*}{\multicolumn{2}{|c|}{$\begin{array}{l}\text { Std. Mean Difference } \\
\text { Random, } 95 \% \mathrm{Cl} \\
\end{array}$}} & \multirow{3}{*}{$\begin{array}{r}\text { Weight } \\
1.65 \%\end{array}$} & \multirow{3}{*}{$\begin{array}{l}\text { Std. Mean Difference } \\
\text { Random, 95\% Cl } \\
-0.3[-0.46,-0.14]\end{array}$} \\
\hline & \multirow{2}{*}{$\frac{\mathbf{N}}{458}$} & \multirow{2}{*}{$\frac{\operatorname{Mean}(\mathbf{S D})}{8.9(6.4)}$} & \multirow{2}{*}{$\frac{\mathbf{N}}{224}$} & \multirow{2}{*}{$\frac{\text { Mean(SD) }}{11(8.2)}$} & & & & \\
\hline & & & & & + & & & \\
\hline Abrams 1980 & 761 & $6.4(5.3)$ & 380 & $7.3(5.7)$ & + & & $1.83 \%$ & $-0.17[-0.29,-0.04]$ \\
\hline Andlaw 1975 & 364 & $6.1(5)$ & 376 & $7.7(5.2)$ & + & & $1.73 \%$ & $-0.31[-0.46,-0.17]$ \\
\hline Ashley 1977 & 246 & $4.4(4)$ & 243 & $5.6(4.6)$ & + & & $1.57 \%$ & $-0.27[-0.45,-0.09]$ \\
\hline Brudevold 1966 & 955 & $5.6(6.1)$ & 323 & $7(6.1)$ & + & & $1.82 \%$ & $-0.24[-0.37,-0.11]$ \\
\hline Buhe 1984 & 859 & $13(7.9)$ & 427 & $16.6(9.2)$ & + & & $1.86 \%$ & $-0.43[-0.55,-0.31]$ \\
\hline Cahen 1982 & 1300 & $3.5(3.2)$ & 708 & $4.1(3.5)$ & + & & $1.97 \%$ & $-0.16[-0.25,-0.06]$ \\
\hline Di Maggio 1980 & 22 & $4.5(1)$ & 20 & $11.6(3.5)$ & r & & $0.22 \%$ & $-2.75[-3.61,-1.88]$ \\
\hline Dolles 1980 & 24 & $1.9(2.7)$ & 23 & $2.3(3)$ & * & & $0.44 \%$ & $-0.13[-0.7,0.44]$ \\
\hline Fanning 1968 & 422 & $9.7(6.4)$ & 422 & $12.2(6.4)$ & + & & $1.77 \%$ & $-0.4[-0.54,-0.27]$ \\
\hline
\end{tabular}




\begin{tabular}{|c|c|c|c|c|c|c|c|}
\hline \multirow{3}{*}{$\begin{array}{l}\text { Study or subgroup } \\
\text { Fogels } 1979\end{array}$} & \multicolumn{2}{|c|}{$\begin{array}{c}\text { Fluoride } \\
\text { Toothpaste }\end{array}$} & \multicolumn{2}{|c|}{ Placebo } & \multirow{2}{*}{$\begin{array}{c}\text { Std. Mean Difference } \\
\text { Random, } 95 \% \mathrm{Cl} \\
\end{array}$} & \multirow{3}{*}{$\begin{array}{r}\text { Weight } \\
1.87 \%\end{array}$} & \multirow{3}{*}{$\begin{array}{l}\text { Std. Mean Difference } \\
\begin{array}{c}\text { Random, 95\% Cl } \\
-0.27[-0.38,-0.15]\end{array}\end{array}$} \\
\hline & \multirow{2}{*}{$\frac{\mathbf{N}}{890}$} & \multirow{2}{*}{$\frac{\text { Mean(SD) }}{6.8(5.5)}$} & \multirow{2}{*}{$\frac{\mathbf{N}}{449}$} & \multirow{2}{*}{$\frac{\text { Mean(SD) }}{8.3(6.1)}$} & & & \\
\hline & & & & & + & & \\
\hline Forsman 1974 & 414 & $2.9(3.4)$ & 145 & $3.3(3.6)$ & + & $1.51 \%$ & $-0.09[-0.28,0.09]$ \\
\hline Forsman 1974a & 262 & $5.2(4.7)$ & 132 & $5.7(4.9)$ & + & $1.42 \%$ & $-0.09[-0.3,0.12]$ \\
\hline Glass 1978 & 178 & $5.3(6)$ & 168 & $7.4(7.7)$ & + & $1.4 \%$ & $-0.3[-0.51,-0.09]$ \\
\hline Glass 1983 & 567 & $2.4(3)$ & 286 & $3.2(4)$ & + & $1.74 \%$ & $-0.24[-0.38,-0.1]$ \\
\hline Hanachowicz 1984 & 473 & $5.3(4.5)$ & 472 & $7.2(5.6)$ & + & $1.81 \%$ & $-0.38[-0.51,-0.25]$ \\
\hline Hargreaves 1973 & 163 & $5.4(4.8)$ & 140 & $7.2(5.6)$ & + & $1.33 \%$ & $-0.34[-0.57,-0.11]$ \\
\hline Hargreaves 1973a & 146 & $5.7(4.9)$ & 138 & $8(5.9)$ & + & $1.3 \%$ & $-0.41[-0.65,-0.18]$ \\
\hline Hargreaves 1973b & 146 & $10.7(7)$ & 151 & $13.8(8)$ & + & $1.32 \%$ & $-0.42[-0.65,-0.19]$ \\
\hline Held 1968a & 19 & $5.5(4.8)$ & 17 & $8(6)$ & $\longrightarrow$ & $0.34 \%$ & $-0.45[-1.12,0.21]$ \\
\hline Held 1968b & 14 & $6.1(5.1)$ & 18 & $5.6(4.9)$ & + & $0.31 \%$ & $0.1[-0.6,0.8]$ \\
\hline Hodge 1980 & 597 & $6.4(5.2)$ & 202 & $7.8(5.5)$ & + & $1.66 \%$ & $-0.27[-0.43,-0.11]$ \\
\hline Horowitz 1966 & 329 & $4.9(3.8)$ & 309 & $5.9(4.8)$ & + & $1.68 \%$ & $-0.23[-0.39,-0.07]$ \\
\hline Howat 1978 & 253 & $5.7(5.5)$ & 242 & $7.7(6.4)$ & + & $1.57 \%$ & $-0.33[-0.51,-0.15]$ \\
\hline Jackson 1967 & 438 & $7.2(4.7)$ & 433 & $8.2(5.5)$ & + & $1.79 \%$ & $-0.19[-0.32,-0.06]$ \\
\hline James 1967 & 406 & $4.3(5.2)$ & 397 & $5.2(5.4)$ & + & $1.76 \%$ & $-0.18[-0.32,-0.04]$ \\
\hline James 1977 & 403 & $8.2(6)$ & 379 & $11.8(7.4)$ & + & $1.74 \%$ & $-0.54[-0.68,-0.39]$ \\
\hline Kinkel 1972 & 354 & $2.1(2.9)$ & 345 & $3.4(3.7)$ & + & $1.71 \%$ & $-0.38[-0.53,-0.23]$ \\
\hline Kleber 1996 & 77 & $1.7(2.8)$ & 79 & $1.6(2.1)$ & $\Rightarrow$ & $0.99 \%$ & $0.03[-0.29,0.34]$ \\
\hline Koch 1967 & 64 & $11.5(9.3)$ & 60 & $19.2(8.8)$ & $\rightarrow-$ & $0.82 \%$ & $-0.85[-1.22,-0.48]$ \\
\hline Koch 1967a & 60 & $11.9(6.8)$ & 60 & $23(10.4)$ & $\rightarrow$ & $0.76 \%$ & $-1.26[-1.65,-0.86]$ \\
\hline Koch 1967b & 32 & $6.6(4.3)$ & 38 & $10.7(7.4)$ & $\rightarrow$ & $0.57 \%$ & $-0.66[-1.14,-0.17]$ \\
\hline Mainwaring 1978 & 791 & $7(6)$ & 316 & $8.3(6.6)$ & + & $1.8 \%$ & $-0.21[-0.35,-0.08]$ \\
\hline Marthaler 1965 & 145 & $5.3(3.8)$ & 124 & $7.7(4.7)$ & + & $1.26 \%$ & $-0.57[-0.81,-0.32]$ \\
\hline Marthaler 1965a & 42 & $11.3(7.6)$ & 32 & $15.3(8.6)$ & 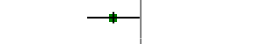 & $0.6 \%$ & $-0.48[-0.95,-0.02]$ \\
\hline Marthaler 1970 & 43 & $3.4(2.5)$ & 57 & $4.4(3.1)$ & $\rightarrow$ & $0.74 \%$ & $-0.33[-0.73,0.07]$ \\
\hline Marthaler 1970a & 23 & $2.6(2.1)$ & 20 & $4(2.7)$ & $\cdots$ & $0.39 \%$ & $-0.57[-1.18,0.05]$ \\
\hline Marthaler 1974 & 50 & $5.6(5.5)$ & 59 & $8.4(5.8)$ & $\rightarrow$ & $0.78 \%$ & $-0.49[-0.87,-0.11]$ \\
\hline Mergele 1968 & 197 & $4.8(3.3)$ & 190 & $5.6(4.3)$ & + & $1.46 \%$ & $-0.19[-0.39,0.01]$ \\
\hline Muhler 1955 & 219 & $1.6(2.4)$ & 225 & $2.4(3.1)$ & + & $1.52 \%$ & $-0.31[-0.5,-0.13]$ \\
\hline Muhler 1970 & 201 & $2.9(3.5)$ & 235 & $4.1(4)$ & + & $1.51 \%$ & $-0.31[-0.5,-0.12]$ \\
\hline Murray 1980 & 750 & $4.5(5.3)$ & 356 & $6.4(6)$ & + & $1.81 \%$ & $-0.35[-0.48,-0.23]$ \\
\hline Naylor 1967 & 494 & $7.9(5.1)$ & 479 & $9.2(6.2)$ & + & $1.82 \%$ & $-0.23[-0.35,-0.1]$ \\
\hline Naylor 1979 & 319 & $8.1(6.1)$ & 306 & $10.4(6.5)$ & + & $1.66 \%$ & $-0.37[-0.53,-0.21]$ \\
\hline Peterson 1967 & 634 & $7.6(5.6)$ & 320 & $9.2(6.1)$ & + & $1.78 \%$ & $-0.27[-0.4,-0.14]$ \\
\hline Peterson 1979 & 467 & $2.9(3.7)$ & 245 & $3.2(3.9)$ & + & $1.68 \%$ & $-0.08[-0.24,0.07]$ \\
\hline Reed 1973 & 1128 & $3.5(4.2)$ & 397 & $4(4.2)$ & + & $1.87 \%$ & $-0.11[-0.23,0]$ \\
\hline Reed 1975 & 168 & $3(3.3)$ & 176 & $4.3(4.2)$ & + & $1.4 \%$ & $-0.34[-0.55,-0.13]$ \\
\hline Ringelberg 1979 & 370 & $5.1(5.9)$ & 186 & $6.3(7.4)$ & + & $1.57 \%$ & $-0.17[-0.35,0]$ \\
\hline Rule 1984 & 460 & $4.6(4.7)$ & 416 & $6.4(4.7)$ & + & $1.78 \%$ & $-0.39[-0.52,-0.25]$ \\
\hline Segal 1967 & 338 & $2.7(3.3)$ & 310 & $3.3(3.7)$ & + & $1.68 \%$ & $-0.18[-0.34,-0.03]$ \\
\hline Slack 1967 & 356 & $5.6(5.3)$ & 340 & $5.6(5.6)$ & $t$ & $1.71 \%$ & $-0.01[-0.15,0.14]$ \\
\hline Slack 1967a & 376 & $5.6(4.8)$ & 381 & $6(5.7)$ & + & $1.74 \%$ & $-0.06[-0.2,0.08]$ \\
\hline Slack 1971 & 821 & $10.7(7.7)$ & 289 & $12.8(8.3)$ & + & $1.78 \%$ & $-0.28[-0.41,-0.14]$ \\
\hline Thomas 1966 & 309 & $2.8(2.9)$ & 155 & $4.1(4.1)$ & + & $1.49 \%$ & $-0.37[-0.56,-0.17]$ \\
\hline Torell 1965 & 335 & $8.1(6.9)$ & 333 & $10.2(6.6)$ & + & $1.69 \%$ & $-0.31[-0.46,-0.15]$ \\
\hline Torell 1965a & 148 & $10.1(5.1)$ & 137 & $10.8(6.2)$ & + & $1.31 \%$ & $-0.12[-0.36,0.11]$ \\
\hline
\end{tabular}




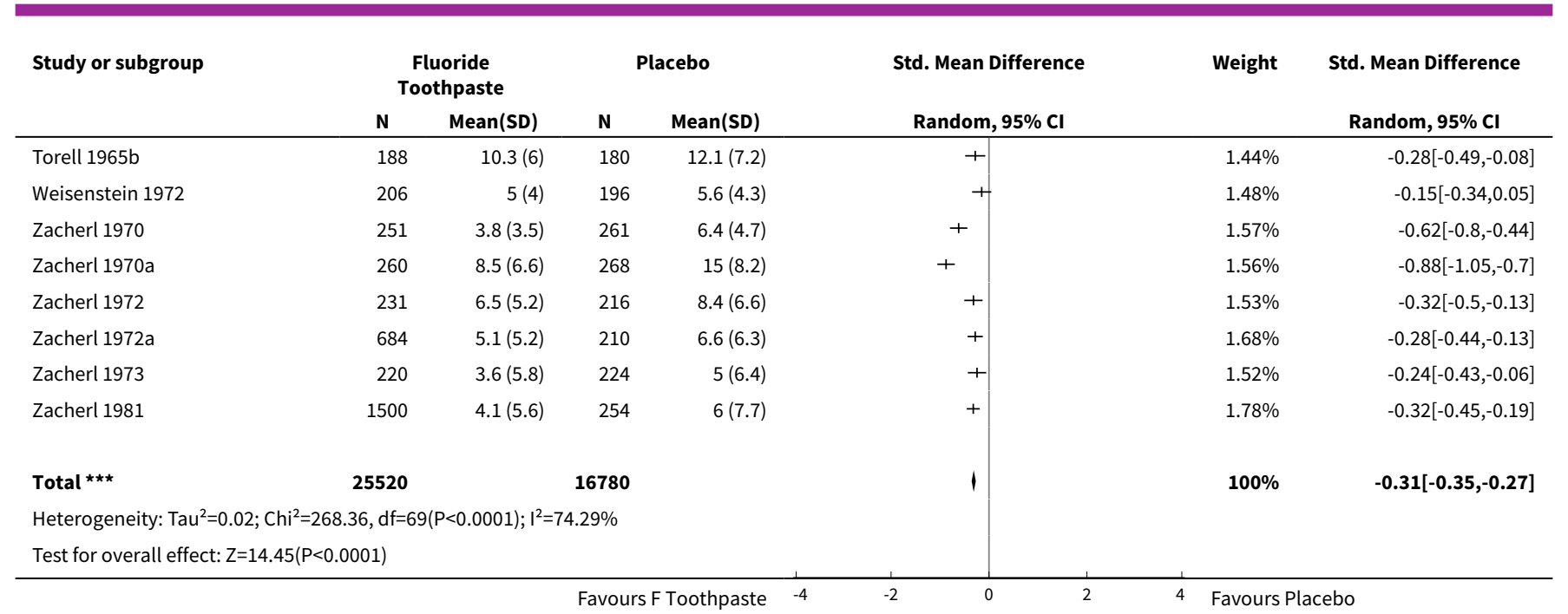

Analysis 1.4. Comparison 1 Fluoride toothpaste versus placebo, Outcome 4 D(M)FT increment (SMD) - nearest to 3 years (53 trials).

\begin{tabular}{|c|c|c|c|c|c|c|c|}
\hline \multirow[t]{2}{*}{ Study or subgroup } & \multicolumn{2}{|c|}{ Fluoride toothpaste } & \multicolumn{2}{|c|}{ Placebo } & \multirow{2}{*}{$\begin{array}{c}\text { Std. Mean Difference } \\
\text { Random, } 95 \% \mathrm{Cl}\end{array}$} & \multirow[t]{2}{*}{ Weight } & \multirow{2}{*}{$\begin{array}{c}\text { Std. Mean Difference } \\
\text { Random, } 95 \% \mathrm{Cl}\end{array}$} \\
\hline & $\mathbf{N}$ & Mean(SD) & $\mathbf{N}$ & Mean(SD) & & & \\
\hline Abrams 1980 & 761 & $3.4(3.7)$ & 380 & $4(4.1)$ & + & $2.48 \%$ & $-0.15[-0.28,-0.03]$ \\
\hline Andlaw 1975 & 364 & $3.7(2.8)$ & 376 & $4.6(2.7)$ & + & $2.32 \%$ & $-0.3[-0.45,-0.16]$ \\
\hline Blinkhorn 1983 & 184 & $2.5(2.4)$ & 184 & $3.5(2.6)$ & + & $1.86 \%$ & $-0.42[-0.63,-0.22]$ \\
\hline Brudevold 1966 & 955 & $2.6(2.8)$ & 323 & $3.3(2.8)$ & + & $2.46 \%$ & $-0.27[-0.39,-0.14]$ \\
\hline Buhe 1984 & 859 & $4.7(3)$ & 427 & $5.6(3.3)$ & + & $2.53 \%$ & $-0.3[-0.42,-0.19]$ \\
\hline Cahen 1982 & 1300 & $1.6(1.3)$ & 708 & $1.9(1.3)$ & + & $2.71 \%$ & $-0.21[-0.3,-0.12]$ \\
\hline Di Maggio 1980 & 22 & $2(0.2)$ & 20 & $4(1)$ & & $0.24 \%$ & $-2.83[-3.71,-1.96]$ \\
\hline Fogels 1979 & 890 & $4.2(4.2)$ & 449 & $4.8(4.5)$ & + & $2.56 \%$ & $-0.13[-0.24,-0.01]$ \\
\hline Gish 1966 & 165 & $3.1(2.7)$ & 163 & $3.7(2.7)$ & + & $1.79 \%$ & $-0.19[-0.41,0.02]$ \\
\hline Glass 1978 & 178 & $3.2(3.1)$ & 168 & $4.3(3.6)$ & + & $1.82 \%$ & $-0.32[-0.53,-0.11]$ \\
\hline Glass 1983 & 567 & $1.5(1.7)$ & 286 & $2.1(2.4)$ & + & $2.33 \%$ & $-0.31[-0.45,-0.16]$ \\
\hline Hanachowicz 1984 & 473 & $3.2(2.6)$ & 472 & $4.4(3)$ & + & $2.44 \%$ & $-0.41[-0.54,-0.28]$ \\
\hline Hargreaves 1973 & 163 & $3.1(3.5)$ & 140 & $3.8(3.9)$ & + & $1.72 \%$ & $-0.17[-0.4,0.05]$ \\
\hline Hargreaves 1973a & 146 & $4.2(4.2)$ & 138 & $6(5.1)$ & + & $1.67 \%$ & $-0.38[-0.61,-0.14]$ \\
\hline Hargreaves 1973b & 146 & $7.2(5.6)$ & 151 & $8.1(6)$ & + & $1.71 \%$ & $-0.15[-0.38,0.07]$ \\
\hline Held 1968 & 32 & $0.3(1)$ & 31 & $4.5(4.3)$ & $\longrightarrow$ & $0.55 \%$ & $-1.33[-1.88,-0.78]$ \\
\hline Held 1968a & 19 & $2.6(3.2)$ & 17 & $4.3(4.2)$ & $\longrightarrow$ & $0.4 \%$ & $-0.45[-1.11,0.22]$ \\
\hline Held 1968b & 14 & $0.9(1.8)$ & 18 & $2.2(2.9)$ & 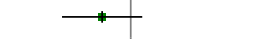 & $0.36 \%$ & $-0.51[-1.22,0.2]$ \\
\hline Hodge 1980 & 597 & $3.7(2.7)$ & 202 & $4.7(2.9)$ & + & $2.2 \%$ & $-0.39[-0.55,-0.23]$ \\
\hline Horowitz 1966 & 329 & $2.2(1.8)$ & 309 & $2.7(2.1)$ & + & $2.24 \%$ & $-0.23[-0.38,-0.07]$ \\
\hline Howat 1978 & 253 & $3.2(2.7)$ & 242 & $4.4(3.1)$ & + & $2.07 \%$ & $-0.4[-0.58,-0.22]$ \\
\hline Jackson 1967 & 438 & $4.6(3.1)$ & 433 & $5.1(3.1)$ & + & $2.41 \%$ & $-0.17[-0.3,-0.04]$ \\
\hline James 1967 & 406 & $2.3(2.6)$ & 397 & $2.5(2.3)$ & + & $2.37 \%$ & $-0.11[-0.25,0.02]$ \\
\hline Kleber 1996 & 77 & $1.1(1.7)$ & 79 & $1(1.5)$ & - & $1.23 \%$ & $0.01[-0.3,0.33]$ \\
\hline Koch 1967 & 64 & $6.1(3.4)$ & 60 & $9.3(3.3)$ & $\mp$ & $0.99 \%$ & $-0.95[-1.32,-0.58]$ \\
\hline Koch 1967a & 60 & $5.1(2.6)$ & 60 & $7.2(3.6)$ & + & $1.01 \%$ & $-0.67[-1.03,-0.3]$ \\
\hline Koch 1967b & 32 & $2.1(1.9)$ & 38 & $3(3.2)$ & - & $0.7 \%$ & $-0.33[-0.8,0.15]$ \\
\hline Koch 1967c & 127 & $3.4(2.5)$ & 128 & $3.6(3.2)$ & + & $1.6 \%$ & $-0.06[-0.31,0.19]$ \\
\hline Lind 1974 & 592 & $2.5(2.7)$ & 575 & $3.6(2.9)$ & + & $2.54 \%$ & $-0.39[-0.51,-0.28]$ \\
\hline
\end{tabular}




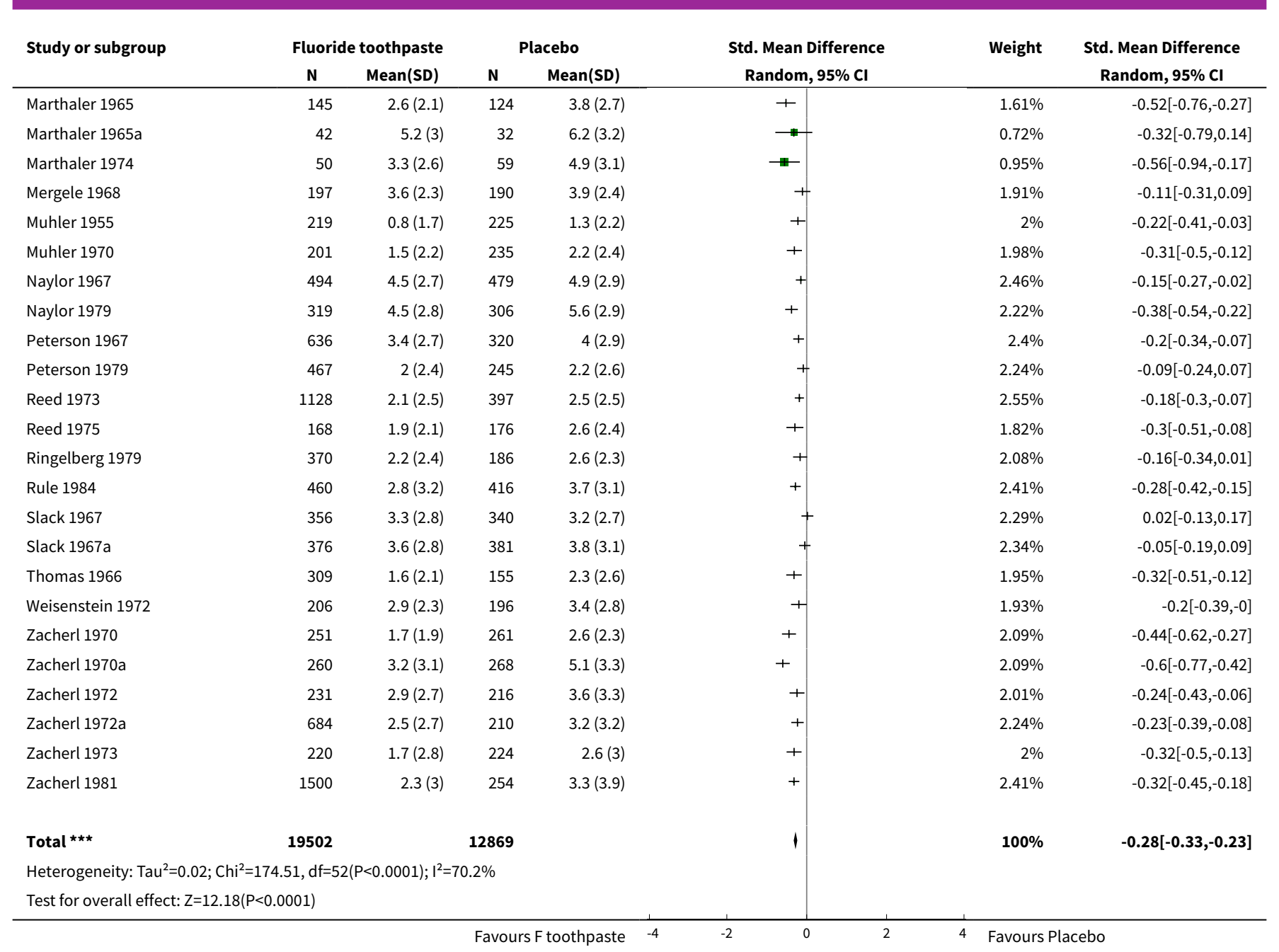

Analysis 1.5. Comparison 1 Fluoride toothpaste versus placebo, Outcome 5 Developing one or more new caries ( 6 trials).

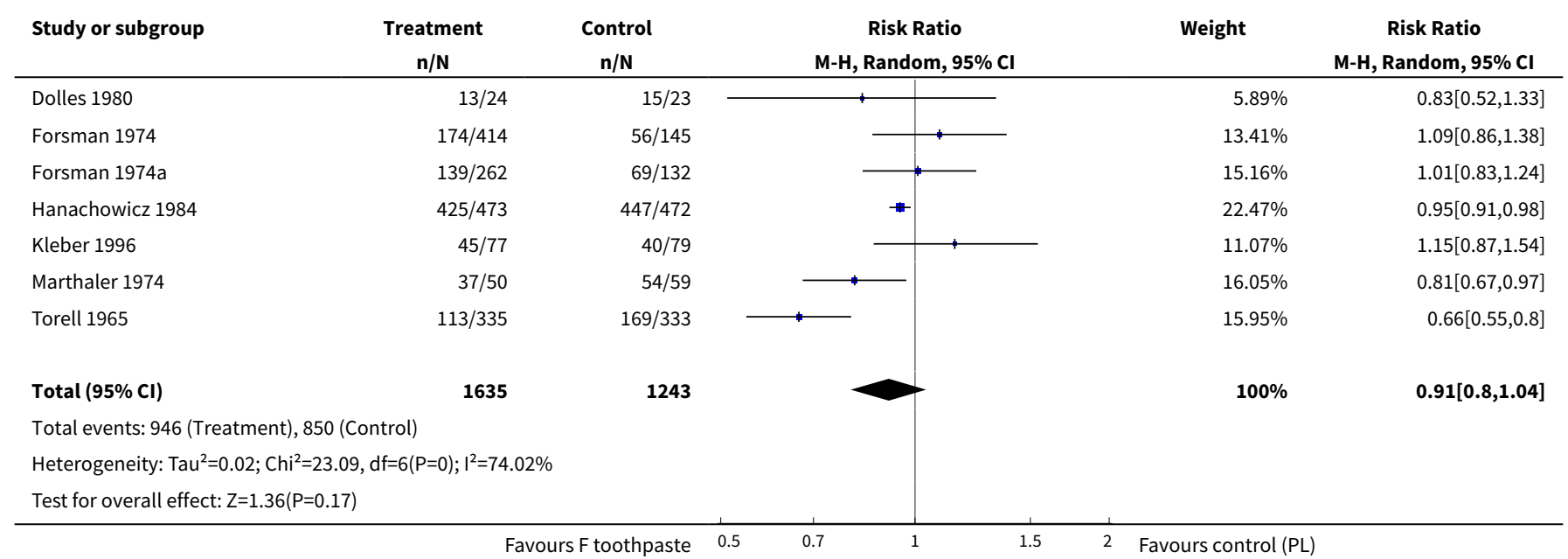


Analysis 1.6. Comparison 1 Fluoride toothpaste versus placebo, Outcome 6 Acquiring extrinsic tooth staining (5 trials).

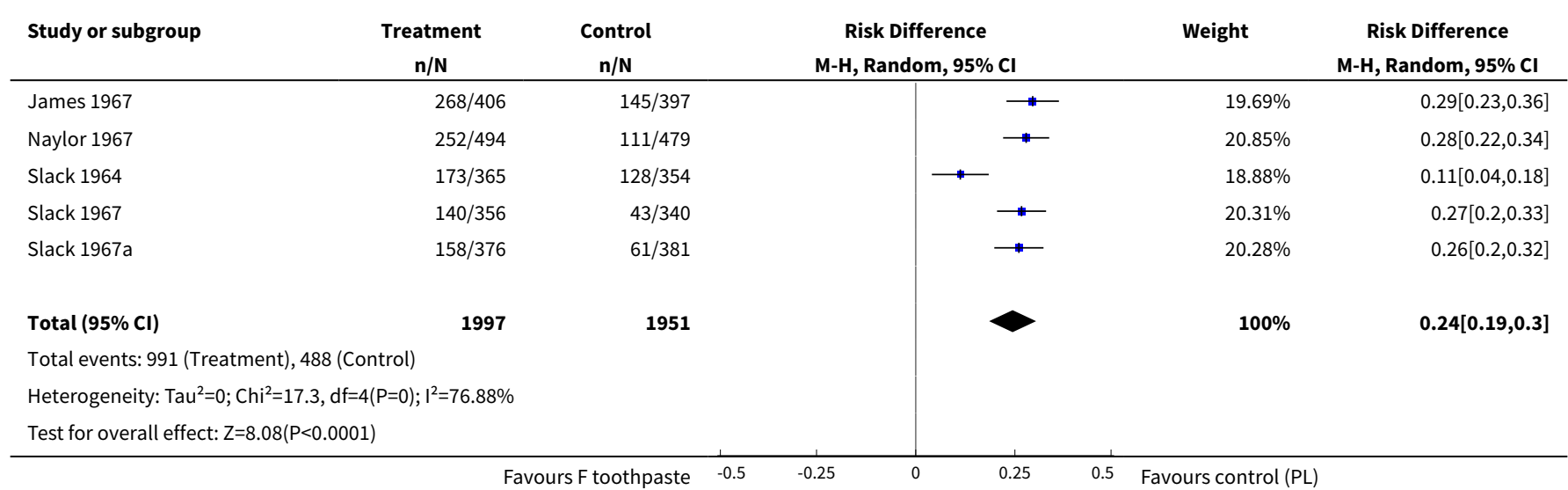

ADDITIONAL TABLES

Table 1. Meta-analyses of prevented fractions

\begin{tabular}{|c|c|c|c|c|c|}
\hline Analysis & $\begin{array}{l}\text { Number of } \\
\text { studies }\end{array}$ & RE estimate & $95 \% \mathrm{Cl}$ & $\begin{array}{l}\text { Meta-analysis } P \text { - } \\
\text { value }\end{array}$ & Heterogeneity test \\
\hline $\mathrm{D}(\mathrm{M}) \mathrm{FS}$ - all studies & 70 & $24 \%$ & $21 \%$ to $28 \%$ & $P<0.0001$ & $Q=489.89(69 \mathrm{df}) ; P<0.0001$ \\
\hline$D(M) F T$ - all studies & 53 & $23 \%$ & $19 \%$ to $28 \%$ & $P<0.0001$ & $Q=541.04(52 \mathrm{df}) ; P<0.0001$ \\
\hline
\end{tabular}

Table 2. Random-effects metaregression analyses of prevented fractions: D(M)FS

\begin{tabular}{|c|c|c|c|c|c|}
\hline Characteristic & $\begin{array}{l}\text { Number of } \\
\text { studies }\end{array}$ & $\begin{array}{l}\text { Slope esti- } \\
\text { mate }\end{array}$ & $95 \% \mathrm{Cl}$ & Slope interpretation & P-value \\
\hline Mean baseline caries & 67 & $0.7 \%$ & $\begin{array}{l}(0.07 \% \text { to } \\
1.3 \%)\end{array}$ & $\begin{array}{l}\text { Increase in PF per unit increase in } \\
\text { mean baseline caries }\end{array}$ & 0.03 \\
\hline Fluoridated water & 56 & $3.2 \%$ & $(-4 \%$ to $11 \%)$ & $\begin{array}{l}\text { Higher PF in presence of water fluori- } \\
\text { dation }\end{array}$ & 0.4 \\
\hline $\begin{array}{l}\text { Background fluo- } \\
\text { rides }\end{array}$ & 56 & $0.6 \%$ & $(-6 \%$ to $8 \%)$ & $\begin{array}{l}\text { Higher PF in presence of any back- } \\
\text { ground fluoride }\end{array}$ & 0.9 \\
\hline $\begin{array}{l}\text { Concentration of flu- } \\
\text { oride }\end{array}$ & 69 & $8.3 \%$ & (1\% to $16 \%)$ & Increase in PF per 1000 ppm F & 0.03 \\
\hline $\begin{array}{l}\text { Frequency of tooth- } \\
\text { brushing }\end{array}$ & 70 & $14 \%$ & ( $6 \%$ to $22 \%)$ & $\begin{array}{l}\text { Increase in PF moving from once to } \\
\text { twice a day }\end{array}$ & $<0.0001$ \\
\hline $\begin{array}{l}\text { Intensity (freq times } \\
\text { conc) }\end{array}$ & 69 & $5.9 \%$ & $(3.0 \%$ to $8.9 \%)$ & $\begin{array}{l}\text { Increase in PF equivalent to doubling } \\
\text { from once to twice a day and increas- } \\
\text { ing by } 1000 \text { ppmF }\end{array}$ & $<0.0001$ \\
\hline
\end{tabular}


Table 2. Random-effects metaregression analyses of prevented fractions: D(M)FS (Continued)

\begin{tabular}{llllll} 
Mode of use & 70 & $-11 \%$ & $(-18 \%$ to $-4 \%)$ & $\begin{array}{l}\text { Lower PF with unsupervised tooth- } \\
\text { brushing }\end{array}$ & 0.03 \\
\hline $\begin{array}{l}\text { Allocation conceal- } \\
\text { ment }\end{array}$ & 70 & $3.2 \%$ & $(-7 \%$ to $13 \%)$ & $\begin{array}{l}\text { Higher PF with poorly concealed allo- } \\
\text { cation }\end{array}$ & 0.5 \\
\hline Drop out & 70 & $2.6 \%$ & $\begin{array}{l}(0.2 \% \text { to } 5 \%) \\
\text { Increase in PF per 10 drop outs }\end{array}$ & 0.04 \\
\hline $\begin{array}{l}\text { Length of follow up } \\
70\end{array}$ & $0.8 \%$ & $\begin{array}{l}(-4.2 \% \text { to } \\
5.7 \%)\end{array}$ & $\begin{array}{l}\text { Increase in PF per extra year of follow } \\
\text { up }\end{array}$ & 0.8 \\
\hline $\begin{array}{l}\text { SMFP vs NaF (indi- } \\
\text { rect comparison) }\end{array}$ & 32 & $-2.6 \%$ & $\begin{array}{l}(-11.8 \% \text { to } \\
6.5 \%)\end{array}$ & PF lower among SMFP trials & 0.6 \\
\hline $\begin{array}{l}\text { AmF vs NaF (indirect } \\
\text { comparison) }\end{array}$ & 15 & $3.2 \%$ & $\begin{array}{l}(-11.0 \% \text { to } \\
17.3 \%)\end{array}$ & PF higher among AmF trials & 0.7 \\
\hline $\begin{array}{l}\text { SnF2 vs NaF (indirect } \\
\text { comparison) }\end{array}$ & 29 & $-4.8 \%$ & $\begin{array}{l}(14.1 \% \text { to } \\
4.5 \%)\end{array}$ & PF lower among SnF2 trials & 0.3 \\
\hline
\end{tabular}

\section{APPENDICES}

\section{Appendix 1. MEDLINE search strategy}

(a) [("DENTAL-CARIES" explode all subheadings or "DENTAL-CARIES-ACTIVITY-TESTS" all subheadings or "DENTAL-CARIESSUSCEPTIBILITY" all subheadings or CARIE* or DMF*) and (("FLUORIDES" explode all subheadings or "FLUORIDES,-TOPICAL" explode all subheadings or FLUOR* or AMF or AMINE F OR SNF2 OR STANNOUS F OR NAF OR SODIUM F OR APF OR SMFP OR MFP OR MONOFLUOR*) or ("CARIOSTATIC-AGENTS" explode all subheadings or "DENTAL-PROPHYLAXIS" explode all subheadings or "DENTIFRICES" explode all subheadings or "MOUTHWASHES" explode all subheadings or CARIOSTA* or PROPHYLA* or ANTICARI* or ANTI CARI* or VARNISH* or LACQUER* or DURAPHAT or GEL* or TOOTHPASTE* or TOOTH PASTE* or PASTE* or DENTIFRIC* or MOUTHRINS* or MOUTH RINS* or RINS* or MOUTHWASH* or MOUTH WASH*))].

(b) [((explode FLUORIDES/ all subheadings) or (explode FLUORIDES-TOPICAL/ ALL SUBHEADINGS) or (FLUOR*) or (AMF or AMINE F OR SNF2 OR STANNOUS F OR NAF OR SODIUM F OR APF OR MFP OR SMFP OR MONOFLUOR* OR DURAPHAT)) and ((CARI $\left.{ }^{\star}\right)$ or (DMF*) or (TOOTH $\left.{ }^{\star}\right)$ or $\left(\right.$ TEETH $\left.^{\star}\right)$ or $\left(\right.$ DENT $^{*}$ in TI, in AB, in MESH)) or ((explode CARIOSTATIC-AGENTS/ all subheadings) or (ANTICARI* or ANTI CARI*) or (explode MOUTHWASHES/ all subheadings) or (MOUTHWASH* or MOUTH WASH*) or (MOUTHRINS* or MOUTH RINS ${ }^{\star}$ ) or $\left(\right.$ VARNISH* or LACQUER $\left.{ }^{\star}\right)$ )].

\section{Appendix 2. LILACS/BBO search strategy}

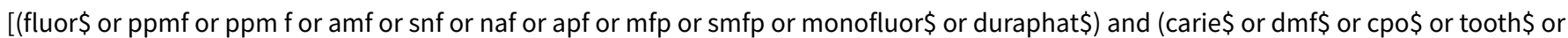

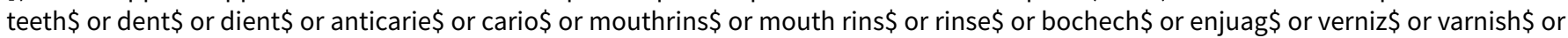
barniz\$ or laca $\$$ or gel or gels)] and [random $\$$ or aleatori or acaso $\$$ or azar $\$$ or blind $\$$ or mask or cego $\$$ or cega $\$$ or ciego $\$$ or ciega $\$$ or placebo $\$$ or(clinic $\$$ and (trial\$ or ensaio $\$$ or estud\$)) or (control\$ and (trial\$ or ensaio $\$$ or estud\$))].

\section{Appendix 3. Supplementary MEDLINE search strategy}

[(CARIE* or (DENT* near CAVIT*) or TOOTH* DECAY* or DMF* or (explode "DENTAL-CARIES"/ ALL SUBHEADINGS)) and (FLUOR* or APF* or NAF $^{\star}$ or AMINE F OR SNF* or ACIDULATED* PHOSPHATE* FLUORID* or ACIDULATED* FLUORID* or PHOSPHATE* FLUORID* or SODIUM* FLUORID* or AMINE* FLUORID* or STANNOUS* FLUORID* or (explode "FLUORIDES"/ ALL SUBHEADINGS)) and (TOOTHPASTE* or TOOTH ${ }^{\star}$ PASTE* $^{*}$ or DENTIFRICE* or PASTE*) or (explode "DENTIFRICES"/ all subheadings)].

\section{WHAT'S NEW}

\begin{tabular}{lll}
\hline Date & Event & Description \\
\hline 17 November 2016 & Review declared as stable & This Cochrane review is no longer being updated.
\end{tabular}




\begin{tabular}{lll}
\hline Date Event Description & Den
\end{tabular}

A more up-to-date Cochrane review on fluoride toothpastes of different concentrations for preventing dental caries in children and adolescents is available, whose objectives were to determine the relative effectiveness of fluoride toothpastes of different concentrations in preventing dental caries in children and adolescents, and to examine the potentially modifying effects of baseline caries level and supervised toothbrushing. Please see Walsh T, Worthington HV, Glenny AM, Appelbe P, Marinho VCC, Shi $X$. Fluoride toothpastes of different concentrations for preventing dental caries in children and adolescents. Cochrane Database of Systematic Reviews 2010, Issue 1. Art. No.: CD007868. DOI: 10.1002/15651858.CD007868.pub2.

\section{H I S T O R Y}

Protocol first published: Issue 3, 2000

Review first published: Issue 1, 2003

\begin{tabular}{lll}
\hline Date & Event & Description \\
\hline 27 August 2008 & Amended & Converted to new review format. \\
\hline
\end{tabular}

\section{CONTRIBUTIONS OF AUTHORS}

All authors contributed to the development of the protocol. Valeria Marinho (VM) wrote the protocol, conducted searches, selected studies and extracted data. Julian Higgins (JH) duplicated the study selection and data extraction in a sample of studies, and Stuart Logan (SL) or Aubrey Sheiham (AS) were consulted where necessary. VM entered and analysed the data in consultation with JH. VM prepared the full review and all authors were active in its revision and approval.

\section{DECLARATIONS OF INTEREST}

None known.

\section{SOURCES OF SUPPORT}

\section{Internal sources}

- Department of Epidemiology and Public Health (UCL), UK.

- Systematic Reviews Training Unit, Institute of Child Health (UCL), UK.

- Medical Research Council, UK.

\section{External sources}

- CAPES - Ministry of Education, Brazil.

\section{NOTES}

This Cochrane review is no longer being updated.

A more up-to-date Cochrane review on fluoride toothpastes of different concentrations for preventing dental caries in children and adolescents is available, whose objectives were to determine the relative effectiveness of fluoride toothpastes of different concentrations in preventing dental caries in children and adolescents, and to examine the potentially modifying effects of baseline caries level and supervised toothbrushing. Please see Walsh T, Worthington HV, Glenny AM, Appelbe P, Marinho VCC, Shi X. Fluoride toothpastes of different concentrations for preventing dental caries in children and adolescents. Cochrane Database of Systematic Reviews 2010, Issue 1. Art. No.: CD007868. DOI: 10.1002/15651858.CD007868.pub2. 
INDEX TERMS

\section{Medical Subject Headings (MeSH)}

Dental Caries [ ${ }^{\star}$ prevention \& control]; Fluorides [*therapeutic use]; Randomized Controlled Trials as Topic; Toothpastes [ ${ }^{\star}$ therapeutic use]

\section{MeSH check words}

Adolescent; Child; Humans 